\title{
TOURISM AND THE ENVIRONMENT: THE RESPONSE OF PRIVATELY OWNED ACCOMMODATION BUSINESSES IN DA NANG CITY, VIETNAM
}

\author{
By \\ Trang Thi Doan Nguyen
}

A thesis submitted to the Victoria University of Wellington in partial fulfilment of requirements for the degree of Master of Development Studies

School of Geography, Environment and Earth Science Victoria University of Wellington 


\section{TABLE OF CONTENTS}

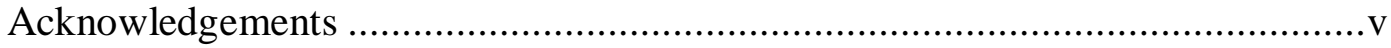

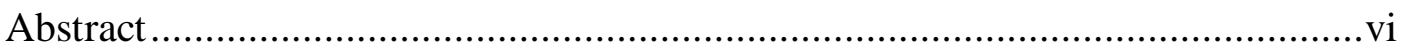

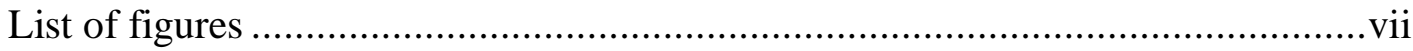

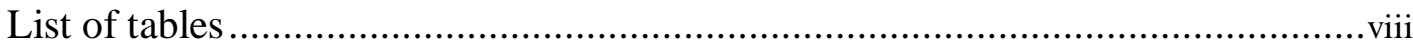

Chapter 1: INTRODUCTION.............................................1

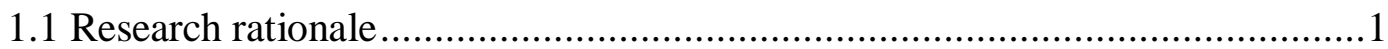

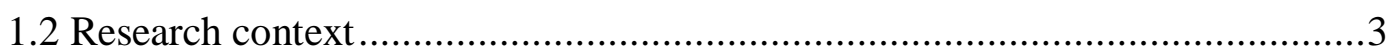

1.3 Research questions, objectives and significance ..................................

1.3.1 Research questions .................................................................

1.3.2 Research objectives .............................................................

1.3.3 Research significance .............................................................

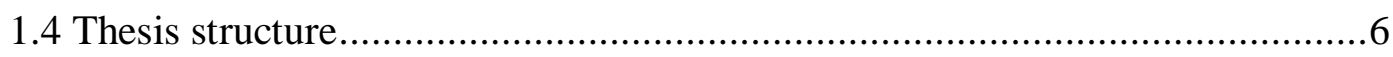

Chapter 2: SUSTAINABLE DEVELOPMENT AND TOURISM ..................8

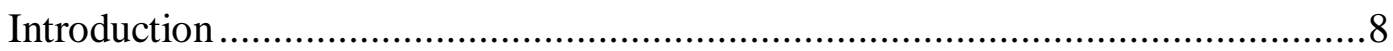

2.1 Sustainable development...............................................................

2.2 The private sector and its role in sustainable development ..........................11

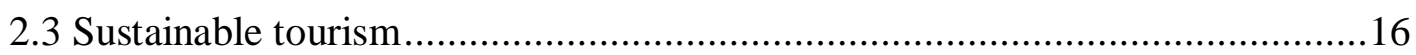

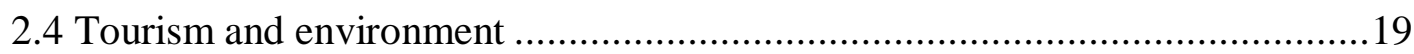

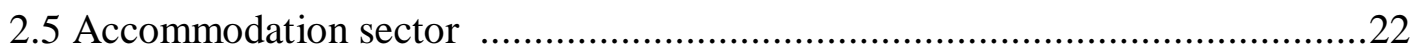


Conclusion

Chapter 3: METHODOLOGY

Introduction

3.1 Approach and method

3.2 Data collection procedure 32

3.2.1 Research location. 32

3.2.2 Interviewees and data sources... 36

3.2.3 How to recruit interviewees? 38

3.3 Data analysis procedure 42

3.4 Ethical, health and safety issues ...... 44

3.4.1 Ethical issues in data collection, data analysis and writing .44

3.4.2 Health and safety issues .45

3.5 Fieldwork reflection .46

3.6 Positionality and power. .46

3.7 Fieldwork limitations 47

Conclusion 48

\section{Chapter 4: SUSTAINABLE DEVELOPMENT AND TOURISM IN} VIETNAM AND DA NANG

Introduction 49

4.1 Context of Vietnam 49 
4.1.3 Sustainable development framework in place.

4.1.4 Tourism and accommodation sector development after 1986

4.1.5 Sustainable tourism development framework in place.

4.2 Context of Da Nang city .

4.2.1 Geographic characteristics. .61

4.2.2 Tourism planning process. 63

4.2.3 Social and economic features .64

4.2.4 Local sustainable development framework in place .66

4.2.5 Tourism and accommodation sector development. .67

4.2.6 Local sustainable tourism development framework in place... .69

Conclusion 71

Chapter 5: RESEARCH FINDINGS .72

Introduction .72

5.1 Objective 1: Hotel managers' awareness of sustainability issues .74

5.2 Objective 2: Environmental practices hotel managers are using and their motivations

5.3 Objective 3: Difficulties that prevent hotel managers from conducting environmental practices .86 
5.4 Objective 4: Collaboration between the city government and the accommodation businesses

Conclusion 92

Chapter 6: DISCUSSION AND RECOMMENDATIONS

6.1 Research implications ..... .94

6.1.1 Commercial concern or social concern?. 94

6.1.2 Does hotel size relate to the extent of managers' awareness and their actions towards environmental protection? . .96

6.1.3 Legal involvement of enterprises in environmental protection. .98

6.1.4 Is existing collaboration between the government and privately owned accommodation businesses sufficient?. 100

6.2 Possible solutions .104

6.3 Research limitations... .105

6.4 Recommendations for future research .105

Concluding remarks. .106

References .109

Appendices. .125

Appendix 1: Ethics Approval..... .125

Appendix 2: Information Sheet 126

Appendix 3: Consent Form. 127 


\section{ACKNOWLEDGEMENTS}

First of all, I would like to express my sincere gratitude to the New Zealand government who granted me with the New Zealand-ASEAN Scholar Awards. If I had not been selected in the first place, I would not have had a chance to study in such an amazing educational environment as New Zealand. The two year period in New Zealand has opened up my mind, enriched my living experience and widened my network. No doubt in this wonderful country I have spent some of the most beautiful days of my life.

I would also like to extend my gratitude to Victoria University of Wellington for the great assistance offered to me as a scholarship holder, especially Victoria International and Student Learning Support. Their constant support helped me to complete my Master degree to the best level possible.

I would like to convey my special thanks to my supervisor, Professor John Overton for his invaluable advice, feedback and encouragement throughout my research. He was friendly, caring and funny. All of these characteristics together with his wisdom made me feel totally inspired and comfortable to work with him.

My deepest gratitude is sent to my family in Vietnam. Their unwavering encouragement helped me overcome the ups and downs during the two years that I studied in New Zealand. Thank you for being healthy so that I could feel released to focus on my studying.

Last but not least, a big thank you to my friends in Vietnam, in New Zealand, my Development Studies fellows, my flatmates for always staying by my side, being my "bins", my studying, dining, shopping and travelling partners. Your company made my days in New Zealand complete. 


\begin{abstract}
The purpose of the study is to investigate the response of privately-owned hospitality enterprises in Da Nang city, Vietnam to environmental concerns. The study is inspired by global growing attention to how sustainable development in general and sustainable development in the tourism industry in particular can be promoted, especially the environmental aspect. Given the vital role of the private sector in achieving sustainable development and the fact that in the context of Vietnam, the private sector is still a less powerful economic player than the stateowned sector, the study only focuses on the privately-owned hotels. The study was conducted with the aims of (i) filling in the gap of understanding of the issue in developing countries, (ii) seeing how effective the private sector's contribution in Da Nang city and in Vietnam in general has been in promoting sustainable tourism development, and (iii) coming to suitable recommendations, based on the research results, to increase the effectiveness of the private sector in sustainable tourism development. Qualitative methodology was used. Fifteen hotel managers participated in the semi-structured interviews. Some governmental officers also joined the research to provide supplementary information. The research findings show that the hotel managers in Da Nang city generally had good understanding of relevant environmental issues in the accommodation sector and tourism industry. All hotels researched were using environmental practices but the smaller ones tended to have less practices. Noticeably, not all hotels were using obligatory practices described by laws. Reducing costs was the most chosen motivation for hotels to go green. Simultaneously, it was picked up by most participants as the biggest difficulty that prevented them from pursuing an environmental path. The research also revealed a weak collaboration between the city government and the accommodation businesses in dealing with environmental concerns.
\end{abstract}




\section{LIST OF FIGURES}

Figure 1: Thesis structure

Figure 2: The scope of the concept of the environment

Figure 3: Recruitment process of hotel managers

Figure 4: Recruitment process of officers

Figure 5: Interview process

Figure 6: Data analysis procedure

Figure 7: Map of Vietnam

Figure 8: Number of tourist arrivals 1990-2013

Figure 9: Tourism planning process

Figure 10: GDP growth rate of Da Nang and Vietnam (per cent)

Figure 11: Number of tourists to Da Nang city in the period 2001-2013

Figure 12: Hotel managers' thinking of the private sector's role in sustainable development

Figure 13: Relationship between hotel business and environmentally sustainable development

Figure 14: Hotel managers' difficulties in adopting environmental practices

Figure 15: Forecast of hotel growth in Da Nang city in the period 2014-2020 


\section{LIST OF TABLES}

Table 1: Potential consequences of tourism on the environment

Table 2: List of interviewees

Table 3: Types of enterprises by capital and number of staff

Table 4: Information of hotels and hotel managers joining the research

Table 5: Motivations of hotel managers to apply environmental practices

Table 6: Environmental practices hotel managers had been using 


\section{CHAPTER 1: INTRODUCTION}

\subsection{Research rationale}

The past decades have witnessed an explosive growth in tourism into one of the largest and most powerful industries in the world (Scheyvens, 2002; Telfer \& Sharpley, 2008). The statistics from the World Tourism Organization reveal that over 25 million tourists travelled abroad in the 1950s. The same number of tourists was recorded as entering the United Kingdom alone annually by 2004 while the number of international tourist arrivals reached 760 million (World Tourism Organization, 2005, as cited in Telfer \& Sharpley, 2008). The number of international tourists has been increasing and so has the number of destinations. Steadily, developed countries have ceased to become the only favourable tourism market. Developing countries have been placing themselves on the global tourism map. The increasing flow of tourists into a country means more income created, more people employed, more foreign currency imported and more government budgets balanced. With such impressive impacts, tourism is seen as "a developmental catalyst" in the developing world and therefore a pivotal industry to be focussed on (Telfer \& Sharpley, 2008, p.2).

However, the explosive growth of tourism has raised questions about its negative environmental impacts. According to Kasim (2006), construction of largescale hotels causes habitat loss and land erosion due to site clearance. Tourism related elements such as transport, accommodation and recreation consume a huge amount of energy but simultaneously generate large quantities of waste and carbon dioxide. Similar ideas are shared by Buckley (2011) in his research on tourism and environment. Further, Peeters and his team's research (2010) reveals that if tourism were a country, its contribution to the total $\mathrm{CO}_{2}$ emission globally would come fifth after the United States, China, the European Union and Russia. Also, studies suggest that the increasing flows of tourists to a certain destination can result in severe degradation to that place due to exceeding carrying capacity (Buckley, 2011; Hobson \& Essex, 2001; Kasim, 2006). 
The negative impact of tourism to the natural environment has been long recognized and dealt with. As a response to the call for sustainable development, the term "sustainable tourism" has come to life as guide for sustainable development in the industry. According to the World Tourism Organization (1998), sustainable tourism is defined as one which:

Meets the needs of present tourist and host regions while protecting and enhancing opportunities for the future. It is envisaged as leading to management of all resources in such a way that economic, social, and aesthetic needs can be fulfilled while maintaining cultural integrity, essential ecological processes, biological diversity and life support systems. (p.21)

As suggested in this definition, the environment is thought to be in need of "an ethical treatment" together with economic and social aspects (Jayawardena, Patterson, Choi, \& Brain, 2008, p.266). The environmental dimension of sustainability remains central to these conceptions of sustainable tourism, certainly in terms of the public imagination. Within the scope of the proposed research, this environmental aspect of sustainable tourism will be focussed on.

Among the sub-sectors of the tourism industry, the accommodation sector is highlighted as one of the major ones that contribute most to environmental impacts. Most of the services provided by this sector are resource-intensive, and therefore considerable amounts of energy such as electricity, together with water, food and non-durable products are consumed. APAT's (2002) study suggests that these components make up to 75 per cent of all environmental impacts in the sector. Waste is probably the most visible effect that the sector has on the environment and a less visible impact is the emission of carbon dioxide and other air pollutants (Bohdanowicz, 2005; Bohdanowicz, 2006; Candrea \& Bratucu, 2012). Therefore, how the accommodation businesses respond to environmental issues will produce significant changes to the conservation of nature, and thereby promote sustainable development. 
To achieve sustainable development, the participation of different stakeholders is said to be vital. The private sector is among these stakeholders (United Nations, 2011). It generates most production, creates jobs, goods and services, raises income and improves people's lives, thereby helping them emerge from poverty (International Finance Corporation, 2011). It affects the natural environment negatively through mass production accompanied by high consumption of energy and disposal of waste and gas emissions, but at the same time reduces those negative effects through the application of technologies and environmental management practices (Kulovesi, 2007). Therefore, the involvement of the private sector in promoting sustainable development in general, and environmentally sustainable development in particular is obviously of great importance.

The promotion of sustainable development worldwide has required all industries to review themselves and respond accordingly. Tourism is not an exception. Being one of the most energy-intensive sectors in tourism, the accommodation sector plays a significant role in reducing these negative effects on the environment. These considerations have inspired the researcher to conduct research on the response of accommodation businesses to environmental concerns. The research setting is in Da Nang city, Vietnam. In particular, the research will examine privately owned accommodation businesses.

\subsection{Research context}

Since 1986, Vietnam has been allowing different players to join the economy. More and more private enterprises have been set up. Together with a significant increase in number, there has been an increase in the contribution of those private businesses to the country's development. Consequently, recent years have witnessed the government's efforts to make the private sector feel more comfortable and facilitate economic activities by implementing favourable policies. However, in reality, the effectiveness of these policies is claimed to be minimal and the government's attempt is insufficient (Le \& Nguyen, 2005). Therefore, selecting Vietnam as the research setting is meaningful in a sense that it will help to reveal how 
the collaboration between the state and the private sector operates in a context where the private sector's voice is considered to be less powerful.

Da Nang city was chosen as the research location for a number of reasons. First, since it is the driving force for the growth of the central region where it is located, its sustainable development is of great significance, not only for itself but also for the whole region. Second, the city is becoming increasingly popular among both domestic and international visitors. Its pristine natural landscapes, central location and proximity to world cultural heritage sites are assets to tourism development. Another justification for choosing Da Nang city as the research area is that since 2008, becoming an environmental city by 2020 has been one of the city's key objectives (ISET, 2011). Accordingly, environmental concerns have been integrated in all social as well as economic policies. Given this, the way accommodation enterprises respond to the environmental issues will be even more important. Therefore, the proposed research will provide a better understanding of the issue in Da Nang city and then offer necessary recommendations for the city's government and the national government in general to manage the industry more sustainably.

\subsection{Research questions, objectives and significance}

\subsubsection{Research questions}

\section{Central research question:}

How do privately owned accommodation businesses in Da Nang city, Vietnam respond to environmental concerns?

\section{Sub-research questions:}

(i) How do privately owned accommodation businesses in Da Nang city understand sustainability issues? 
(ii) What environmental practices are privately owned accommodation businesses adopting in Da Nang city?

(iii) What motivates privately owned accommodation businesses in $\mathrm{Da}$ Nang city to integrate environmental concerns into their businesses?

(iv) What prevents privately owned accommodation businesses in $\mathrm{Da}$ Nang city from adopting voluntary environmental tools and the government's environmental management measures?

(v) How successful is the collaboration between the city government and privately owned accommodation businesses in Da Nang city?

\subsubsection{Research objectives}

The key objective of this research is to contribute to the implementation of sustainable tourism in Vietnam. By conducting this research, it is hoped to gain an understanding of:

(i) The awareness of privately owned accommodation enterprises of sustainability issues.

(ii) The environmental instruments that accommodation enterprises are using in response to environmental concerns.

(iii) The motivations that drive accommodation enterprises to adopt environmental practices.

(iv) The difficulties that accommodation enterprises are facing when using environmental instruments.

(v) The collaboration between the city government and the accommodation businesses to promote sustainable tourism development.

\subsubsection{Research significance}

The significance of the research is reflected in a number of ways. First, knowledge about the environmental attitudes of hotel managers in Da Nang city and 
in Vietnam in general will be found, which contributes to the limited literature about the issue in developing countries. Second, the research will reveal how effective the private sector is in promoting sustainable tourism development in Vietnam's context. Finally, by exploring the collaboration between the government and the private sector, the research will give some suggestions for efforts to achieve sustainable development in the accommodation sector in particular and the tourism sector in general.

\subsection{Thesis structure}

The thesis will be divided into six chapters with the flow as described in the chart below. Chapter 2 reviews the literature on sustainable development; the role of the private sector in sustainable development; sustainable tourism development; and the connection between the environment and the accommodation industry. Chapter 3 discusses the methodology the researcher used to approach participants and collect data, and issues that came up during the field research. Chapter 4 clarifies the research setting by providing information on the context of Vietnam in general and Da Nang city in particular. Also, this chapter offers an overview of national and local environmental regulations. Chapter 5 presents the results of the field research with information collected from participants. The final chapter discusses the research findings and offers recommendations for future research. 


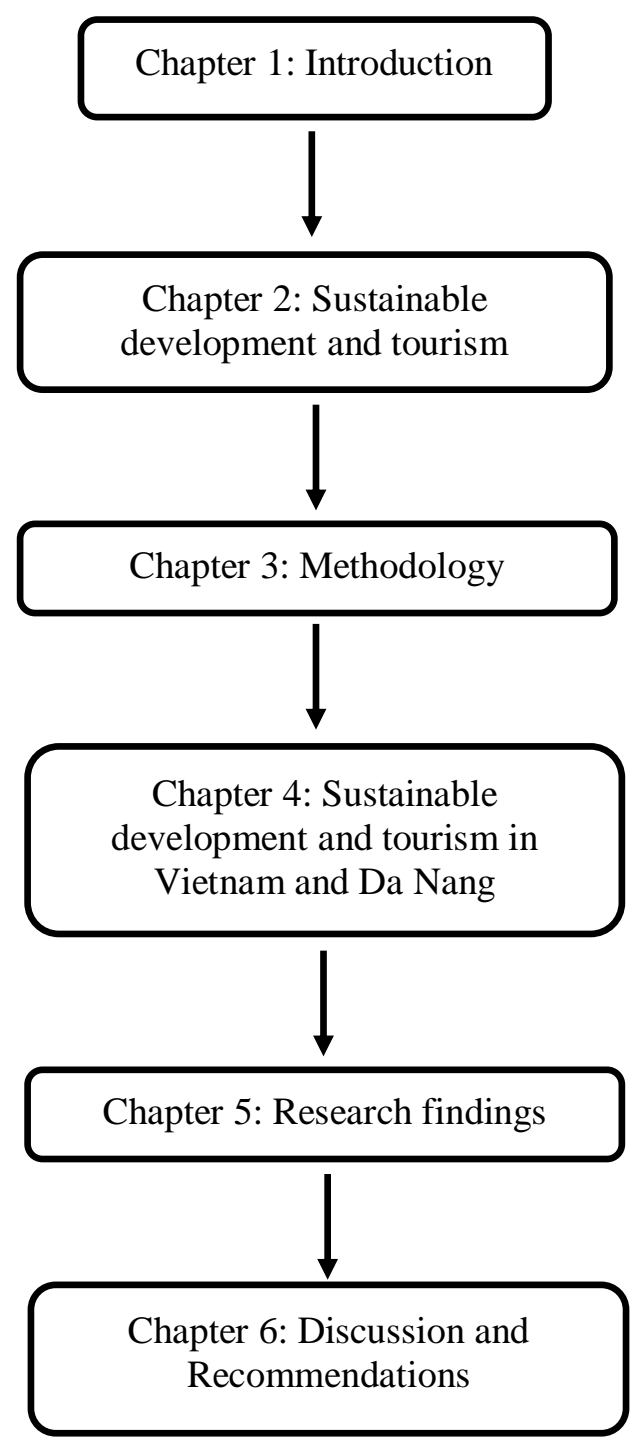

Figure 1: Thesis structure 


\section{CHAPTER 2: SUSTAINABLE DEVELOPMENT AND TOURISM}

\section{Introduction}

The following literature review provides the conceptual background for the research. It addresses five major points. First, the concept of sustainable development is presented: how it has been introduced and developed over the past decades, and its components. The second section reveals the role of the private sector in sustainable development. In this section, some corporate codes of conduct to contribute to the achievement of sustainable development are presented. Third, the concept of sustainable development in a specific industry - tourism - is examined. This is then followed by a section on the tourism-environment relationship. Finally, the accommodation sector is analysed in detail, including its impacts on the environment, and a brief summary of previous studies on the response of this sector to environmental concerns.

\subsection{Sustainable development}

Since late last century, sustainable development has become a dominant development model in developed as well as developing countries (Castro, 2004). It has manifested itself in a large number of international and national policies, agreements, conferences and academic articles. It has gained favour among different actors involved in the development world including academics, environmentalists, governmental officers and aid organizations. This is addressed by Castro (2004) who suggests that sustainable development is probably "one of the few areas of agreement between these disparate groups" (p.195). However, it was not until the late 20th century that the concern for sustainable development became prominent. This issue had already been raised as early as the $18^{\text {th }}$ century by thinkers such as Malthus as they were worried about the paucity of natural resources (Baker, 2006). In 1972, the "Limits to growth" report (Meadows, Meadows, Randers, \& Behrens, 1972) was published. By studying different variables including global population, global 
industrial production, pollution, food production and resource utility, they concluded that if these variables continued their existing trends and rates, the possible carrying capacity of the planet would be exceeded in the next 100 years. They fundamentally questioned the notion of growth and argued for sustainable strategies of economic activity.

The concept of sustainable development challenges conventional theories of development which are said to be rooted in a Western growth context (Baker, 2006; Sofield, 2003). Within those theories, modernization seems to be the most common approach to development (Baker, 2006). The theory defines development as a continuous process from traditional to modern. In order to catch up with developed countries, developing ones should invest more in sophisticated technology, boost urbanization and increase market activity. The theory claims that the natural environment should be utilized as a source of input for the modernization process, which is seen as "one of the hallmarks of modernization" (Baker, 2006, p. 2).

Although the term "sustainable development" first came to public attention in 1980 when it was mentioned in the World Conservation Strategy by the International Union for Conservation of Nature and Natural Resources (IUCN, 1980), its concept started burgeoning at the United Nations Conference on the Human Environment held in Stockholm in 1972. In this conference, the idea that human activities can harm the environment and therefore we must take responsibility to protect and improve it not only for our own sake but also for future generations' was highlighted. The report from the conference also confirmed that the growing population and consumption would increasingly reduce the globe's carrying capacity (United Nations, 1972). However, it was not until 1987 that the term was officially defined in the Brundtland report which was introduced in the World Commission on Environment and Development. According to the report, sustainable development is development which "seeks to meet the needs and aspirations of the present without compromising the ability to meet those needs of the future" (United Nations, 1987, p.34). More clearly: 
Sustainable development is a process of change in which the exploitation of resources, the direction of investment, the orientation of technological development, and institutional change are all in harmony and enhance both current and future potential to meet human needs and aspirations. (United Nations, 1987, p. 38)

The Brundtland definition of sustainable development has been criticized for its simplicity and vagueness (Abdel Wahaab, 2003; Baker, 2006; Harris, 2000; Redclift, 2008). According to Redclift (2008), needs themselves change over time. It is questionable whether the needs of this generation and next generations will be the same since the socio-economic conditions may vary leading to the variation of needs. Hence, "where does development come into the picture?" (Redclift, 2008, p.279). He also added that needs may vary in different contexts. For one society, a fresh and clean environment is necessary but for another, material wealth is what is sought. Therefore, different societies conditioned in different contexts may produce different definitions of sustainable development. However, although being criticized, the Brundtland definition is still considered the most well known and most often cited definition of sustainable development so far (Bansal, 2002; Castro, 2004). The reason could be the political advantage that the unclear definition brings about because "it has allowed groups with different and often conflicting interests to reach some common ground upon which concrete policies can be developed" (Baker, 2006, p. 27). A similar opinion is held by Vernon, Essex, Pinder, and Curry (2003).

Generally, there are three aspects of sustainable development including economic, social and environmental (Abdel Wahaab, 2003; Baker, 2006; Bansal, 2002; Harris, 2000; Institute of Company Secretaries of India, 2010). The economic aspect refers to the growth with which goods and services are produced continuously, to financial maintenance, usage, allocation and distribution of resources. A socially sustainable system refers to the achievement of social equity, sufficient supply and fair distribution of social services, and people's empowerment to participate in decision making process. Finally, environmental sustainability means maintenance 
of the resource base, ecosystem and biodiversity. Some people think that the sustainability of economic and social systems depends strongly on the environmental systems as economic activities require the utilization of natural resources for manufacturing and from that social demands are addressed. Other people think these three aspects are mutually supported and development is thought to be sustainable if these aspects can be achieved at the same time. However, as Harris points out, we can maximize only one objective at a time and therefore in reality, it is difficult to avoid "trade-offs" (Harris, 2000, p.6). This opinion is shared by Overton (1999) when he said sustainable development is "a concept that represents a compromise" (p.3).

\subsection{The private sector and its role in sustainable development}

Participation is one of the principles of sustainable development. According to Achterberg (1993), the promotion of sustainable development involves making difficult decisions related to many aspects of one's life such as financial issues or forms of behaviour. Participation of different stakeholders enables the achievement of a consensus based on which such decisions are grounded. As the Brundtland report argues that "making the difficult choice involved in achieving sustainable development will depend on the widespread support and involvement of informed public and non-governmental organisations, the scientific community, and industry" (United Nations, 1987, p.22).

Added to that, Dryzek (1992) argued that it is only through participation that the needs of the current generation, coming generations and other species will be fully recognized. This opinion is shared by Pepper (1998). Furthermore, the principle implies that sustainable development cannot be achieved by the actions of governments alone. Rather, different stakeholders and partnerships among different parties should be established to boost sustainable development. With this in mind, the Brundtland report argued that the "rights, roles and participation" of these stakeholders "in development planning, decision-making, and project implementation should be expanded" (United Nations, 1987, p.22). 
Among different stakeholders involved in sustainable development, the private sector occupies a crucial position (Business Action for Sustainable Development 2012, 2011; International Finance Corporation, 2011; United Nations, 1992). First, it makes a major contribution to economic growth. According to the International Finance Corporation's (2011) report, the greater the investment is made by the private sector, the faster the economy grows. Specifically, the private sector contributes most to national income, provides most employment and is critical for livelihoods. The World Bank's (2004) report shows that the private sector provides more than 90 per cent of jobs in developing countries. Regarding social aspects, by creating jobs, the private sector helps people escape poverty. Livelihood opportunities available to women allow them to reinforce their economic and social position in society, changing the conventional view of their roles. Moreover, the private sector improves people's lives by providing basic services such as infrastructure, education, healthcare and finance (Business Action for Sustainable Development 2012, 2011; International Finance Corporation, 2011; United Nations, 1992). In environmental terms, it is suggested that it can help to improve the natural environment through application of technologies and environmental management practices (Kulovesi, 2007). The involvement of the private sector in sustainable development strategies is a core element of neoliberal theories of development. There is a belief that the private sector will boost economic growth and the market will be capable of incorporating environmental as well as social concerns. This represents a neoliberal view of sustainable development that equates it with sustainable economic growth (Brenner \& Theodore, 2005).

However, for some social and environmental critics, the participation of the private sector in promoting sustainable development is ambiguous at best. These ưiters argue that a firm's activities require resources. Industrial enterprises need natural resources, either renewable or non-renewable resources, to put in production process. For service enterprises, they need different types of natural resources such as air, water or fauna and flora (Institute of Company Secretaries of India, 2010). Hence, firms deeply depend on the environment for its growth but at the same time 
their misuse is destroying it. Through mass production, firms have been blamed for over consumption of natural resources, and disposal of hazardous waste and gas emissions into the environment (Kulovesi, 2007). In addition to natural resources, firms need social resources such as human capital and social capital for operation (Institute of Company Secretaries of India, 2010). Human capital regards aspects such as "skills, motivation and loyalty of employees and business partners" while social capital refers to "the quality of public services, such as a good educational system, infrastructure or a culture supportive of entrepreneurship" (Institute of Company Secretaries of India, 2010, p.76). Thus, since business growth is built on environmental and social inputs, businesses "owe the society [...] ethical obligations" (Yam, 2013, p.76). That explains why the involvement of the private sector in promoting sustainable development is contentious.

As has been suggested, the private sector can play a significant role in achieving the triple bottom line of sustainable development (economic, environmental and social). Although it has been receiving blame for environmental damage, without the involvement of the private sector, sustainable development is unlikely to be achieved (Bansal, 2002; Business Action for Sustainable Development 2012, 2011; Witherell \& Maher, 2001). The role of businesses in sustainable development was once addressed by the former United Nations Secretary General Kofi Annan in a conference held by Business Action for Sustainable Development: "more and more we are realizing that it is only by mobilizing the corporate sector that we can make significant progress. The corporate sector has the finances, the technology and the management to make this happen" (as cited by Wade, 2005, p. 186). Sharing a similar opinion, Witherell and Maher (2001) argue that "sustainable development, which depends on growth, will not be achieved without the private sector" (p.62).

Due to such an important role the private sector plays in sustainable development, its participation is seen as increasing over time. According to Business Action for Sustainable Development 2012 (2011), the private sector has been deeply 
involved in many United Nations and international conferences promoting sustainable development. It is said to "have been following the United Nations climate change process right from the beginning" (Kulovesi, 2007, p.146). A wide range of associations have been born to assist the private sector to realize its economic, social and environmental goals. Some of them that are worth mentioning include the United Nations Global Compact, with ten guiding principles for businesses; the International Chamber of Commerce Business Charter for sustainable development, which offers enterprises a basis of friendly environmental practices; the World Business Council for sustainable development vision 2050; or the ICC World Chambers Federation network, which organizes capacity building activities for small and medium enterprises (Business Action for Sustainable Development 2012, 2011). Being increasingly aware of their social and environmental responsibilities, more and more businesses are believed to have already put sustainability aa a top priority of their operation. A growing number of voluntary codes of conduct have been introduced to help businesses in which the two most wellknown ones are corporate social responsibility and the ISO 14000 series of environmental management standards.

The concept of corporate social responsibility can be traced back to $1950 \mathrm{~s}$ with the well-known author Howard Rothmann Bowen, the "father of corporate social responsibility" (Yam, 2013, p.77). According to Bowen (1953), in addition to pursuing economic objectives such as revenue growth or profitability, businesses should perform their responsibility to society by thinking of the negative social and environmental impacts that they can create, and then operating in a proper way to reduce these impacts. That is what corporate social responsibility is about. Originally, Bowen's introduction of corporate social responsibility stemmed from the social responsibility of businesses at that time. However, Huge and Waas (2011) believe it is the concept of sustainable development featured in United Nations conferences since 1992 that has led to the re-emergence of corporate social responsibility globally, and that sustainable development is the "mother concept" of corporate social responsibility (Huge \& Waas, 2011, p.9). The OECD (2001) defines corporate social 
responsibility as "the business contribution to sustainable development" (cited in Huge \& Waas, 2011, p.9) while the World Business Council for sustainable development sees corporate social responsibility as "the continuing commitment by business to behave ethically and contribute to economic development while improving the quality of life of the workforce and their families as well as the local community and society at large" (WBCSD, 2002, p.3).

Corporate social responsibility is a form of self-regulation within businesses but is increasingly considered "a feature of new societal governance" towards sustainable development (Moon, 2007, p.302). Moon (2007) argues that for some reasons, current governments are confronting difficulties in meeting social expectations. The fact that corporate social responsibility makes enterprises respond more appropriately to social and environmental concerns will partly help governments tackle those difficulties. He also points out that in some circumstances, especially in developing countries, as there is a lack in implementation and management capacity or the unwillingness of the governments to deliver social welfare, it is the private sector which will replace the state's position and handle social tasks. Besides, Moon believes that corporate social responsibility has resulted in "new ways of business engagement with society and government" (p.302) such as forms of public private partnership through which social demand will be met more effectively.

Unlike corporate social responsibility, the ISO 14000 series, which was brought about by the International Organization for Standardization in 1996 as a response to Agenda 21 (out of the Rio Earth Summit in 1993), only focuses on the environmental dimension of business operations. It includes a number of standards that assist businesses to establish environmental goals and how to achieve them (Bansal, 2002; Clapp, 1998). The series encompasses different activities within businesses such as environmental auditing, environmental labelling or environmental analysis. Among all the 14000 series, ISO 14001 - environmental management systems - is considered the most popular measure. It helps enterprises contribute to 
sustainable development by requiring them to run a management system that reduces the severe impacts to the environment. ISO 14001 is favoured by both states and businesses. For states, ISO 14001 increases their anticipation that the private sector will enhance its role in improving environmental conditions. For businesses, ISO 14001 sets out the specific parts of operation that they should focus on and then apply environmental practices.

The fact that these two codes of conduct have been increasingly employed in the business world does not mean they do not have any limitations. Some claim that as they are rooted in a developed country context either because they were born there or due to the major representation of developed countries in organizations such as the International Organization for Standardization, there is a question of whether these codes are appropriate in developing countries and then beneficial to governments as well as businesses there. Other critics argue that these practices assist businesses to recognize the ways to polish their image in public eyes for their own sake rather than to foster sustainable development (Bansal, 2002; Clapp, 1998; Herrmann, 2004). Besides, some businesses find it challenging to employ these voluntary codes of conduct due to the high cost of application; the high cost of certification (in case businesses want to be certified ISO standards); or slow returns on investment and dubious results.

\subsection{Sustainable tourism}

Tourism has been among the fastest growing sectors of the global economy (Costache, 2012; Jovicic \& Sinosich, 2012; Kasim, 2006; United Nations, 1999). In the 1950s, 25 million people were recorded as travelling abroad. By 1997, the number increased to 617 million and then to 1.087 billion in 2012. The number is estimated to continue rising and reach 1.6 billion people by 2020 (Costache, 2012). In economic terms, the industry has been contributing trillions of dollars to the global economy and creates millions of jobs worldwide (World Travel and Tourism Council, 2013). In the year 2000 , the total contribution of the industry to the economy was US\$2 
trillion. The number tripled in 2012, making up 9 per cent of global GDP. The absolute number of people that are involved in the industry has also been increasing. In 2000, tourism provided 150 million jobs for the labour market. The number then climbed to 261 million in 2012 and is forecast to reach 338 million by 2023 (World Travel and Tourism Council, 2013).

Tourism has long been considered a recipe for development, especially in developing countries. In 1999, 80 per cent of Poverty Reduction Strategy Papers introduced by the International Monetary Fund mentioned tourism as an important economic sector to be beneficial to the poor (Mann, 2005, as cited in Scheyvens, 2012). Costache (2012) argues that these countries possess pristine natural and cultural sites that are assets to tourism development. Compared to other industries, tourism does not require costly investment such as infrastructure or highly skilled staff if countries select nature-based activities as their major type of tourism service. This, according to the United Nations (1999) and World Tourism Organization (2014), is particularly true for very small and small island developing states with acute shortages of resources. As such, the tourism industry tends to be suitable for these countries to focus on in the short and medium terms. Also, tourism is believed to be the best way for these countries to boost their economies; pay their overseas debts (Costache, 2012); and a key role in achieving the Millennium Development Goals by 2015 (Francesco Frangialli, Secretary-General of the UNWTO, as cited in Scheyvens, 2012) as it creates more jobs and income for local people and generates more foreign currency. These above reasons explain why tourism has occupied a pivotal position in countries' development plans (Costache, 2012; Sharpley, 2000; United Nations, 1999). According to the World Tourism Organization (1998), tourism is a key economic sector in 11 out of 12 developing countries that make up 80 per cent of the poor worldwide (as cited in Ashley, Boyd, \& Goodwin, 2000). The report by the World Travel and Tourism Council (2013) also reveals that Asia, Pacific, Latin America and sub-Saharan Africa were among the fastest growing tourism destinations in 2012. 
The initiation and development of the concept of "sustainable development" has forced specific industries to review their own path of development. Tourism is not an exception with the term "sustainable tourism" brought to life. A simple definition of sustainable tourism that responds to the Brundtland definition of sustainable development is such as "forms of tourism which meet the needs of tourists, the tourism industry, and host communities today without compromising the ability of future generations to meet their own needs" (Swarbrooke, 1999, p.13).

In detailed terms, sustainable tourism, according to World Tourism Organization (1998), is defined as one which:

Meets the needs of present tourist and host regions while protecting and enhancing opportunities for the future. It is envisaged as leading to management of all resources in such a way that economic, social, and aesthetic needs can be fulfilled while maintaining cultural integrity, essential ecological processes, biological diversity and life support systems. (p.21)

The above definition shows that, in order for tourism to be sustainable, it must take three aspects of development including economic, social and environmental into account. Similar to its mother concept, the definition of sustainable tourism has been criticized for being "patchy, disjointed and often flawed with false assumptions and arguments" (Mbaiwa, 2011, p.49). One possible reason for that may lie in the fact that the tourism industry includes a wide range of segments and therefore it is “complex" and "fragmented" (Mbaiwa, 2011, p.50).

In 1996, an action plan named "Agenda 21 for the Travel and Tourism industry: Towards environmentally sustainable development" was launched (Swarbrooke, 1999). This is based on the Rio Earth Summit results in 1992 with an aim to detail what the tourism industry should follow to contribute to the achievement of sustainable development. Ten principles were mentioned. Overall, they highlight 
the important roles of women and indigenous peoples in tourism development and the participation of people from the local level in tourism-related decision making processes. In terms of the environment, travel and tourism should place environmental protection at the centre of tourism activities; protect and restore the planet's ecosystem; help people to live in harmony with nature and respect international laws concerning environmental protection (World Travel and Tourism Council, 2002, as cited in Swarbrooke, 1999).

The concept of sustainable tourism is particularly crucial for developing countries which have been struggling with problems caused by the rapid expansion of tourism. In these countries, due to massive tourism development without appropriate planning for the long run, the environment has been badly damaged as the number of tourists has exceeded the possible carrying capacity, the cultural values have been violated with the penetration of foreign cultures imported by travellers. In economic terms, since policies have not been maintained to keep up with the increasing growth, a huge amount of profit has been transferred abroad while the host countries have not fully enjoyed the benefits that they should expect (Costache, 2012; United Nations, 1999).

\section{$2.4 \quad$ Tourism and environment}

Tourism has often been known as the "smokeless industry" (Cater, 2008, p.331). However, for some critics, that perception seems not to be so anymore since the industry has been blamed for causing serious impacts on the environment. At the same time, supporters argue that the industry can contribute to environmental conservation in a number of ways (Beech \& Chadwick, 2006; Cater, 2008; Swarbrooke, 1999). These two contradictory opinions denote a complicated relationship between tourism and environment. This was once highlighted by Holden (2008) when he addressed that the two terms "can be interpreted as intricate systems, where actions taken in one part of the system have consequences for its other component parts" (p.xv). 
Before digging into this relationship, what constitutes the environment should be addressed. Swarbrooke (1999) divides the environment into five segments: the natural environment, the farmed environment, the built environment, natural resources and wildlife. Each segment is detailed in Figure 1 as follows:

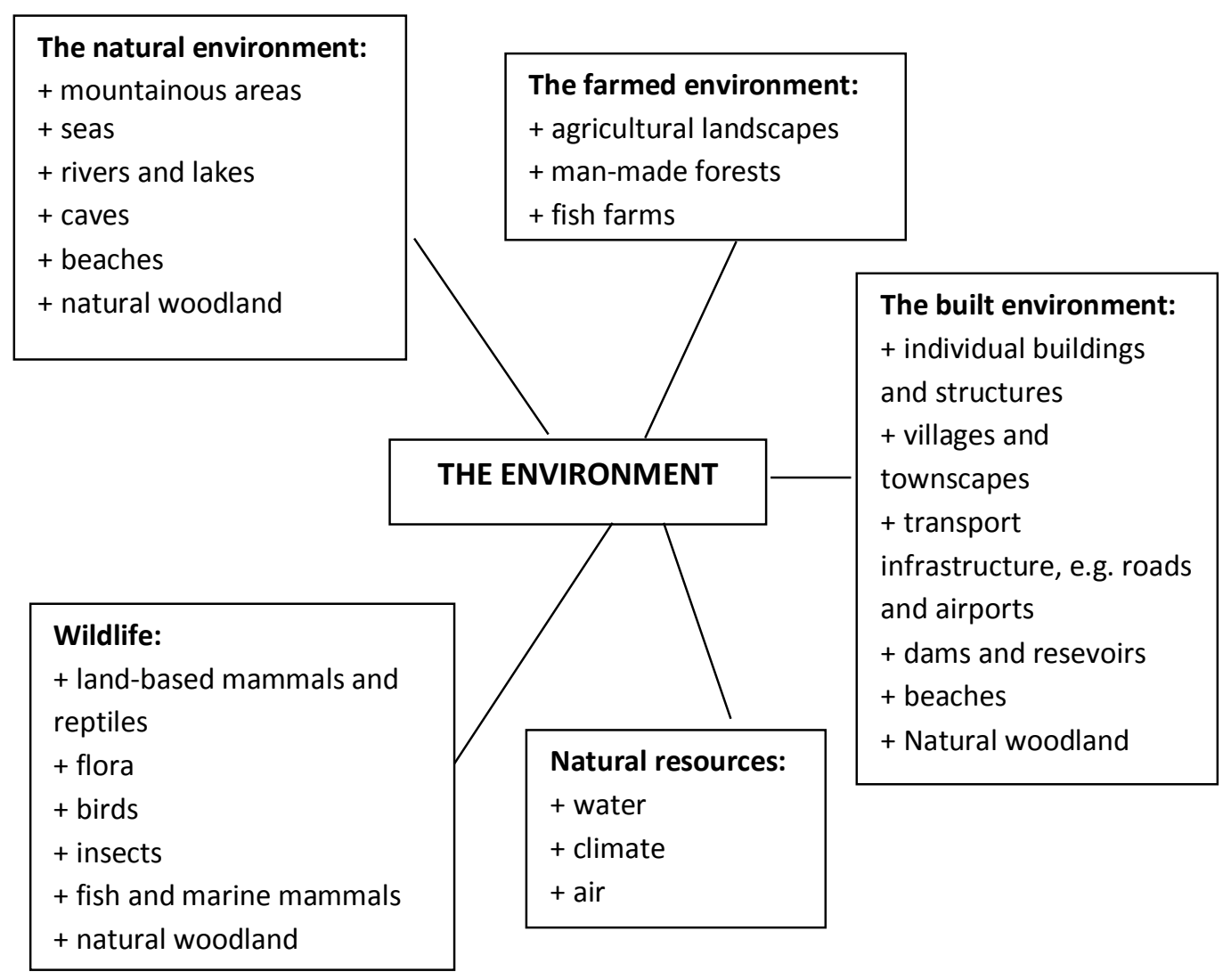

Figure 2: The scope of the concept of the environment

(Source: Swarbrooke, 1999, p.50)

Accordingly, tourism's activities can create impacts on each environmental segment in a number of ways. These impacts are summarised in Table 1 below: 


\begin{tabular}{|c|c|}
\hline $\begin{array}{l}\text { Environmental } \\
\text { segment }\end{array}$ & Potential consequences \\
\hline $\begin{array}{l}\text { The natural } \\
\text { environment }\end{array}$ & $\begin{array}{l}\text { - increasing disappearance of floral and faunal } \\
\text { species } \\
\text { - water, air and noise pollution } \\
\text { - land erosion } \\
\text { - depletion of natural resources } \\
\text { - visual disturbance }\end{array}$ \\
\hline $\begin{array}{l}\text { The farmed } \\
\text { environment }\end{array}$ & $\begin{array}{l}\text { - destroyed crops, possibly by tourists or fire } \\
\text { caused by tourists } \\
\text { - increasingly narrowed farmland to give space } \\
\text { for tourism infrastructure } \\
\text { - shared water supplies }\end{array}$ \\
\hline $\begin{array}{l}\text { The built } \\
\text { environment }\end{array}$ & $\begin{array}{l}\text { increasing degradation as number of tourists } \\
\text { exceeds the possible carrying capacity }\end{array}$ \\
\hline Natural resources & $\begin{array}{l}\text { - reduced water supply as serving tourism } \\
\text { activities } \\
\text { - polluted water sources due to disposal of } \\
\text { sewage, waste and fuel to the environment } \\
\text { - polluted air due to carbon dioxide emissions }\end{array}$ \\
\hline Wildlife & $\begin{array}{l}\text { - destroyed habitats } \\
\text { - affected feeding habits } \\
\text { - disrupted breeding patterns } \\
\text { increasing disappearance of floral and faunal } \\
\text { species }\end{array}$ \\
\hline
\end{tabular}

Table 1: Potential consequences of tourism on the environment

(Source: Buckley, 2011; Hobson et al., 2001; Kasim, 2006; Swarbrooke, 1999)

The tourism industry is believed to contribute to environmental conservation in a number of ways. Tourism motivates governments to protect the environment as 
it is the basis for tourism to develop. Swarbrooke (1999) argues that without this motivation, the environment is subject to more damage as a result of industrialization and urbanization, especially in developing countries. UNEP (n.d.) points out that tourism provides funds directly to the conservation of sensitive areas from entrance fees paid by visitors. Other financial instruments such as eco taxes, income taxes, taxes on sales or license fees for special recreational activities can, on the one hand, influence the way tourists decide their activities and on the other hand, contribute to governmental revenues that can be used for conservation programmes. Examples from wildlife viewing mentioned by Cater (2008) can illustrate this argument. A lion in Amboseli National Park in Kenya is estimated to earn US\$515,000 from tourists through its lifetime. In Botswana, recreational activities pertaining to elephants contribute US\$39 million to the GDP. Tourism also has the potential to raise the public awareness of environmental issues by bringing people closer to nature. This kind of connection tends to affect people more strongly than normal educational activities such as reading newspapers or watching television programmes (Swarbrooke, 1999; UNEP, n.d.).

\subsection{Accommodation sector}

The accommodation industry is considered the largest sector within the tourism industry (Adesina \& Ngozi, 2013; Bohdanowicz, 2005; Bohdanowicz, 2006; Candrea \& Bratucu, 2012; Hsieh, 2012; Kasim, 2007; Kasim \& Scarlat, 2007). Its introduction is attached with that of the tourism industry as it provides the most fundamental services for tourists: a place to stay and food to eat when they are away from home. Swarbrooke (1999) reveals a simple typology of the accommodation sector which includes three parts: serviced accommodation, non-serviced accommodation, and food and drink outlets. Serviced accommodation includes hotels, resort complexes, cruise-ships, motels while self-catering places, caravans, tents and youth hostels make up non-serviced accommodation. Food and drink outlets consist of restaurants, bars, fast food outlets and family-owned eating places. As can be seen, the accommodation industry encompasses a wide range of services, each of 
which affects the environment to some extent. These impacts of a single service could be insignificant, but this will not be the fact if impacts of all services are considered as a whole. As such, it becomes one of the sectors in the tourism industry that makes the biggest contribution to environmental deterioration.

The accommodation sector has been blamed as "among the most energyintensive and water consuming sectors of the tourism industry" (Candrea \& Bratucu, 2012, p.467). Waste is probably the most tangible effect that the sector has on the environment. Depending on type and size, hotels can generate different amounts of waste. On average, a guest can create over one $\mathrm{kg}$ of solid waste per day, which means many tons of waste can be generated each month (Bohdanowicz, 2005). It is estimated that about 50 per cent of this solid waste produced can be recycled or reused; the figure can be higher in developed countries (Bohdanowicz, 2005; Kasim \& Scarlat, 2007). This means if hotels have a good waste classification system and well operated waste treatment plants, the impacts of waste on the environment can be reduced significantly. Unfortunately, this is not always the case and as a result, a huge amount of waste is disposed into the environment, making destination countries struggle to solve the problem that is likely to threaten the tourism industry. This is even worse in island countries (Kasim, 2007).

Compared to solid waste, carbon dioxide emissions have probably the least visual environmental impact of the accommodation sector. However, that does not indicate that its impact is minor. Peeters and his team's research (2010) reveals that if tourism were a country, its contribution to the total carbon dioxide emission globally would come fifth after the United States, China, the European Union and Russia, and the accommodation sector plays a considerable part in that. There is no doubt hotels need a great deal of energy to run facilities for heating, air-conditioning, lighting, washing, and cooking etc. The use of electricity and types of fossil fuel to generate power are conducive to the emission of carbon dioxide and other air pollutants, contributing to global warming (Bohdanowicz, 2005; Peeters et al., 2010; Kasim \& Scarlat, 2007). As estimated, a typical hotel will release an average of 160 
to $200 \mathrm{~kg}$ of $\mathrm{CO}_{2}$ per $\mathrm{m}^{2}$ of room floor area every year (Energy Efficiency Office, 1994, as cited in Bohdanowicz, 2005). With the increasing growth rate of the hospitality sector on a global scale, this environmental impact is believed to become more and more significant.

Another worrying environmental impact that the accommodation sector can have on the environment pertains to the water supply (Bohdanowicz, 2005; Kasim, 2007; Kasim \& Scarlat, 2007). Hotels consume a huge amount of water not only for basic services but also for recreational activities. Typically, a luxury hotel in a tropical climate will use from 1,000 to 1,400 cubic metres of water daily while that number for a typical household in similar conditions is 1.12 cubic metres of water (Socioeconomic \& Environmental Research Institute of Palau Pinang, 1999, as cited in Kasim, 2007). In Spain, statistics show that 0.88 cubic metres of water is used by one tourist per day while one citizen consumes approximately 0.25 cubic metres per day (World Wildlife Fund, 2003, as cited in Kasim, 2007). Obviously, water consumption by a tourist is much higher than that by a local household member and therefore, a large water supply must be secured for tourist activities. For the countries that depend on dammed reservoirs, rivers and lakes, the heavy demand for water from accommodation businesses can exhaust these sources. Another issue related to the water supply facing the sector is its quality (Bohdanowicz, 2005; Kasim, 2007; Kasim $\&$ Scarlat, 2007). The more water is used, the more sewage will be generated. Hazardous waste is produced as well through hotel maintenance tasks or infrastructure construction such as golf courses which require a large amount of fertilizers. A lot of sewage that is disposed into the environment, especially to the sea and rivers without treatment, has contaminated the water sources, destroyed the landscape and affected the lives and livelihoods of people living in surrounding areas.

Given the impact of the accommodation sector on the environment, the fact that accommodation businesses understand and integrate protective measures into their operation will produce significant and positive changes to the natural environment, thereby promote sustainable tourism and then sustainable development. 
Fortunately, it is not until recently that these businesses have become aware of their remarkable capacity pertaining to this matter. Since the 1990s, a number of initiatives in the hospitality industry have been born, some of which worth mentioning include the International Hotels Environmental Initiative launched by the Prince of Wales in 1993, and the Asia Pacific Hotels Environmental Initiative in 1994 (Mensah, 2006). Other general initiatives for businesses such as ISO 14000 series of environmental management systems or social corporate responsibility are also employed in the accommodation industry. However, basically, these codes of conduct are forms of voluntary regulation with the aim of encouraging businesses rather than obligating them.

Inspired by this issue, a number of scholars have conducted studies into the hospitality managers' environmental attitude in recent years. Some scholars (Candrea \& Bratucu, 2012; Chan, 2008; Chan \& Wong, 2006; Erdogan \& Baris, 2007; Gil, Jimenez \& Lorente, 2001; Hobson \& Essex, 2001; Kirk, 1998; Mensah, 2006; Stabler \& Goodall; 1997; Tzschentke, Kirk \& Lynch, 2004; Vernon et al., 2003) explored the response of hotel managers towards environmental issues in a single location while others (Bohdanowicz, 2005; Bohdanowicz, 2006) investigate regional variations. Some of these studies examined the accommodation units as a whole while some just focused on small and medium ones as large sized units were thought to have more capital resources and motivation to integrate environmental issues into their operation than the small and medium ones. The methodology varied from study to study, depending on the number of participants. Some used email-based questionnaires while others used semi-structured interviews or focus groups.

Although each study explored different aspects relating to the response of hotel managers to environmental concerns, generally there are four major aspects that can be mentioned including the awareness of hotel managers of environmental impacts and initiatives; motives to deploy environmental protection measures; actions made by hotels to reduce environmental impacts; and challenges hotels face when deploying those protection measures. 


\section{Hotel managers' awareness of environmental impacts and initiatives}

Before examining the motives and actions to reduce environmental impacts that the accommodation sector creates, it is essential to know the level of environmental awareness of hotel managers. Some studies reveal disappointing results. In research conducted by Hobson and Essex (2001) in Plymouth, United Kingdom, most of the participants showed a high level of understanding of the environmental role in the tourism industry. Of the participants, 77 per cent ranked the issue to be important or very important. However, although highlighting the environmental role, many hotel managers thought that their businesses had no responsibility towards environmental damage.

Exploring the environmental awareness of 135 hotel managers in Guernsey using a self-completed questionnaire, Stabler and Goodall (1997) found out that, although more than 75 per cent of participants recognized that environmental deterioration would put Guernsey tourism under threat, only 8 per cent and 4 per cent thought the tourism industry and accommodation sector respectively contributed significantly to this issue. 18 per cent were well aware of sustainable tourism and 7 per cent knew about the International Hotels Environmental Initiative. Using a similar research method, Mensah (2006) found a similar result. Exploring the hotel industry in the greater Accra region of Ghana, Mensah discovered that environmental management, as the majority of participants answered, meant "keeping their surroundings green and attractive with flowers and other ornamental plants" (p.424). This is considered "a very narrow view" (Mensah, 2006, p.424) as environmental management consists of a wider range of actions rather than just keeping the hotels' look green. The study also shows that most of the hotels did not have environmental policies, neither verbal nor written. 23 per cent of participants said this was not necessary while 18 per cent thought their hotels were too small to require such policies. 
Unlike the previous studies, Erdogan and Baris (2007) examined the understanding of hotel managers about the existing international and national environmental initiatives in the accommodation industry in Ankara, Turkey. Using both qualitative (in-depth interviews) and quantitative (email-based questionnaires) methods, Erdogan and Baris revealed a general lack of concern among participants about environmental practices. When asked about the practices such as ISO 14001, energy-saving and recycling systems, only 20 per cent of participants reported that they had sufficient knowledge, 30 per cent thought it insufficient while 32.5 per cent had no understanding. Regarding the national initiative called the Pine Award, among more than 30 hotels that received the awards by 2005, almost half of the managers (46.2 per cent) had no knowledge of this award while 30.8 per cent had very little. These results show the low level of understanding among hotel managers about environmental protection tools, which could be grounded from the inadequate information, training and communication between the relevant governmental offices and the hotel industry.

Fortunately, some studies reveal more positive attitudes. In a study examining the hotels around Europe by Bohdanowicz (2005), eight out of ten participants thought environmental protection was crucial for the development of the tourism industry, and nearly 100 per cent agreed that their businesses affected the natural environment, ranking that impact from medium to substantial. Regarding the environmental institutions which offer guidelines and advice for hotels to be ecofriendly, an average of 40 per cent were aware of the existence of certain institutions. Although there was a difference in percentage between chain-affiliated and independent hotels (51.4 per cent and 24.2 per cent respectively), the average figure was still optimistic. One year later, in 2006, Bohdanowicz conducted a similar study but with hotels in Sweden and Poland only. The results were consistent with that of the above study. However, for both cases, Bohdanowicz suggested a need to treat results with caution considering that the hotel managers overstated their environmental commitment in order to build up good public image. 


\section{Motives to deploy environmental protection initiatives}

Chan and Wong (2006) examined the motivations for getting ISO 14001 certification of hotels in Hong Kong, Macau, Shenzhen and Guangzhou. 1,097 questionnaires were sent out but only 164 replies were received. In spite of this low response rate, the study provided some insights into why hotels deploy environmental protection measures. The study reveals eight motives that were mostly picked up by hotel managers: (i) corporate governance, which means that the more involved the corporate office is in planning and implementation, the higher the possibility that its branches will adopt the standards; (ii) ISO benefits such as cost saving, improvement of process efficiency, etc; (iii) top managers' environmental concern; (iv) legislation which refers to the government's assistance to encourage enterprises to "go green"; (v) market trend; (vi) fear of trade barriers that pertain to environmental requirements; (vii) customers' interest in environmentally friendly establishments; and (viii) the environmental participation of competitors. Obviously, none of these motives deal with the concern for environmental protection. Instead, they all stemmed from the needs of the business in question, which is understandable as they are profit-oriented units.

Cost saving is another reason behind the application of environmental practices (Ayuso, 2006; Stabler \& Goodall, 1997; Tzschentle et al., 2004). According to the findings of Tzschentle et al. (2004), this is the major motive among hotels in Scotland resulting from the rising costs of water, energy and waste disposal. Finding it difficult to affect customers' usage of energy, the hotels had to employ operationally efficient facilities. In addition, some held the belief that as environmental practices allowed good management, they benefited the businesses, especially small firms in terms of finance in the long run. Ayuso (2006) shared similar findings in his study of Spanish establishments. Environmental practices were believed to minimize operational costs and secure medium and long-term profits. This motive was selected by 26 per cent of the hotel managers in the research conducted by Stabler and Goodall (1997). 
Another motivation comes from the pressure of stakeholders (Ayuso, 2006; Gil et al., 2001). Gil et al. (2001) identified the closest stakeholders to hotels including "shareholders, government, travel agencies and tour operators, chain or hotel association, customers, competitors, employees, non-governmental organizations [...], and suppliers" (p.464). Each stakeholder affected the decision of hotels to go green to a different extent. Added to the list, Kirk (1995) mentioned the relationships with the local community. In Ayuso's (2006) research, customers and tour operators have the biggest influence. Ethical concerns also drive hotels to adopt environmental measures, though sadly not many studies show this. According to Tzschentle et al. (2004), there were three major reasons for hotel managers to be ethically concerned: (i) "to do my bit", (ii) "it's the responsible thing to do" and (iii) "it's the right thing to do" (p.119). Generally, these answers were rooted in the sense of being responsible to the society and future generations.

Difficulties that prevent hotels from employing environmental protection measures

Studies show that, for hotels that are using environmental protection measures and those who are not, the difficulties they experience fall into two major categories: cost-related issues and lack of information and knowledge. Although cost saving is one of the reasons that motivate businesses to adopt environmental practices as explored above, this is, interestingly, the biggest difficulty that businesses face concerning the same issue. Chan (2008), examining the barriers to apply for Environmental Management Systems in the Hong Kong hospitality industry, found out that a huge amount of money had to be spent on implementation and maintenance tasks if hotels wanted to go for Environmental Management Systems. This sum of money would be used to pay for extra staff, equipment purchases, and Environmental Management Systems related costs such as consulting fees, application fees, etc. More than half of the participants in a study by Hobson and Essex (2001) expressed their similar concern over the financial cost at the beginning of an environmental protection path. Adding to this, Candrea and Bratucu (2012) revealed that most of 
their participants were reluctant to become eco-friendly, given their concerns over fluctuating tourist flows and reduced revenues. If such things happened, they felt the money gained could not compensate for the spent costs. Consistent with the result of low level awareness of environmental impacts and initiatives among hotel managers, lack of information and knowledge is another difficulty. In Chan's study (2008), participants admitted that they had little access to sources of information about environmental issues and initiatives. Even when being aware of environmental impacts that their businesses caused to the environment, they did not know how to start or what to do, given the lack of professional advice or guidelines.

\section{Conclusion}

Sustainable development has become a favourable concept among different actors involved in the development world and a popular development model for countries to follow. Although it is made up from three elements including economic, social and environmental aspects, the environmental aspect tends to be of centre concern given the growing pressure society's growth has been placing on the environment. The popularity of this development concept has required each specific sector to review itself in order to have an appropriate response. Tourism cannot escape that requirement, especially when it has been considered one of the fastest growing economic sectors in the world. The literature revealed that the accommodation sector, the largest sector within the tourism industry, had significant positive and negative impacts on the environment. Therefore, the response of this sector, either good or bad, would lead to corresponding changes in the environment.

Inspired by this issue, a number of scholars have conducted research into the hospitality managers' environmental attitudes in recent years. Some scholars looked at the reasons why hospitality enterprises use environmental tools while other studies focused on the adoption of environmental instruments alone. Some explored the behaviours of hotel managers towards environmental issues in a single location while others investigated regional variations. In such studies, some examined the 
accommodation units as a whole while some just focused on small and medium ones since large sized units are thought to have more capital resources and motivations to integrate environmental issues into their operation than the small and medium ones. Regardless of the variation among the existing studies, they have all provided insight into why and how accommodation businesses react to the increasing concern over environmental problems, and have offered valuable suggestions as to what governments should do in order to develop their tourism industry in a more environmentally friendly way.

However, studies on the issue are still restricted in some specific locations. To the best of my knowledge, there are few studies on the same issues in many developing countries, which is a significant gap. In developing countries, tourism has been identified as one of the crucial industries for their socio-economic development. At the same time, environmental conditions are thought to be worst in less developed countries. For this reason, this study on the issue will be extremely valuable. This encourages me to carry out research on the topic of environmental perceptions of hotel establishments in my hometown Da Nang city, Vietnam. Moreover, I decided to examine the privately owned accommodation businesses only. The literature reveals the vital role of the private sector in sustainable development. They have financial potential, technological power and managing models to promote sustainable development. In addition, as they depend on environmental and social input to grow, promoting sustainable development is the ethical obligation they should fulfil. Therefore, to achieve sustainable development, the government's sole action is believed to be ineffective unless it gains collaboration from other stakeholders, particularly the private sector. 


\section{CHAPTER 3: METHODOLOGY}

\section{Introduction}

This chapter will explore the methodology used to answer the major research question and five sub research questions outlined in chapter one. First, it examines the approach and method to conduct the fieldwork before outlining two essential procedures including data collection and data analysis. The final part of the chapterpresents some ethical, health and safety issues, fieldwork reflection, issues of positionality and power, and some limitations of the field research.

\subsection{Theoretical approach and method}

Mikkelsen (1995) draws on some challenges that development practitioners and researchers usually meet in the field, one of which is the respect for the local community's cultures, beliefs and ways of living. According to the scholar, this respect is the foundation for communication between the researchers and the researched. Furthermore, these cultures, beliefs and ways of living are thought to rule people's actions. By understanding these values, development practitioners and researchers are able to examine problems that the local community faces and then look for suitable solutions. As this thesis examines developmental issues, its approach and methodology draw on Mikkelsen's views. Accordingly, the social constructionist epistemological approach is used to investigate the environmental attitude of accommodation businesses in Da Nang city, Vietnam. According to Loseke (2003), there are five tenets of this approach:

$>\quad$ In the world of constructionist researchers, conditions are not social problems until they are claimed by people;

$>\quad$ The constructionist approach pays attention to human beliefs and how those beliefs shape people's understandings of the world; 
$>\quad$ The constructionist approach seeks to know what influences human beliefs in the world;

$>\quad$ While the objectivist approach often makes claims about how the world should be set up, the constructionist approach stresses how these claims can be constructed to make a better world;

$>\quad$ If the objectivist approach answers a series of questions of "what", the constructionist approach answers questions of "how".

This epistemological approach suits because the research is interested in the attitudes and behaviours of hotel managers. It aims to seek understandings of how they construct ideas and practices about environmental issues.

However, Loseke (2003) also points out some criticisms that the constructionist approach faces. First, she wonders whether social constructionism diverts "our attention from more important questions about social problems" (p.166) by spending time and energy on understanding conditions. Second, the approach is criticized for lack of "explicit value judgments" (Loseke, 2003, p.166) as for scholars following the approach, what is right or wrong does not matter. Another criticism that confronts constructionist researchers is that their studies are rarely concerned with the extent of truthfulness in participants' answers.

Following this approach, qualitative methodology will be used as it suits the social constructionist epistemology which seeks to understand how people think and behave. Qualitative methodology is based on the view that knowledge is context specific.

All human experience has context. There are always preconditions and prior circumstances - there is always a history. And invariably, the larger context is a complex reality that defies simple explanation. Yet to even attempt to understand a facet of social life without at least partially reconstructing both the instructional and historical 
settings within which it is rooted would be folly. Our understanding would be flawed from the outset. (Hunter, 1991, p.3, as cited in Steinberg \& Cannella, 2012, p.33)

Regarding the same issue, different contexts may produce dissimilar findings. Also, within the same context, people may have different understandings of an issue depending on the viewpoints, cultures, beliefs or religions they are exposed to. That explains why qualitative research usually requires the researcher to go to the field, where the interviewees are, to collect data. Using this, qualitative methods allow the researcher to explore the research question deeply by capturing the participants' actual opinions, thoughts, feelings and experiences (Creswell, 2003). Also, employing this approach, the researcher desires to see the "insider view", not the "outsider view" that he/she imposes on the participants (Mason, 2002, p.56).

Qualitative methodology guides the choice of methods which ask people what they think and do. Semi-structured interviews are used for a number of reasons. First, it allows the researcher to change the order or refine the questions when needed as "the inquirer learns what to ask and to whom it should be asked" (Creswell, 2003, p.181). Second, semi-structured rather than structured interviews will be conducted in order to make communication between the researcher and the researched more flexible and open. As a result, rapport can be built between the researcher and the researched as some questions are designed to make the interviewees feel comfortable and relaxed before the interview starts. Also, the research psrticipants can focus on what they are most concerned with and raise questions when necessary (Creswell, 2003; Mason, 2002). Another strength of the semi-structured interview is that since it empowers the interviewees to ask questions themselves and sometimes the issues raised may not have been thought of by the interviewer before, yet may have significance for the research. That explains why the technique is called "inter-view" - "a mutual exploration of the issues" (Nichols, 1991, p.13). 
However, interview-based qualitative research has some limitations. Hammersley (2005) summarizes three major criticisms: (i) it would be impossible for researchers to know whether the research participants are telling the truth; (ii) discrepancy between words and actions, which means the researched may say what they do not actually do; and (iii) because of the two mentioned criticisms, the data collected through interviews is considered incomplete compared to those collected from participant observation which gives researchers greater access to what informants do.

During the field research, some quantitive data were also collected from the interviewees. These data were analysed quantitatively (tables and graphs) necessarily representative of all managers because of small sample size.

\subsection{Data collection procedures}

\subsubsection{Research location:}

Da Nang city in Vietnam is chosen as the research location for a number of reasons. Located at the heart of Vietnam, the city, together with other provinces of the central and highland region, forms a key economic zone of the country. The city's development is the driving force for the growth of the whole region. Also, it is among the favourite destinations for domestic as well as international visitors to Vietnam. Surrounded by long white sandy beaches and mountains, it possesses many beautiful landscapes that are valuable resources for tourism development. It is also at the midpoint of three world cultural heritage sites including the ancient capital of Hue, Hoi An ancient town and My Son sanctuary. With such favourable conditions, tourism is considered one of the key industries of the city (Tourism portal Da Nang city, 2011).

The second justification for choosing Da Nang city as the area for research is that Da Nang is one of a few cities in the country that has paid serious attention to the environmental protection with a number of valuable policies. One of them is the 
scheme to build up Da Nang into an environmental city by 2020 approved in 2008 by the People's Committee of the city (ISET, 2011). Accordingly, environmental concerns are taken into consideration in all social as well as economic activities. The intended purpose of the scheme is to create a safe and healthy environment for local people, investors and tourists to the city. Under this circumstance, the way accommodation enterprises respond to the environmental issues will be even more important. However, since so far there is no study examining this issue in Da Nang city, the proposed research will provide a better understanding of the issue in the city and then offer necessary recommendations for the city government and Vietnamese government in general to manage the industry sustainably.

\subsubsection{Interviewees and data sources}

There were two groups of interviewees investigated. The first group were managers of privately owned hotels. This specific group of hotels was selected as the private sector has been playing an increasingly important role in the country's social and economic development. However, although Vietnam has been undergoing a strong flow of capital investment and striving to create the best working environment possible for private enterprises, there remain doubts over the communication channel between the government and the private sector, and the state-owned firms being prioritized over the private ones. Therefore, selecting this group as participants allowed me to see the connection between the government and the sector.

The hotels were divided into three categories based on their size: large, medium and small. The reason to break hotels into different sizes was to increase the possibility of generalizing the research findings for the whole accommodation sector as the literature shows that the size of hotels plays a big role in affecting managers' responses to environmental concerns. The number of hotel managers was planned to be fifteen with five from each category. The actual numbers of hotel managers turned out to be five from the large hotels, four from the medium and six from the small hotels. See Table 2 below for a list of interviewees according to the three categories: 


\begin{tabular}{|l|l|l|l|l|l|}
\hline \multicolumn{2}{|l|}{ Large hotels } & \multicolumn{2}{l|}{ Medium hotels } & \multicolumn{2}{l|}{ Small hotels } \\
\hline No. & $\begin{array}{l}\text { Code } \\
\text { number }\end{array}$ & No. & $\begin{array}{l}\text { Code } \\
\text { number }\end{array}$ & No. & $\begin{array}{l}\text { Code } \\
\text { number }\end{array}$ \\
\hline 1 & LH1 & 1 & MH1 & 1 & SH1 \\
\hline 2 & LH2 & 2 & MH2 & 2 & SH2 \\
\hline 3 & LH3 & 3 & MH3 & 3 & SH3 \\
\hline 4 & LH4 & 4 & MH4 & 4 & SH4 \\
\hline 5 & LH5 & & & 5 & SH5 \\
\hline & & & & 6 & SH6 \\
\hline
\end{tabular}

Table 2: List of interviewees

(Source: Author)

The research aimed to explore the response of privately owned accommodation businesses only, which was stressed during the recruitment process. However, one medium sized hotel that was state-run agreed to join, and I was not aware of its state-owned status until the interview. After the interview, I was confused about whether I should integrate its data into my research. Then I decided to use these data to make a minor comparison with what had been obtained from the privately owned businesses, from which some recommendations could be offered for future research.

The second group of interviewees included officers from the Tourism Association of Da Nang city, and relevant city departments including the Department of Culture, Sports and Tourism and the Environmental Protection Agency which works under Department of Natural Resources and Environment. The expected number of interviewees for the second group was three with one officer from each department. However, when I was in the field and tried to contact the officials, it turned out to be harder than I anticipated. Finally, I was able to access the chairman of the Tourism Association of the city and had a face-to-face interview with him. The 
officer from the Department of Culture, Sports and Tourism agreed to join the project but did not want an interview. Instead, the officer sent me an email, providing some information about the current situation of the issue in Da Nang in recent years, some policy documents and public websites. Regarding the Environmental Protection Agency, I tried to contact its head but he postponed the interview several times reasoning that he was too busy. I discussed this issue with my supervisor and then decided to work with public reports rather than waiting. Although the data collected from these officers was not the primary one, it was needed for in-depth analysis.

In addition to the two sources of information above, data was also gathered from some state run websites, some of which worth mentioning include http://www.chinhphu.vn/portal/page/portal/chinhphu/trangchu run by the Vietnamese Government, http://www.vietnamtourism.gov.vn/ run by the Vietnam National Administration of Tourism, http://ktxh.danangcity.gov.vn/home.aspx?page=SSVNCATEGORY9 and http://www.danang.gov.vn/portal/page/portal/danang/trang_chu run by the People's Committee of Da Nang city. These websites are very helpful and informative. They provide updated policy documents and reports at the national and local level, information and statistics on the tourism industry, background of Da Nang city and problems that the city faces around the environmental protection.

\subsubsection{How to recruit interviewees?}

\subsubsection{The recruitment process of hotel managers is summarized in the chart} below:

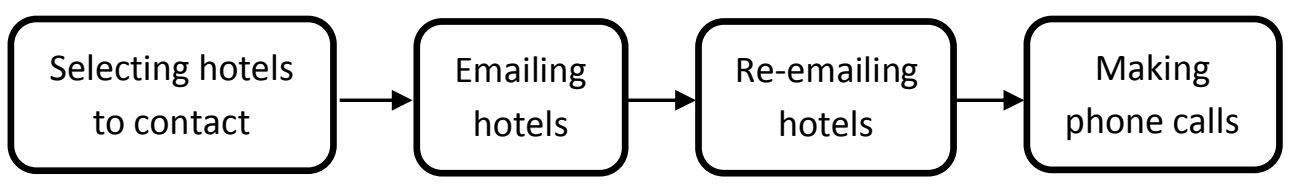

Figure 3: Recruitment process of hotel managers 
(i) Selecting hotels to contact: Randomly selected from the list posted on the Da Nang Tourism website. The number of stars indicated the size of hotel. In this research I decided to distinguish hotels' size according to the Decree No 56/2009/ND-CP on Assisting Medium and Small enterprises approved in 2009 (Government portal, 2009). There were two aspects indicating the size of enterprise, namely total capital and size of workforce. The division is addressed in the following table:

\begin{tabular}{|l|l|l|}
\hline $\begin{array}{l}\text { Size of } \\
\text { enterprise }\end{array}$ & \multicolumn{1}{|c|}{ Total capital } & $\begin{array}{l}\text { Number } \\
\text { of staff }\end{array}$ \\
\hline Large & $\begin{array}{l}\text { Over VND 50 billion (equivalent to } \\
\text { US \$2,500,000) }\end{array}$ & $\begin{array}{l}\text { Over } \\
100\end{array}$ \\
\hline Medium & $\begin{array}{l}\text { VND 10 billion to VND 50 billion } \\
\text { (US \$500,000 to US \$2,500,000) }\end{array}$ & $50-100$ \\
\hline Small & $\begin{array}{l}\text { Under VND 10 billion (US } \\
\$ 500,000)\end{array}$ & $\begin{array}{l}\text { Under } \\
50\end{array}$ \\
\hline
\end{tabular}

Table 3: Types of enterprises by capital and number of staff

(Source: Government portal, 2009)

Later when I interviewed those who agreed to join the research, I would know exactly what size the hotel was and then grouped them into three. The planned number of interviewees was fifteen managers with five from each size type. However, at the end of the research there were five from the large hotels, four from the medium and six from the small hotels.

(ii) Emailing hotels: Da Nang tourism website provided links to specific hotels. Accessing those sites, I could obtain the information including address, contact email and phone number. I started sending out emails in which I attached the ethics approval from the university and the information sheet of the research which 
briefly addressed the topic, purpose, significance of the research, the rights of the interviewees, and my responsibilities regarding the information they provided. The method of emailing was helpful to ask for participation in a number of ways. First, I could deliver sufficient information to help potential participants get an overall picture of my project. Second, the participants could have time to consider whether they wanted to join or not and then arrange a date. However, the disadvantage of this way of communication was that it took time. The email, when received, had to go through many administrative levels before it reached the general managers. As the hotels usually received lots of emails every day, my email could easily be forgotten and then no reply was made.

(iii) Re-emailing hotels: I re-emailed those people who had not responded within two weeks. The purpose of this step was to remind them in case they had forgotten or to invite them in case the previous emails had not reached them.

(iv) Making phone calls: I decided that this step would be the last option if I received only a few positive responses through email. In contrast with email, by making phone calls, I could not deliver sufficient information about my research, and my participants would not have much time to consider the invitation thoroughly. Unfortunately, there were only a few hotels with the general manager's phone number included on the hotel's website. I decided to contact all people that I know with the hope that some of them might have phone numbers for the general managers not listed. In this way, with the power of word of mouth, I finally got some phone numbers and started making phone calls.

\subsubsection{The recruitment process of officers is summarized in the chart below:}

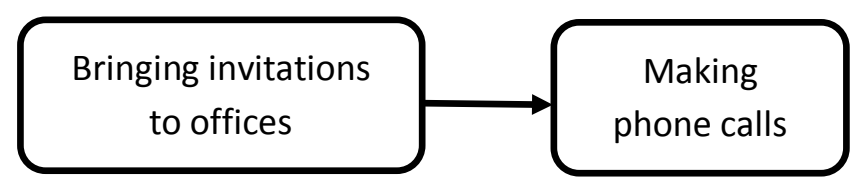

Figure 4: Recruitment process of officers 
The process of recruiting participants for the second group was quite different from the above. As I used to work for the city government previously, I was aware that officers rarely used emails to handle their tasks. All documents must be sent by post to the office or brought there yourself, and will be checked by the administrative room before reaching the head of departments. Therefore, at the same time when I sent out emails to hotels, I myself brought my invitation packages to three offices I mentioned above, namely the Tourism Association of Da Nang city, the Department of Culture, Sports and Tourism and the Environmental Protection Agency. The ethics approval and the information sheet were included in each package. Some days later, I called the administrative room of the three offices to confirm that my letters had arrived.

\subsubsection{Interview process}

As there were two groups of participants, there were two question lists for interview. The interview process went through the following stages:

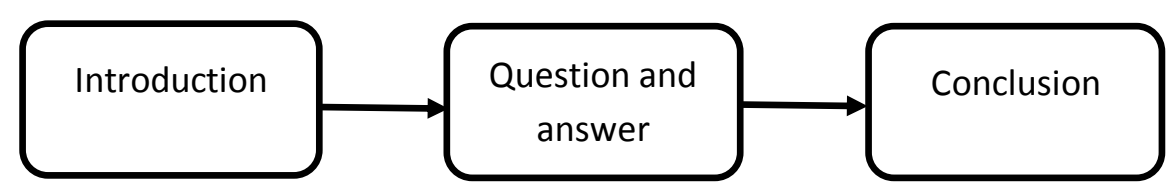

Figure 5: Interview process

(i) Introduction: I covered all issues mentioned in the information sheet that had been sent out as a reminder to the interviewees and to allow them to question anything that they felt unsure about. A consent form was given to the participant for his/her signature. However, there were only five interviewees who agreed to sign. The others explained that they felt uncomfortable and therefore they chose to deliver verbal agreements instead. At this stage, I also asked each participant whether they wanted me to record the interview or take notes. Nine of them agreed on recording while seven interviewees preferred that I took notes. 
(ii) Question and answer: At this stage, questions were asked and answers were provided. To put my participants at ease, I told them to answer the ones they felt comfortable answering and leave the ones they did not. The interviewees were also allowed to ask for clarification if they did not understand the questions provided or question anything else if they wanted.

(iii) Conclusion: I reminded the participants about the follow-up tasks that they had asked for when we went through the consent form such as a copy of transcripts, a record of the interview or a summary of the research to be returned to the participants, and confirmed to send them as soon as I could.

\subsection{Data analysis procedure}

The data analysis went through the following steps:

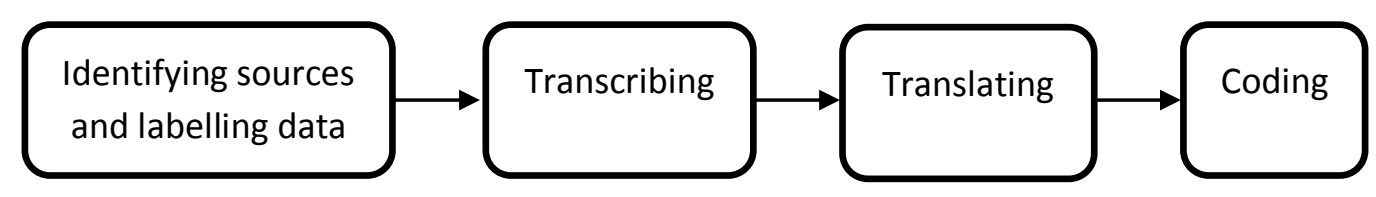

Figure 6: Data analysis procedure

(i) Identifying sources and labelling data: After an interview was completed, usually there were some documents that I had to deal with including the recording or the note, the transcript, the translated version, and the consent form (if any). Therefore, this stage was necessary to ensure the interviewee's documents would not become confused with those of the other interviewee's. Guest, Namey and Mitchell (2013) suggest three things that need to be distinguished:

* Source ID: In the case of this research, a source was a person. I named my interviewees with the codes I mentioned above. "LH1", "LH2", "LH3", "LH4" and "LH5" for managers of large hotels numbered 1, 2, 3, 4 and 5 respectively. 
Similarly, "MH1", "MH2", "MH3", "MH4” and "MH5" for medium hotel managers and "SH1", "SH2", "SH3", "SH4" and "SH5" for small hotel managers.

Data labels: The physical data such as the note and the consent form must be labelled to address that these data were associated with certain sources. Therefore, all data provided by LH1 would be labelled with LH1. Data from others would be done similarly.

* File name: Electronic files such as the recording, the transcript, and the translated version were kept in my laptop. They must be linked with certain sources, therefore I named the files with LH1 as a reminder that these files had been collected from LH1, for example the LH1 recording, LH1 transcript or LH1 translated version. File names from other sources would be similarly named.

(ii) Transcribing: After all data were organized, transcription commenced. I decided to transcribe myself rather than having someone do it. This task was simple yet boring and time-consuming. In my case, as I was not undertaking discourse and linguistic analysis, verbatim transcription was unnecessary (Guest et al., 2013).

(iii) Translating: All my interviews were conducted in Vietnamese and transcribed in Vietnamese. Since English is the language of analysis, I translated all transcripts into English. According to Guest et al. (2013), there are two approaches to translation: (a) source recording in language $\mathrm{A} \rightarrow$ transcription in language $\mathrm{A} \rightarrow$ translation of transcript in language B and (b) source recording in language $\mathrm{A} \rightarrow$ transcription/translation into language B (p.288). I applied the first approach as English is not my mother language and therefore it was hard to transcribe and translate in English at the same time.

(iv) Coding: According to Strauss (1987), "coding... is an essential procedure... The excellence of the research rests in large part on the excellence of the coding" (p.27). In qualitative research, there are many ways to code but they all share the same goal. That is to help researchers to get to know the meaning and focus 
on "specific characteristics" of the data they collect which are originally "unstructured and messy" (Richards \& Morse, 2013, p.149). In my case, I decided to code manually rather than use computer software. Initially I decided to code by categories which followed closely the questions I used for interviews (Barbour, 2008). The categories are as follows:

\section{$>\quad$ Perceptions of hotel managers \\ $>\quad$ Environmental practices hotel managers are using \\ $>\quad$ Reasons for using or not using environmental practices \\ $>\quad$ Collaboration between private hotels and the authorities}

Next, for each category, I started by doing literal coding using my participants' own words and expressions. After that, I moved to a more focused coding procedure (Hesse-Biber, 2010). At this stage, I did not place a label on certain segment of text to describe what it was, rather I looked for a code description that would help me to develop the understanding of what the interviewees were saying (Hesse-Biber, 2010). To do this, I looked through all literal codes of all interviews, and then compared them. Hence, the analysis was moved from "a literal to a more abstract level"' (Hesse-Biber, 2010, p.192).

\subsection{Ethical, health and safety issues}

\subsubsection{Ethical issues in data collection, data analysis and writing}

During data collection, analysis and writing, there are some ethical issues the researcher needs to be well aware of. In this research's case, ethical issues matter even more because "in-depth interviewing opens up what is inside people qualitative inquiry may be more intrusive and involve greater reactivity than surveys, tests, and other quantitative approaches" (Patton, 1980, p.356). Before going to the field to collect data, usually the researcher needs to get their research plans checked and approved at their universities (Creswell, 2003; Marshall \& Rossman, 2011). In 
my case, I needed to obtain ethics approval from Victoria University's Human Ethics Committee. As I collected information from people, this step was essential to examine whether my research topic was appropriate and whether the issues pertaining to participants would be taken into sufficient consideration. In order to get the human ethics approval, I submitted my ethics application package which included the form, the research proposal, the information sheet, the consent form and question lists I developed. Since the information sheet and the consent form were then handed to participants, they were designed to help them understand my research, my responsibilities towards their privacy and safety so that they would not confront any consequences after engaging in the research. Also, their right to participate voluntarily and withdraw information that they had provided at any time was mentioned in the consent form. Permission was granted by the ethics committee before the field research commenced.

To protect the identities of my participants, at the coding stage, pseudonyms were used (Creswell, 2003). I used the terms "LH1", "LH2", "LH3", "LH4" and "LH5" for managers of large sized hotel 1, 2, 3, 4 and 5 respectively. Similarly, "MH1", "MH2", "MH3", "MH4" and "MH5" for medium hotel managers and "SH1", "SH2", "SH3", "SH4" and "SH5" for small hotel managers. I also used these pseudonyms at the analysis stage when I quoted from interviews. The data, when collected, was kept in my laptop with a passcode. After being analysed, the data will be kept for two years before being destroyed. This is to ensure that the data cannot be exposed to others who may use them for different purposes (Creswell, 2003).

\subsubsection{Health and safety issues}

Although Da Nang city is my hometown, there remained need for me to pay attention to my own health and safety. I took care of myself in order to finish the data collection within the design timeframe. 


\subsection{Fieldwork reflection}

One challenge that confronted me when I was in the field was dealing with different types of interviewees. Some interviewees were very interested in my research, expressing that environmental protection was one of their concerns. As such, they did not mind spending a great deal of time with me. Not only did they give me very detailed and informative answers to the questions I asked, they also advised me on how to improve my questions in order to serve my research better. I found myself truly inspired after meeting those people. However, there were some who agreed to join the interview voluntarily but during the interview, they showed annoyance and gave very short answers. It appeared that they wanted to end the interview as soon as possible. I found this challenge interesting as I had a chance to see people's reactions to environmental issues, and also the way academic research occurred.

Another challenge was how to deal with irrelevant and longwinded answers. In some cases, the interviewees did not understand the questions and instead answering around the question subject area. Most of my interviewees were older than me, so it would be impolite if I stopped them half way through or showed little interest in what they said. I negotiated with myself and decided that it would be better to listen to them till the end and go back to the question afterward. By doing this, the interviewees would feel respected and valued, and in some cases, the answers were irrelevant to the questions yet triggered certain points meaningful to the research that I had not thought of previously.

\subsection{Positionality and power}

In the field, there were moments when I found myself in the same world with my interviewees. We all spoke the same language, had similar Asian appearance, 
culture, politics, and concerns over what was happening in our country and city. Also, as my interviewees were hotel managers, they had a similar level of education as mine. This somehow made our talks more comfortable and open. During the conversations, the interviewees sometimes mentioned experiences I used to face before, so I easily understood their answers. Hence, being an insider enabled me to approach people, start conversations and obtain information. To the group of governmental officers, at first I thought I was an insider since I used to work for the government, so at least we shared something in common such as concerns over the city's issues, the way we worked together, the networking between us. However, approaching this group turned out to be more difficult and more time-consuming than I had anticipated. I realized that they treated me as a student, not a colleague anymore. This way, I became an outsider to the world in which I used to be an insider.

Power is another issue that a researcher must pay attention to in the field. The researcher and the researched, depending on their own positionalities, will have certain power over each other. In my case, I had power over my interviewees because I triggered the research, I designed it in the way that I wanted and was the one to handle the information I collected from them. Meanwhile my participants could decide whether or not to join the research and provide reliable information. From my perspective, I tried to balance the power by keeping my interviewees well informed of my research, my responsibilities and their rights as I mentioned above or letting them to decide a time and place for the interview at their convenience. All of these were done with the hope that the researched could feel empowered, which might affect the quality of information offered.

\subsection{Fieldwork limitations}

No matter how hard I tried, the research still had some limitations. I was allowed to be in the field for a maximum of three months. During that period of time, I tried to contact as many participants as possible. However, the process of recruitment was more difficult and more time-consuming than I expected. Even when 
I got hotel managers to join, it took them time to arrange a suitable date, and in some cases, the interview's schedule was moved backward. Therefore, the research sample was not as large as hoped. Besides, regarding the second group of interviewees, the number of officers I interviewed was lower than expected. A second limitation related to language. All of my interviewees answered in their native language, Vietnamese. After that, I transcribed and then translated their responses into English. The fact that English is not my native language and some local slang was used by the interviewees made my translation and interpretation challenging, which may have affected the data analysis. Another limitation is about the reliability of information collected. I selected hotel managers as each would know their hotel, and be the person deciding what it should and should not do in response to environmental concerns. However, in some cases, people with lower positions were assigned to meet me on their behalf. Although these people might have vast experience of the issue, still it would have been better if I had been able to have talks with their seniors.

\section{Conclusion}

To examine the environmental attitude of hotel managers, the constructionist epistemological approach was used. Accordingly, I adopted a qualitative method with semi-structured interviews. This method was selected because it allowed me to more deeply discover the thinking and understanding of the participants through open and flexible interactive communication. During the field research, I had opportunities to conduct sixteen face-to-face interviews and one interview via emails. The research itself had its ups and downs, which was common in the world of development practice. As the research location was my hometown and I myself was a local, I had advantages stepping into the field. However, some problems came up such as I could not reach the expected number of participants or access officers of the city departments. Finally, I managed to fulfil the research with valuable information that would help me to examine the topic, taking the country's context into consideration. In addition, the field research enabled me to experience the issues of positionality and power that were popular among development researchers. 


\section{CHAPTER 4: SUSTAINABLE DEVELOPMENT AND TOURISM IN VIETNAM AND DA NANG}

\section{Introduction}

The chapter provides information of the research context - Da Nang city, Vietnam. It is divided into two parts: the context of Vietnam and the context of $\mathrm{Da}$ Nang city. Each part consists of the following points: geographic characteristics, social and economic features, sustainable development framework in place, tourism and accommodation sector development, and sustainable tourism development framework in place.

\subsection{Context of Vietnam}

\subsubsection{Geographic characteristics}

Vietnam's topography is diversified with mountains, deltas and coast. The mountainous area makes up three-fourths of the total area but most of mountains are relatively low. The remaining area is delta which is separated into smaller ones by mountains. The country has a long coastline of 3,260 km (Government Portal, n.d.) 


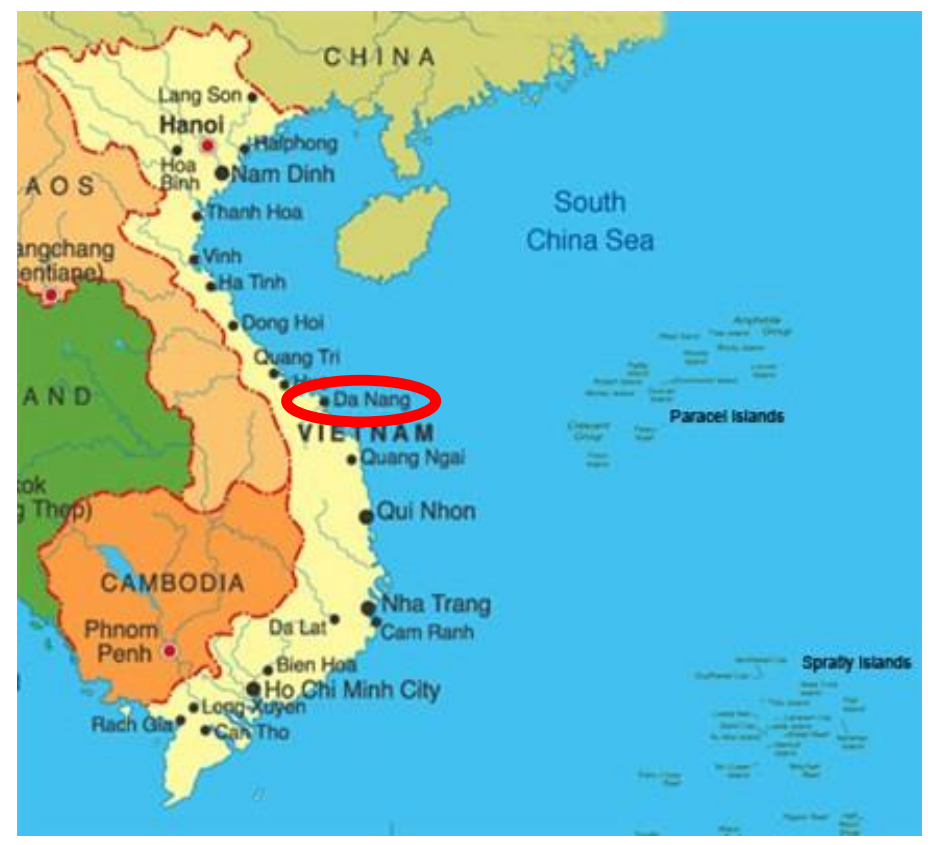

Figure 7: Map of Vietnam

(Adapted from: BaoMoi, by FinancePlus, 2014, retrieved from http://www.baomoi.com/Chu-quyen-lich-su-cua-Viet-Nam-doi-voi-hai-quan-daoHoang-Sa-va-Truong-Sa/122/13980420.epi)

Vietnam is a tropical country with high temperatures and humidity throughout the year. The average temperature fluctuates between $21-27^{\circ} \mathrm{C}$, increasing southwards. There are two climate zones within the country: the northern half of the S-shaped area from Da Nang has four clear seasons (spring, summer, autumn and winter); while the other only has a dry season and a rainy season. According to statistics for 2012, the country's population is 88.8 million (Government Portal, n.d.).

\subsubsection{Social and economic features after 1986}

Years of prolonged war against Western colonization largely destroyed the country of Vietnam. Infrastructure was devastated, and natural and social resources were exhausted. The economy was operated along a centralized model with stateowned enterprises being heavily subsidized by the government and there was an 
absence of the private sector (Asia Invest Programme, 2008). The economic growth rate was as low as 3 per cent in 1986, the inflation rate was recorded at 774.7 per cent in the same year, approximately three-fourths of the population lived in poverty in 1988, and for most of the time in the 1980s, the income growth rate per capita was nearly zero (Asia Invest Programme, 2008; Schaumburg-Müller, 2005; Wang \& Balasubramanyam, 2011). Being aware that continuing with the socialist management model was no longer economically and politically appropriate, the country's leaders reached a turning-point decision in 1986 with the issuance of the Renovation policy, usually known as Doi Moi.

The policy of Doi Moi "has shifted a stagnant economy to a new epoch of economic development" (Nghiep \& Quy, 2000, p.317). With Doi Moi, the economy was transformed to a socialist-oriented market model with the introduction of a six policy reform range including: (i) the removal of central economic management; (ii) the initiation of a market-oriented monetary policy in order to control inflation; (iii) the adoption of an outward-oriented policy in foreign economic trading; (iv) long term land use rights in the agricultural industry; (v) allowance made for the private sector to participate in business activities; and (vi) allowance made for state and private enterprises to operate in foreign markets for both import and export trades (Asia Invest Programme, 2008). Subsequently, two policy milestones were reached with the Foreign Investment Law enacted in 1987 and the Law on Private Business in 1991. Since then, the two Laws have been revised several times in order to facilitate foreign direct investment, create a better environment for businesses to operate and allow the domestic private sector to join foreign direct investment projects.

The country's economy has achieved some remarkable successes since Doi Moi. The economic growth rate averaged around 8 per cent per year, the inflation rate decreased from 3 digits in 1986 to as low as 6 per cent in 1996 (Heberer \& Kohl, 1999; Pham, Moeliono, Nguyen, Nguyen \& Vu, 2012; Schaumburg-Müller, 2005; Wang \& Balasubramanyam, 2011). The population in poverty also declined to 58 per cent in 1993, 37 per cent in 1998 and 29 per cent in 2002 (World Bank, 2011, as cited 
in Wang \& Balasubramanyam, 2011). Considering this, Schaumburg-Müller (2005) believes "few countries - if any - can match such a performance over this period" (p.358). The income growth rate reached 6 per cent annually in the period from 1992 to 2009. Before 1986, Vietnam had to import rice for consumption. After a few years, as reforms in the agricultural sector were carried out, the production volume increased sharply and the country was among the top three rice exporters in the world. According to the statistics for the first half of 2013, the country positions itself as the world's second largest rice exporter after India (Vietnam Trade Promotion Agency, n.d.).

Since Doi Moi, Vietnam has received a significantly increasing flow of foreign direct investment. In 1988, Vietnam attracted only US\$0.32 billion of foreign direct investment. The number increased to approximately US\$2.8 billion in 1993 and US\$9.6 billion in 1996. The years from 1997 to 2002 witnessed a slowdown with the volume of foreign direct investment fluctuating between US\$2.2 billion to US\$6.0 billion (General Statistics Office of Vietnam, 2014). Some argue that this is attributed to the Asian financial crisis in 1997 that affected many countries' economies, some of which were the major foreign investors into Vietnam such as Japan, Singapore or Taiwan, while others think the investors were upset with the country's business environment and regulations pertaining to foreign direct investment (Anwar \& Nguyen, 2010; Wang \& Balasubramanyam, 2011). Since 2002, there has been a sharp climb in foreign direct investment into Vietnam. The number increased from US\$2.99 billion in 2002 to a peak of US\$71.7 billion in 2008 and then US\$16.3 billion in 2012 (General Statistics Office of Vietnam, 2014). A majority of foreign direct investment flows into manufacturing industry, which can be explained by the fact that the Vietnamese labour force has basic education and lower wages compared to other countries in the same region. The real estate, construction, and accommodation and food service industries also attract foreign direct investment.

The introduction of the Law on Private Business has widened the road for domestic private enterprises to join economic activities. In 1992, there were around 
5,000 registered enterprises. The number surged to over 40,000 in 1999, 98,833 in 2005 and 334,562 in 2012 (General Statistics Office of Vietnam, 2014; SchaumburgMüller, 2005). These enterprises, although their contribution to the country's gross domestic product is modest and lower than the foreign direct investment ones, have an enormous role in social terms by generating revenue through retail sales and social consumption services, creating a large number of jobs and increasing income for households. Within the scope of the research, private businesses are understood as non-state ones, therefore include both domestic private businesses and foreign invested businesses.

Although the working environment for the private sector in Vietnam has been improving, much still needs to be done. Le and Nguyen's (2005) study shows three major obstacles to the growth of the private sector in Vietnam. The first concerned land policy. The process to acquire land for trading usually takes years of negotiation, the rigidity of the policy prevents enterprises from expanding their businesses, private enterprises must pay a higher amount of money for land than that paid by state-run enterprises yet gain less favourable grounds. The second obstacle pertains to credit policy. Subsidized by the government, state companies find easy access to credit with simple processes and low interest rates. Private companies find credit much harder to obtain. Export quota is another obstacle. According to Le and Nguyen (2005), given their close relationship with the Ministry of Trade, state enterprises usually win quota bids and get a large export quota allocation for a long period. As can be seen, state owned companies enjoy a wider range of benefits provided by the government compared to private enterprises. In addition, business laws, despite being revised several times, are still complicated and overlapping, perpetuating difficulties for both officers and enterprises. Sometimes the officers take advantage of these complex laws to undertake illegal business practices, which significantly undermine private investors' trust.

In addition to regulations introduced to facilitate economic activities, the country's relationships with international economic organizations has been expanded 
and enhanced over time. In 1995, Vietnam joined the Association of Southeast Asian Nations (ASEAN) and the ASEAN Free Trade Area. Also, Vietnam has been a member of Asia-Pacific Economic Cooperation since 1998 and the World Trade Organization since 2007 after years of negotiation (Pham et al., 2012). Vietnam has also signed a number of economic agreements, both bilateral and multilateral with many countries, which allow for more FDI inflow into the country and the expansion of Vietnamese products being exported internationally.

\subsubsection{Sustainable development framework in place}

Although the term "sustainable development" has only just captured public attention in recent years, it began when the country entered the Doi Moi period in the late 1980s. In 1993, being aware of damage caused by industries to the environment, the government passed a law on environmental protection to sustain natural resources (Le, Hollenhorst, Harris, McLaughlin, \& Shook, 2006). Discussing this issue, O'Rourke (2002) has said that "since the passage of [this law], the government has issued a wide range of decrees, directives, and circulars that flesh out the law, and create implementation instruments to realize the goals of environmental regulation and enforcement" (p.5). Some auxiliary documents are industrial wastewater standards; tax favours for enterprises trading in the environmental sector; and favours for environmental protection activities, etc. The law on environmental protection has been then revised several times in order to keep up with the on-going development situation.

Not only was the environmental issue mentioned in law, it has also featured itself in national development strategies which are published every ten years. After Doi Moi, three national socio-economic strategies came out during the period 19912000, 2001-2010 and 2011-2020. These strategies set the pathway for the country's development in the next decade. In the three strategies, the extent to which environmental concerns and the issue of sustainable development are mentioned and examined is increasing. In the first two strategies, it was recognized that socio- 
economic development is closely associated with environmental protection and improvement which is the responsibility of the whole society. The strategies highlighted that it is essential to actively integrate environmental aspects into national socio-economic plans, programmes and projects, and consider environmental requirements as a vital criterion for evaluating development solutions (Prime Minister of Vietnam, 2011; Prime Minister of Vietnam, 2012). However, it was not until the most recent strategy that the term "sustainable development" was clarified and necessary actions towards environmental protection and sustainable development promotion were detailed.

Simultaneously the state also issues the Strategy to develop Vietnam sustainably 2011-2020 in which sustainable development is defined as the model in which "economic growth is kept in harmony with social growth and protection of the environment and natural resources [...]" (Prime Minister of Vietnam, 2012, p.1). It is defined in the relationship with rapid development. Accordingly, these two models of development are closely associated. Sustainable development is the basis for rapid development while rapid development allows for the creation of resources for sustainable development. The strategy also stresses that these two terms must be taken into simultaneous consideration in planning and policy making process.

Within the strategy, environmental aspects are taken seriously. It points out that the socio-economic development agenda must position environmental protection and improvement as the top priority. The environment protection, according to the strategy, includes the following fields:

Land: Land planning must ensure the balancing of demand of different sectors, avoiding overlapping and misusage. Land must be kept as free as possible from fertilizers, chemicals, wastewater, hard waste or any substances that are harmful to the land.

Water: Water is considered a national asset. More efficient and economical usage of water is a priority. Management of water supply at river 
valleys, downstream areas and under the ground is pivotal. Wastewater treatment and collection in urban areas and industrial zones must be improved constantly.

Mineral resources: Mineral resources must be exploited and consumed appropriately, economically and efficiently, ensuring their long term supply. Research and development of renewable energy resources must be increased.

Forest: Forest exploitation must be optimized, ensuring its constant growth and reproduction. Raising awareness of forest protection must be paid serious attention. Actions against the law are strictly handled.

$>\quad$ Air and noise: Promoting activities of observing, checking, and testing the air environment in urban areas. Limiting dust sources from traffic and construction. Developing solutions to control and decrease air and noise pollution from traffic and civil works.

(Prime Minister of Vietnam, 2012)

These national strategies play a vital role in orientating specialized agencies' activities, performance and goals. Specific master plans for each sector and each provincial government must be positioned within the national strategy. Also, these strategies are what the country must have in order to call for aid assistance projects. In recent years, official development aid has been increasingly poured into environment-related projects. Some of them are construction projects while some enhance management capacity.

Although laws are established and assistance is significant, environmental protection in reality has not been adequate. The enforcement of Environmental Protection Law faces numerous difficulties. From the government's side, the number of public environmental inspectors is claimed to be tiny, namely one inspector per 1,400 enterprises (Le, 2010). Although environmental protection is always said to be 
important, economic growth is still prioritized when conflicts of interest arise. Also, sanctions are not clear and strict enough, inspections are rare after sanctions are made and thereby enterprises prefer being penalized rather than investing in practices to deal with environmental concerns. From the citizens' side, they claim laws to be too many in number, complicated and overlapping. Their understanding of environmental laws is assessed to be simple and limited. Enterprises pay more attention to their benefits in the short term rather than to what the environment means to their community, society and future generations (Ta, 2012).

\subsubsection{Tourism and accommodation sector development after 1986}

With 54 minority groups, around 2000 national historic sites, 125 recognized beaches and forests with diversified flora and fauna systems, Vietnam has great potential for tourism development (Trung \& Kumar, 2005). After 1986 when the Doi Moi policy came out, the tourism industry of the country expanded considerably as more international tourists and foreign direct investment gained entry to the country. Tourist arrivals have increased over the years, from 250,000 in 1990 to 2.5 million in 2001. Then the number tripled to 7.5 million in 2013 (General Statistics Office of Vietnam, 2014). Furthermore, as the economy grew and citizens had more opportunities to travel. The number of domestic tourists has thus increased over the past few years. In 1990, there were only 1 million people travelling around the country. The number jumped up to 11.7 million in 2001 and then 35 million in 2013 (General Statistics Office of Vietnam, 2014). 


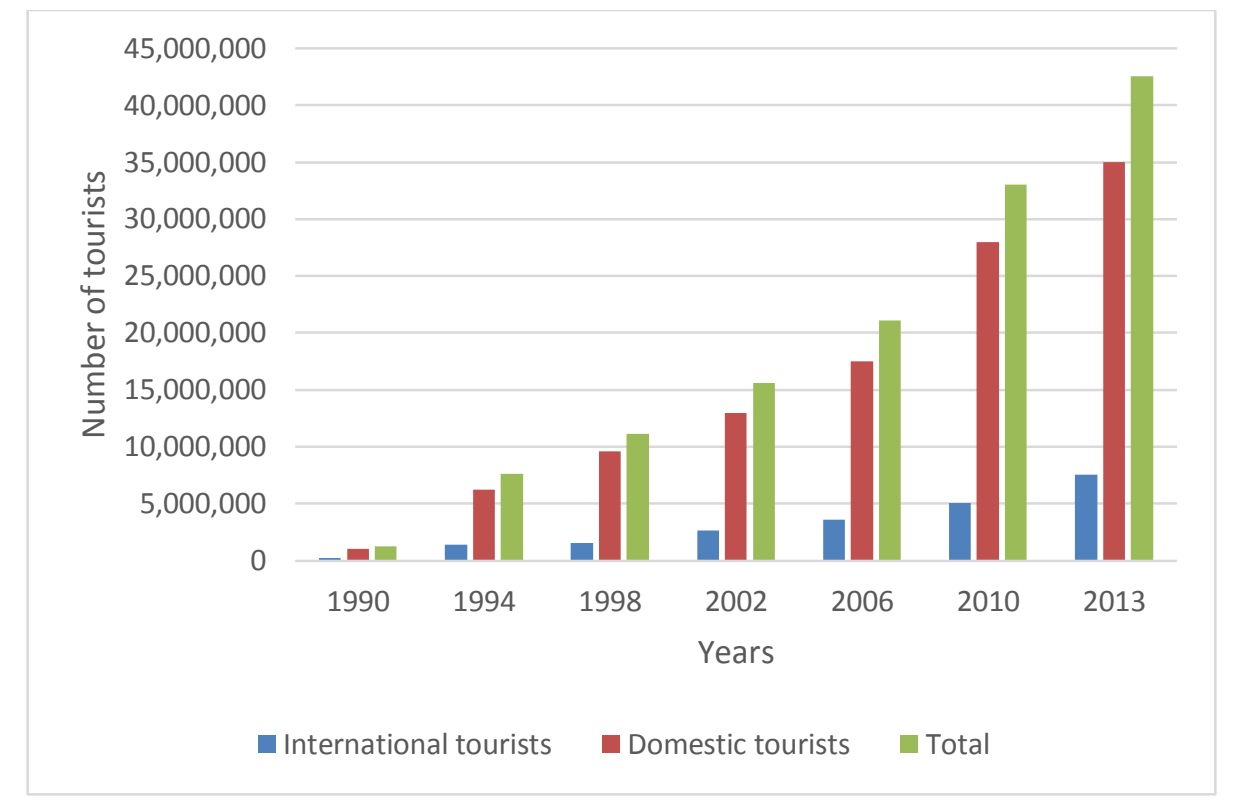

Figure 8: Number of tourist arrivals 1990 - 2013

(Source: General Statistics Office of Vietnam, 2014)

With such a positive achievement, the country expects to welcome around 12 million international tourists and 45 million domestic tourists by 2020 .

Before 1986, the tourism industry was fully subsidized by the government and operated for social welfare rather than profit (Marris, Allcock, \& Sipaseuth, 2003). After 1986, the private sector started entering the market, many services flourished creating thousands of jobs. According to a study by HITT (n.d.), currently there are about 10,800 tour operators and travel agencies, 800 out of which deal with international tourists. The industry attracts a significant number of foreign investment projects, namely 625 as the latest number (HITT, n.d.). The study also reveals that tourism creates about 480,000 direct jobs and 1 million indirect ones.

Tourism's expansion brings about opportunities for the accommodation sector to develop since a need for a place to stay cannot be separated from travelling. In 1993, the whole country had 10,500 hotel rooms. The number grew to 125,400 in 
2004 and then about 331,538 to the first half of 2014 (Mok \& Lam, 1997; Vietnam National Administration of Tourism, 2014). According to the Vietnamese Tourism Association, the hospitality sector contributes 70 per cent to the total revenue of the tourism industry (Nam, 2014). After 1986 when the government ended its monopoly on hotel trading, the accommodation sector has been the playing field of three players, namely the state, foreign investors and domestic private investors. Each player usually serves a different segment of customers (Suntikul, Butler, \& Airey, 2008). In recent years, the number of domestic private hotels has been significantly increasing in response to the emerging trend of backpacking. Their small size with flexible policies suit the tourists who travel on a low budget.

As considered the key industry to be promoted, Vietnam's tourism has been significantly expanded in recent years. However, the rapid development of this industry has brought about problems. According to Tran (2013), the tourism industry is based on three elements, namely air, earth and water, to attract tourists, and all three elements in Vietnam have been seriously deteriorating. More and more old buildings are destroyed, farmland areas are cleared to give space for recreational parks, shopping malls and hotels. Being surrounded by a built rather than the natural environment is not what tourists look for when they travel. Moreover, welcoming an increasing flow of tourists every year puts stress on beauty spots. Tourists come and damage the areas and leave rubbish. Waste treatment in some places is overloaded and as a result, untreated waste is buried under the ground, affecting the underground environment, especially water severely. Hotels and restaurants are established everywhere but there is little attention to be paid to wastewater treatment plants. Consequently, untreated wastewater escapes into the environment. This becomes even worse with hotels and restaurants situated near the beaches. These problems the tourism industry are facing raise a question about rapid development or sustainable development. 


\subsubsection{Sustainable tourism development framework in place}

In response to the national sustainable development strategy, usually each sector issues its own one. However, as far as one can discern, there is no national sustainable tourism development strategy in place. Instead, the national tourism development strategy is issued every ten years. In the latest strategy which is designed to 2020 with a vision to 2030 , sustainable tourism development is defined as the one which "conserves and promotes national cultural values; protects landscape and environment; ensures social security and order" (Ministry of Culture, Sports and Tourism, 2011, p.1). Before this strategy's issuance, such a definition could not be found anywhere in official documents. This can be explained by the government's modest attention to the industry compared to manufacturing industries of which the environmental effects seem to be more visible.

In 2005, the tourism law was issued to address rights and responsibilities of tourists, enterprises, organizations and individuals getting involved in the industry. Although the law is detailed with 88 clauses, those rights and responsibilities are mentioned in a general and simple way. Environmental protection is encouraged rather than obligated. The decree on accommodation businesses was introduced earlier, in 2000, but environmental aspects were apparently totally forgotten. There have been no revised versions of either of these documents since then. Currently, to manage tourism enterprises in general and accommodation enterprises in particular in environmental terms, the authorities apply general documents designed for service industries such as Environmental Law No.52/2005/QH11 issued in 2005, Decree No.117/2009/ND-CP on handling violations against environmental protection in 2009, and Decree No.29/2011/ND-CP on strategic environmental assessment, environmental influence assessment, environmental protection commitment in 2011. It was not until recently that environmental concerns in the accommodation sector captured the attention of both the businesses and the state. However, for certain reasons, policy making did not catch up with the on-going situation. The enterprises either came up with their own practices or adopted "green hotel" criteria from other 
countries. Fortunately, a detailed and comprehensive guideline for eco-friendly hotels was finally introduced by the government. In early 2012, the Ministry of Culture, Sports and Tourism issued a set of criteria for sustainable tourism named Green Lotus. The Green Lotus label will be granted for the accommodation enterprises which conserve the environment proactively, use natural resources economically and effectively, contribute to the preservation of heritage, the growth of local cultural, social and economic situations, and pursue sustainable tourism development. The set includes 81 criteria which are divided into three levels: basic level, encouraging level and high level. With each criterion fulfilled, the hotel will receive a number of points. The number of lotuses granted to the hotel will depend on the total score it gets (Ministry of Culture, Sports and Tourism, 2012). Although the application for the Green Lotus label is totally voluntary, the introduction of this set is a positive and proper step of the government with an aim at encouraging businesses to respond more responsibly to the environment.

\subsection{Context of Da Nang city}

\subsubsection{Geographical characteristics}

Da Nang city is located in the heart of Vietnam, $765 \mathrm{~km}$ from Ha Noi city the capital of Vietnam and $964 \mathrm{~km}$ from Ho Chi Minh city - the biggest city in Vietnam. It plays an important role as the exit to the sea of the Highland provinces of Vietnam and countries including Laos, Cambodia and Thailand to north east asian countries through the East-West economic corridor. The city is equipped with an international airport and harbour. Also, the city is situated very close to well-known world cultural and natural heritage sites including the Phong Nha - Ke Bang national park, Hue imperial city, Hoi An ancient town and the My Son sanctuary, which makes the city a vital and convenient transit spot, particularly for international visitors. All of these facts have made Da Nang an important socio-economic centre of the central region and a driving force for the growth of other provinces in the region (People's Committee of Da Nang city, 2010). 
The Da Nang region is the most urbanized in the country with around 90 per cent living in towns and cities. Its population reached 887,000 in 2009 and 973,840 in 2012. The annual average growth rate of the population in the period from 1997 to 2009 was 1.9 per cent which is higher than that of the whole country (1.3 per cent). Population density has been increasing, from 535 people per $\mathrm{km}^{2}$ in 1997 to 691 in 2009. Generally, its rate is higher than that of the central region and the country with 196 people $/ \mathrm{km}^{2}$ and 259 people $/ \mathrm{km}^{2}$ respectively. However, the density is not equal in all areas. The city's population in 2009 is 770,500 people, making up 86.86 per cent of the whole population of the region (People's Committee of Da Nang city, 2010). In 2008, nearly 50 per cent of the city population joined the labour force, in which 95 per cent were employed. The educational background of the city labour force is generally higher than that of the country. According to the statistics recorded in 2008, 18.7 per cent of the labour force graduated from universities, 22.2 per cent had vocational training and 9.2 per cent stopped studying after high school (People's Committee of Da Nang city, 2010; Socio-economic information of Da Nang city, n.d.)

The city's terrain is diversified. It has plains, mountains with different steepness, rivers, long beaches and coastline, which enables the city to develop a wide range of industries. The plains along the sea are for developing agricultural, manufacturing, service activities and residence. The mountainous areas which account for a larger part of the city area are home of forests, playing the role of "the city's lungs". Da Nang has a tropical monsoon climate with two seasons: a rainy season from August to December; and a dry season from January to July. The city is located in an area that experiences several storms every year. The storms normally occur during the rainy season and as a result tourism activities usually take place during the dry season, especially from May to July (People's Committee of Da Nang city, 2010; Socio-economic information of Da Nang city, n.d.). 


\subsubsection{Tourism planning process}

Decision making processes in Vietnam are "multi-level, multi-player" (Pham et al., 2012, p.36). Consequently, any decision usually takes time, resources, communication and negotiation to be made. Da Nang used to be a part of Quang Nam province. In 1997, it was separated from Quang Nam province to be centrally controlled, and therefore it is under the direct management of the central government. The body of local government complies with the national laws of the state administration. Generally, the process of making a tourism relevant decision is implemented as described in the chart below.
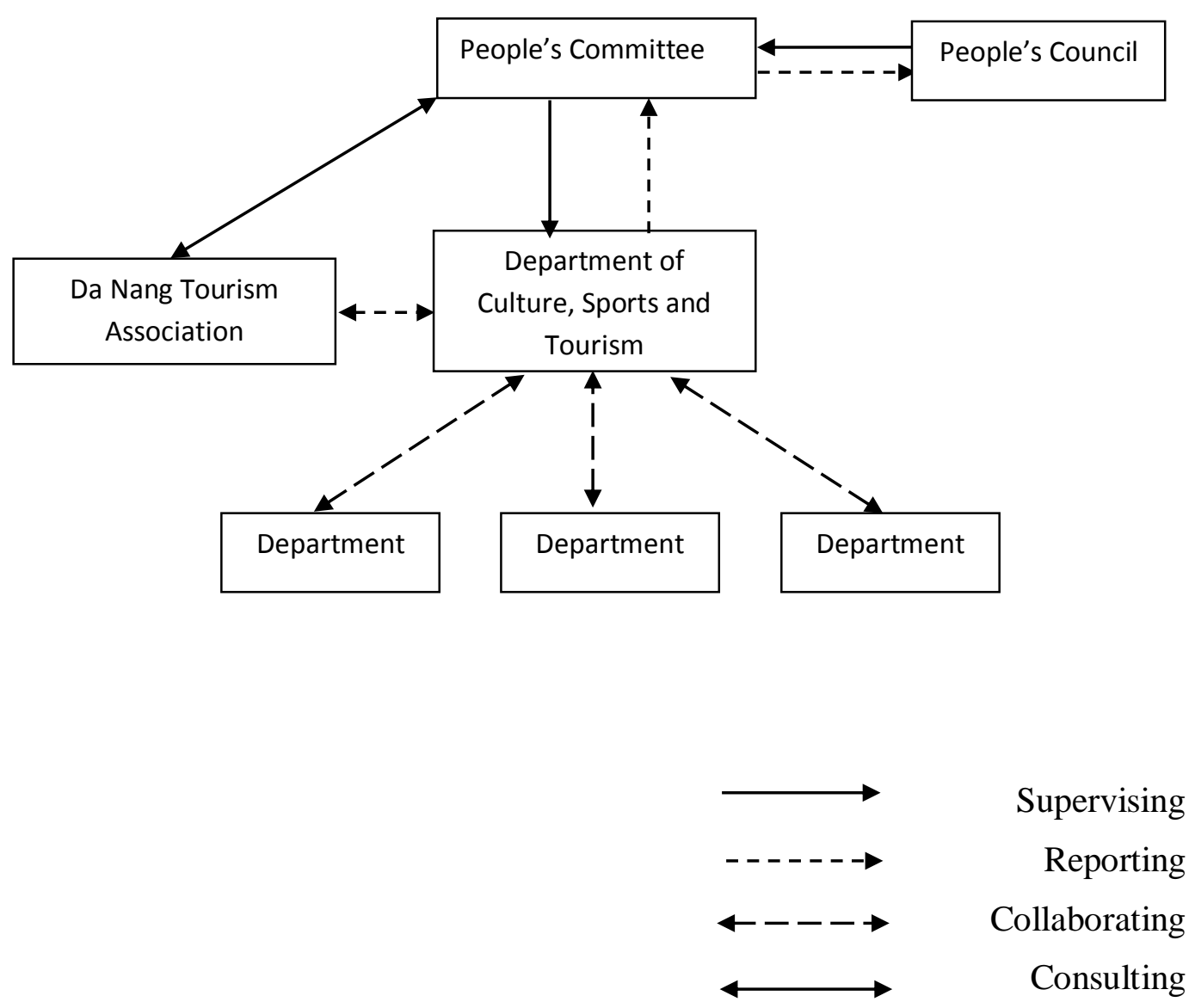

Figure 9: Tourism planning process

(Source: Author) 
The Department of Culture, Sports and Tourism takes the leading role in handling issues of tourism activities. However, before making any suggestion to the City People's Committee for approval, it must have the issues reviewed by other departments and gather opinions from them. After these suggestions are approved by the People's Committee, they are transferred to the City People's Council - the representative body of the Communist Party for a final decision. The Da Nang Tourism Association is an independent agency, operating for the benefits of tourism enterprises. Its role is to collaborate with the Department of Culture, Sports and Tourism to propose reasonable recommendations and when necessary question the People's Committee about its decisions on tourism activities. Generally, it takes a great deal of time for a decision to be made as there are many stakeholders involved.

\subsubsection{Social and economic features}

The fact that Da Nang city was separated from Quang Nam province in 1997 and became one of five municipalities in Vietnam marks a turning point for the city with significant growth in both social and economic terms. The economic structure has been transformed towards service, manufacturing and agriculture and is expected to remain so in the coming years. In 2008, service activities made up 50.09 per cent of the economy, manufacturing and construction made up 45.76 per cent and agriculture made up 4.15 per cent. The economic growth rate is increasing over the years. The annual rate for the period from 2001 to 2008 averages approximately 12 per cent. The GDP growth rate from 2001 to 2010 hovers around 10.1 per cent and 14 per cent, averaging 12.22 per cent annually while these percentages for the whole country are almost half lower, from 5.3 per cent to 8.5 per cent and 7.22 per cent respectively. Export value has been increasing over the years with the major goods and services including seafood, garment and tourism (People's Committee of Da Nang city, 2010). 


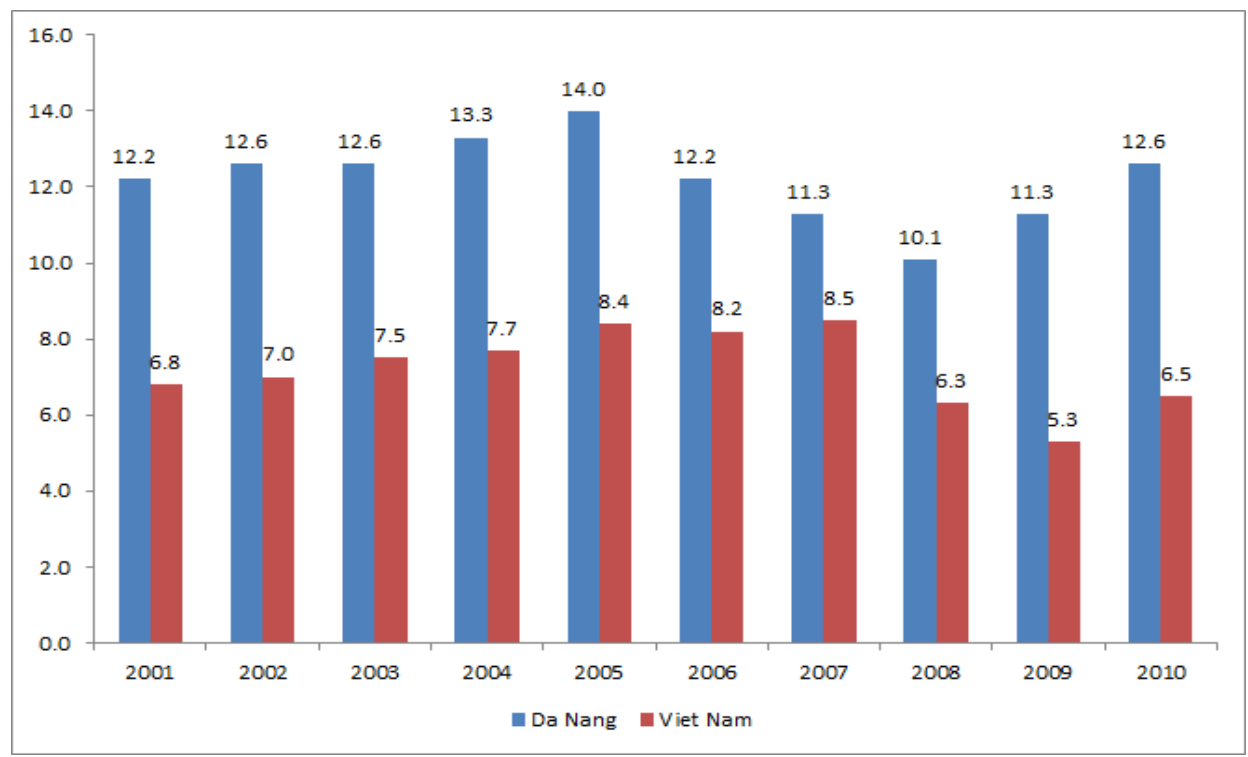

Figure 10: GDP growth rate of Da Nang and Vietnam (per cent)

(Source: People's Committee of Da Nang city, 2010)

Not only has Da Nang been striving to achieve economic expansion, it has also been making considerable efforts to improve the living standards for its citizens. In 2000, the Decision No. 129/2000/QD-UB, ratified by the City People's Committee, was issued with the announcement of the "five Nos" target to be realized within five years from 2001-2005. The "five Nos" target is made up of (i) no poverty, (ii) no illiteracy, (iii) no beggars, (iv) no drug addicts and (v) no robbery. Until 2005, although the "five No" target was not completed as designed, the policy obtained positive results, contributing to an improvement in the city's image. The percentage of poor households decreased from 5.1 per cent at the end of 2001 to 0.13 per cent at the end of 2004. The same period witnessed the decline of 5.16 per cent in the unemployment rate (Da Nang portal, n.d..). There were no illiterate people left in the ages from 6 to 35 and therefore this target continued with people aged over 35 . The remaining Nos also achieved very encouraging results thanks to the determination and cooperation of the city leaders. In 2005, three Yeses were added to the target with the hope that every citizen can have (i) a house, (ii) a job and (iii) a civilized lifestyle. 
To keep up with the on-going development, the five Nos were then revised in 2009 with two new targets for the period from 2009-2015. The first two Nos were replaced with no poor households according to the city criteria and no students quitting at primary and secondary school level (Da Nang portal, n.d.).

\subsubsection{Local sustainable development framework in place}

Being a city that is centrally controlled, Da Nang complies with the national laws and policies pertaining to socio-economic sustainable development, and sets up its own development strategy based on the available national frameworks. One of the notable highlights is the issuance of the scheme "Building Da Nang into an environmental city by 2020 " by the People's Committee in late 2008. Being aware that the constant boosting of urbanization, industrialization and modernization in the city would pose a threat to environmental and biological systems, the city government introduced the scheme taking the city background and sets of criteria for an environmental city in the world into consideration. The scheme specifies three major goals towards 2020 including:

\footnotetext{
$>\quad$ Da Nang becomes an environmentally friendly city with satisfying quality of land, water and air environment, creating safe surroundings for citizens, investors, domestic and international tourists to the city;

$>\quad$ Environmental degradation is minimized; governmental officers' capacity for dealing with environmental issues is strengthened;

$>$ People's awareness of environmental protection is enhanced.
}

(Da Nang People's Committee, 2008)

In order to reach these goals by 2020 , a number of activities have been mentioned in the scheme with specific timelines to be followed. Since 2008, the city's environmental quality has been improved significantly and Da Nang has been continuously considered the cleanest urban area in the country. In 2011, Da Nang 
was named one of the most environmentally sustainable cities in Asia. One year later, it was acknowledged as one of the lowest carbon footprint cities in Asia by AsiaPacific Economic Cooperation. In 2013, the city was one of 33 resilient cities announced by the Rockefeller Foundation (Ministry of Natural Resources and Environment, 2014).

The private sector which is supposed to be one of the vital stakeholders for the environmental protection accounts for a very little part in the scheme. It only proposes that initiatives to encourage businesses to protect the environment should be developed by the city government while the necessities such as what impacts the private sector has on the environment, how it can contribute to solve the issues and what actions they should take are not mentioned. This is claimed to make businesses confused about their possible contribution to the success of the scheme and therefore instead of being proactive to employ environmental practices, they just wait for the city government's intervention.

\subsubsection{Tourism and accommodation sector development}

Da Nang has a long coastline of more than $90 \mathrm{~km}$ which is home to beautiful beaches. Taking advantage of this favourable natural condition, the city has placed marine tourism as the top priority for development. A wide range of relevant activities is organized every year to promote this highlight of the city tourism industry.

Da Nang is on the way to become a tourism centre of central Vietnam and the whole country. The number of tourists, both domestic and international, have been increasing over the years. 


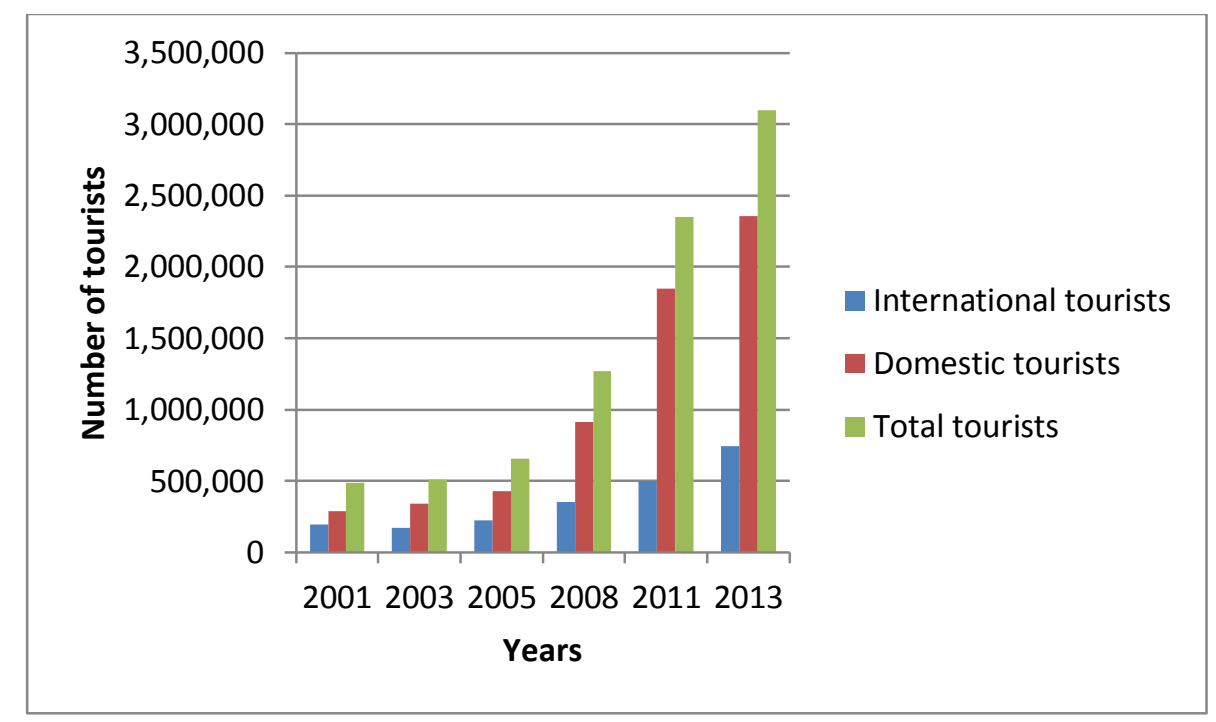

Figure 11: Numbers of tourists to Da Nang city in the period $2001-2013$

(Source: People's Committee of Da Nang city, 2010)

According to the above chart, the number of tourists to Da Nang city increased significantly in the period from 2001-2013, averaging around 30 per cent growth per annum. The growth rate of domestic tourist flow averages 40 per cent while that for international tourist is lower, namely 20 per cent. Da Nang is increasingly becoming the favourite destination for domestic tourists but its appeal to foreign tourists is not as high. Being aware of this, the city is launching a wide range of promotion programmes in order to attract more tourists from all over the world to the city.

In economic terms, the tourism industry has made a noticeable contribution to the city's gross domestic product, namely 5.86 per cent in $2000,4.02$ per cent in 2005 and 4.98 per cent in 2008. Its revenue has risen over the time, averaging approximately 17.08 per cent in the period from 2001-2008. In social terms, the industry has created thousands of jobs. The statistics from 2010 show that there were 4,300 people working in the city's tourism industry, in which females accounted for 33.6 per cent. The industry's expansion has contributed to a declining unemployment rate, creating jobs for people with any educational background and improving 
people's lives. In addition, local citizens benefit from the improved infrastructure and environment which are invested to attract more tourists to the city (People's Committee of Da Nang city, 2010).

To respond to the rising number of tourists to Da Nang, the city's accommodation sector has been expanding significantly, given the increase in the number of hotels and rooms. In the period from 2008 to the first quarter of 2014, the number of hotels tripled from 138 to 403, and the number of hotel rooms increased by almost 3.5 times from 4,239 to 14,107 . In 2008 , the number of medium and small hotels made up 91 per cent of the total number of hotels in the city. This group's number of rooms accounted for 80 per cent of the total rooms. These percentages dropped to 83 per cent and 51 per cent respectively in the first quarter of 2014. This change is due to the increase in the number of 3 to 5 star hotels of which the room number constitutes 49 per cent of the total. According to the forecast to 2020, the total number of hotels in the city will climb by 33 per cent to 569 hotels and the total number of rooms by 80 per cent to around 27,753 rooms (Da Nang Department of Culture, Sports and Tourism, 2014).

\subsubsection{Local sustainable tourism development framework in place}

As far as I am aware, the city government has not issued any master plans to develop local tourism sector sustainably, which probably follows the similar situation of the national level. Instead, the issue of the environment in tourism is integrated in some programmes and planning. In the programme to develop Da Nang's tourism from 2011-2015, the improvement of the city tourism environment is stressed to include the major following tasks:

\footnotetext{
$>\quad$ Step by step to build up Da Nang into an "Environmental city";

100 per cent of solid waste to be collected and treated by 2015 ;

Raising citizens' awareness of the importance of environment in tourism activities;
} 
$>\quad$ Building capacity for the environment and safety teams at sight-seeing spots with an aim at making Da Nang a safe and friendly place for tourists.

(Da Nang portal, n.d.)

As beaches are a valued resource for the city's tourism development, marine protection is one of the prioritized activities. The scheme "Building Da Nang into an environmental city by 2020" highlights the importance of wastewater treatment process so that the volume of untreated wastewater flowing to the sea is minimized as much as possible. As such, a large part of development aid has been poured into this component through both feasibility studies and construction work. Some development projects worth mentioning are projects funded by the World Bank such as the "Da Nang Environmental hygiene" completed in 1997; the "Da Nang Priority Infrastructure Investment" completed in 2013; the "Da Nang Sustainable Development" started in the middle of 2013; the "Urban Water Supply Improvement" project funded by Japan International Cooperation Agency completed in 2003; and the "Da Nang Environmentally and Climate-friendly Urban Development" project funded by the German Federal Ministry for Economic Cooperation and Development completed in 2014.

Environmental issues in the accommodation sector are not mentioned in any official documents. Violations in this sector are handled by laws designed for the service sector. However, hotels located along the beach sometimes get involved in projects that include wastewater treatment. This is understandable since those hotels could be the contributor to either the improvement or the deterioration of the water environment nearby. In the "Da Nang Environmentally and Climate-friendly Urban Development" project, there was a research component named "Special Environmental Improvement District". The component was designed with the purpose of improving the marine environment along a specific area of coastline. All hotels located along this area were invited to participate as collaborators by the city government, working with researchers to find out feasible social and economic 
solutions to better manage this coastline area. Although the component played a minor part within the whole project, it signalled the increasing interest of the government in sharing management responsibilities with the private sector.

\section{Conclusion}

This chapter focused on why the topic of responses of hotel managers to environmental concerns would be valuable in the selected context. Vietnam has started paying serious attention to environmental issues since the late 1980s. After the Renovation period, a number of regulations have been introduced to raise people's awareness of environmental protection and how this could contribute to the country's development. Each specific industry has its own strategies and plans and tourism is not an exception, especially when the industry has been growing rapidly in the past few years. Located in the dynamic economic zone in central Vietnam, Da Nang city has also been placing sustainable development among its top priorities. To pursue this, a number of environmental policies were introduced, a number of environmental projects were conducted. However, although tourism has been one of the key industries of the city, the attention of the government paid to the environmental issue within the industry seems not to be sufficient. 


\section{CHAPTER 5: RESEARCH FINDINGS}

\section{Introduction}

The chapter presents the findings from semi-structured interviews. To address the major research question, some sub-questions were posed with four objectives as mentioned in the introduction chapter. Basing on these objectives, four themes were created for coding as follows:

$>\quad$ Theme 1: Objective 1 - Hotel managers' awareness of sustainable issues

$>\quad$ Theme 2: Objective 2 - Environmental practices hotel managers are using and their motivations

> Theme 3: Objective 3 - Difficulties that prevent hotel managers from adopting environmental instruments

$>\quad$ Theme 4: Objective 4 - Collaboration between the city government and the accommodation businesses

The table below shows some basic information regarding the hotels and hotel managers that the researcher interviewed: 


\begin{tabular}{|c|c|c|c|c|}
\hline & $\begin{array}{c}\text { Ownership } \\
\text { type }\end{array}$ & $\begin{array}{c}\text { Year } \\
\text { when } \\
\text { hotel } \\
\text { started }\end{array}$ & $\begin{array}{c}\text { Number of } \\
\text { years } \\
\text { managers have } \\
\text { worked in } \\
\text { accommodation } \\
\text { industry }\end{array}$ & $\begin{array}{l}\text { Gender of } \\
\text { managers }\end{array}$ \\
\hline LH1 & $\begin{array}{l}\text { Management } \\
\text { contract }\end{array}$ & 2010 & 13 & Male \\
\hline LH2 & $\begin{array}{l}\text { Part of hotel } \\
\text { chain }\end{array}$ & 2011 & 10 & Female \\
\hline LH3 & $\begin{array}{l}\text { Management } \\
\text { contract }\end{array}$ & 2013 & 5 & Male \\
\hline LH4 & $\begin{array}{l}\text { Management } \\
\text { contract }\end{array}$ & 2010 & 15 & Female \\
\hline LH5 & $\begin{array}{l}\text { Management } \\
\text { contract }\end{array}$ & 2009 & 10 & Male \\
\hline MH1 & $\begin{array}{l}\text { Part of hotel } \\
\text { chain }\end{array}$ & 1999 & 14 & Female \\
\hline MH2 & $\begin{array}{l}\text { Owner- } \\
\text { manager }\end{array}$ & 2013 & 12 & Male \\
\hline MH3 & $\begin{array}{l}\text { Owner- } \\
\text { manager }\end{array}$ & 2010 & 8 & Male \\
\hline MH4 & $\begin{array}{l}\text { Part of hotel } \\
\text { chain }\end{array}$ & 2011 & 8 & Male \\
\hline SH1 & $\begin{array}{l}\text { Part of hotel } \\
\text { chain }\end{array}$ & 2013 & 14 & Male \\
\hline SH2 & $\begin{array}{l}\text { Owner- } \\
\text { manager }\end{array}$ & 2012 & 10 & Male \\
\hline SH3 & $\begin{array}{l}\text { Owner- } \\
\text { manager }\end{array}$ & 2006 & 8 & Female \\
\hline SH4 & $\begin{array}{l}\text { Owner- } \\
\text { manager }\end{array}$ & 2012 & 7 & Male \\
\hline SH5 & $\begin{array}{l}\text { Management } \\
\text { contract }\end{array}$ & 2010 & 3 & Female \\
\hline SH6 & $\begin{array}{l}\text { Owner- } \\
\text { manager }\end{array}$ & 2005 & 10 & Male \\
\hline
\end{tabular}

Table 4: Information of hotels and hotel managers joining the research

(Source: Author) 


\subsection{Objective 1: Hotel managers' awareness of sustainability issues}

\subsubsection{Sustainable development}

Before exploring deeper into environmental practices and relevant issues, the hotel managers were asked about their understanding of two concepts: sustainable development and sustainable tourism development. All managers thought that there was no significant difference between these two concepts and as LH1 said:

"Sustainable development is a very general concept. It needs to be defined within a specific field, and as such the concept will be easier to be understood."

This reflects the criticism shown in the literature that the sustainable development definition is too broad and vague. Consequently, instead of instructing people, it makes them confused at how to realize sustainable development (Baker, 2006; Harris, 2000; Redclift, 2008). Seeing no difference, the interviewees gave either one answer or two similar answers to the two questions. All respondents said they had heard of the two terms before. However, in my study, although all knew the terms, the level of knowledge was different. Thirteen out of 15 managers said they came across the terms on a regular basis, in which five managers were from large hotels, three from medium hotels and five from small hotels. The other two (one medium hotel manager and one small hotel manager) said they hardly paid attention to the terms, for which the major reason was that they had no interest in political issues.

"I think sustainable development has something to do with politicians. I saw those terms on government related articles". 
"I heard of the two terms mainly through state newspapers and television programmes. Honestly I don't care much as they are political issues".

The managers got to know about sustainability through self-study, media channels, colleagues, conferences held by national and local tourism agencies and government documents. Besides, there were some other channels. LH3 said his hotel had a specific programme designed to raise staff awareness of sustainable development, and through this he had gained more knowledge of the issue. MH4 and SH1 learned more about sustainable issues when they joined the "Environmentally and Socially Responsible Tourism Capacity Development" programme funded by the European Union in Vietnam.

Defining sustainable development, seven participants, of which two from large hotels, four from medium hotels and one from a small hotel showed good understanding of the concept. All of them replied that sustainable development consisted of three elements: economic growth of enterprises, community development and the environment. MH2, although they showed little interest in the issue, understood the concept well.

"Sustainable development is the long-term development that ensures economic benefits for enterprises, boosts community growth and conserves the environment for future generations".

"Sustainable development is the one in which enterprises develop in the long term, generate benefits and income for people. Also the surrounding communities and environment are cared for". 
"Sustainable development is the development that causes no bad consequences for future generations. Not only does it bring about economic growth but the environmental concern and social benefits are also taken care of".

As can be noticed, fewer LH respondents than MH ones defined the concept thoroughly. This contradicts the thinking that managers of large accommodation businesses are usually more knowledgeable than those of smaller sized ones. The remaining respondents either had a general understanding of the concept or only paid attention to their own hotels' situation. Some thought sustainable development (three managers of large sized hotels) as a stable and long-lasting development and gave no more detail. The others (five managers of small sized hotels) responded that sustainable development meant running their own businesses sustainably with the customer number and revenue being increased annually by investment in staff, services, etc.

"Sustainable development is something that helps my enterprise to develop on the right track and in the long term. For me I just pay attention to my own business, my customers, I don't care about social issues".

\subsubsection{Role of private sector in sustainable development}

The interview continued with the open question of the private sector's role in sustainable development. The answers were divided into four types: very important (40 per cent), important (33.33 per cent), neutral (13.33 per cent), and unsure (13.33 per cent). The further breakdown into different hotel sizes is shown in the chart below: 


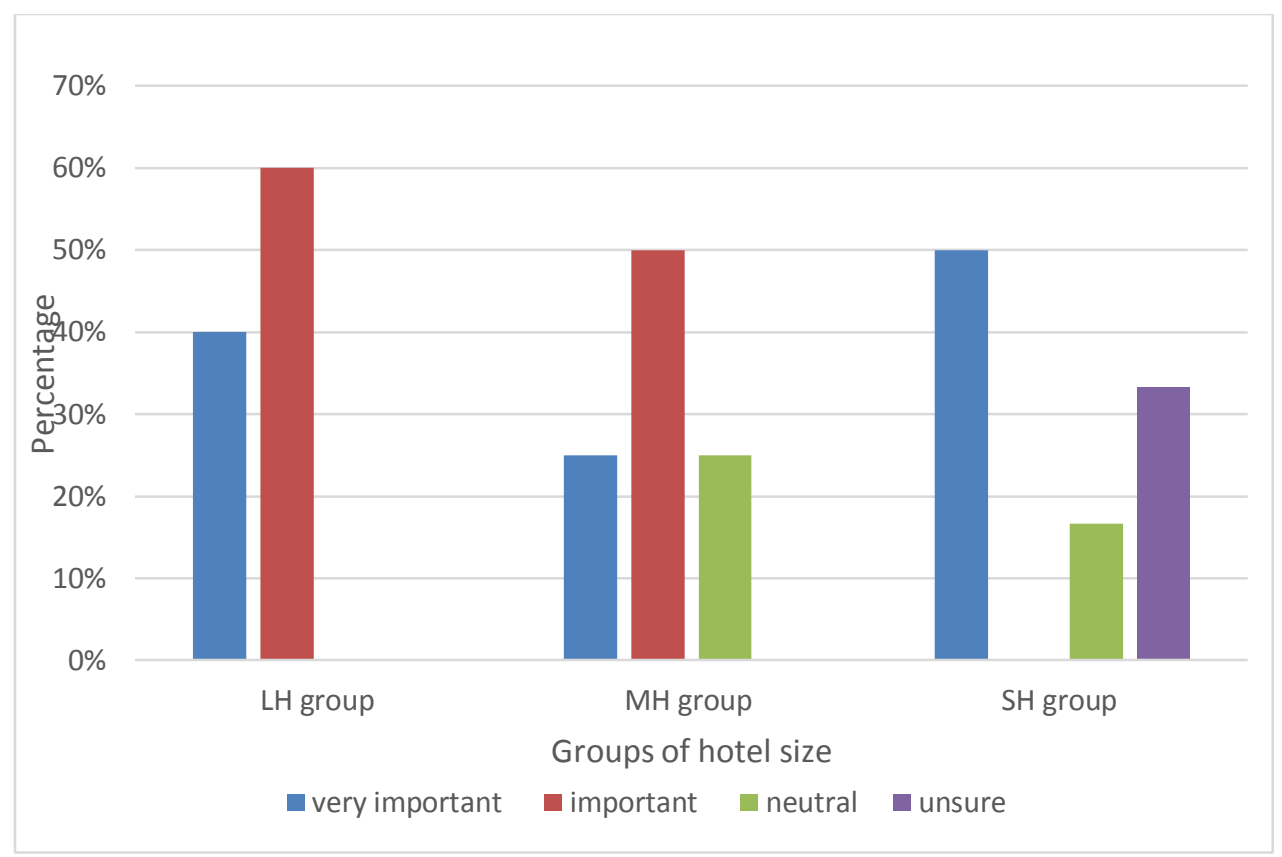

Figure 12: Hotel managers' thinking of the private sector's role in sustainable development

(Source: Author)

The respondents ranked the issue "very important" for two reasons. First, some explained that while the number of private enterprises was significantly higher than that of state-owned enterprises, they tended to pursue their economic targets in the short term and ignore their responsibility towards the society. They would not care for the environment due to high costs. As such, the achievement of sustainable development would depend on how well the private sector played their role towards the environment. The second reason pertains to the capability of the private enterprises. They were said to be more dynamic than the state-run enterprises in terms of trading and management models. As SH5 addressed:

"I think the private sector is more proactive than the public one. Private businesses adapt themselves easily with the current market-orientated trend, create the market diversification and contribute to most of the state budget". 
Hence, as private businesses had great ability and paid a great deal of tax to the government, their role towards sustainable development was undoubtedly important.

Respondents who considered the role of private sector in sustainable development "important" gave a similar explanation as above. They said that the number of private tourism businesses in Da Nang city was very high. Different types of business would have different types of impact, and the total impact would be huge. MH3, although ranking the issue "important", added that the role of the state was more important. He thought in Vietnam, the role of the private sector was still underestimated. They wanted to do a lot of things but their voice was less powerful than the state's. In contrast to this opinion, the thinking of the "neutral" group was that the public and private sectors shared the same role in sustainable development. Clarifying this, MH1 said the most important thing was the leaders' awareness while $\mathrm{SH} 3$ thought the privatization program was progressing rapidly, and increasingly there would be no difference between public and private businesses. The 33.3 per cent of "unsure" respondents were from small sized hotels. The question seemed to be new to both of them, so they felt confused answering the question.

"I suppose the role of the private sector is important. But why important, well, I have never thought of this before... hard question...."

"Honestly I have never thought of this. Well maybe the role of private businesses in sustainable development is important. I'm not sure." 


\subsubsection{Relationship between hotel business and environmentally}

sustainable development

To explore deeper into interviewees' understanding of sustainability related issues, they were asked whether there was any connection between hotel businesses and environmentally sustainable development. It was very encouraging when all interviewees answered that some form of relationship exist between the two elements. However, different interviewees held different thinking of this relationship. Overall, there were three categories of relationship:

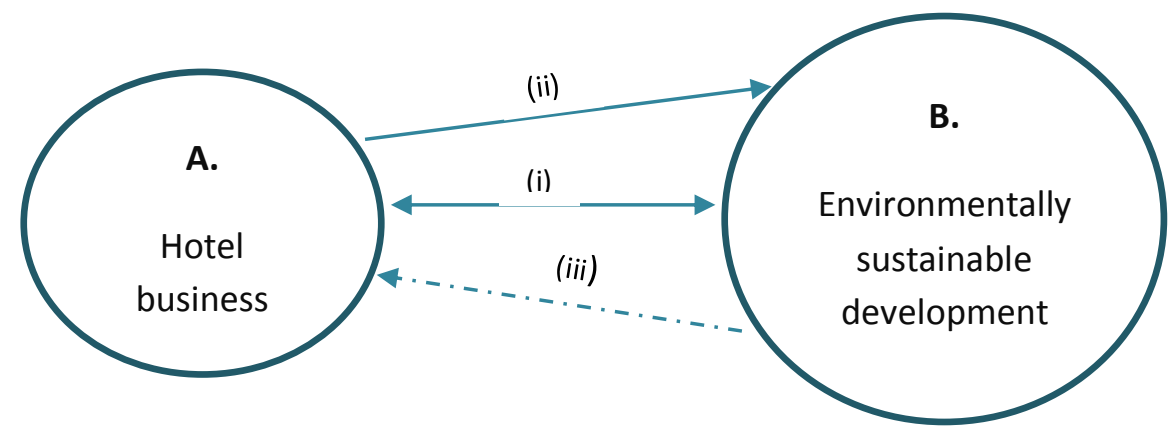

Figure 14: Relationship between hotel business and environmental sustainable development

(Source: Author)

(i) A and B have a two-way relationship: 20 per cent of respondents (one respondent from each group of hotel size) said that the relationship between hotel business and environmentally sustainable development was two-way. All three thought if sustainable development was achieved, the environment would be protected, and the hotel business would then flourish. The environment was believed the first element that tourists paid attention to when travelling. Hence a fresh, clean and safe environment would attract more customers, and then hotel revenue would increase. Among these three respondents, only MH4 mentioned the consequences of climate change on the hospitality sector. Conversely, hotel business affected environmentally sustainable development in good and bad ways. On the one hand, the appearance of hotels improved land conditions, made land useful by creating built 
landscapes. On the other hand, hotels could damage the environment with the wastewater they produced. This issue was highlighted by all respondents. In addition, hotel construction might destroy the landscape on which cultural values were based.

(ii) A to B relationship: Eight out of 15 interviewees said the relationship was one-way and hotel business affected environmentally sustainable development in different ways, making up 53.33 per cent of the total interviewees. Breaking down into hotel sizes, there were 60 per cent of LH participants, 50 per cent of MH participants and 50 per cent of SH participants. Among eight interviewees, half thought hotels' activities, depending how well they were managed, would affect the atmosphere, water supply, resources used to generate electricity while the other half did not give any clarification. SH1 added one interesting point when he said profitable hotels could help to improve the environment by financial contribution to environmental protection funds. Overall, this group accounted for the largest share. While its half could expound their opinions, the remaining seemed to be unsure of their reponses.

(iii) B to A relationship: In contrast with the response of the (ii) group, 26.67 per cent of the interviewees considered the relationship one-way but the environmentally sustainable development had an influence on hotel business. They all agreed that environmental conditions would decide their volume of customers and revenue. Put another way, they made their profit out of the surrounding environment. Therefore, the more sustainable the environment was, the happier they would be. For the LH3, he supposed the relationship would depend on the hotel's location. In his case, he selected "one-way B to A relationship", explaining that:

"My hotel is located in the city centre and the majority of customers are businessmen. Hotels in the city centre have little impact on the environment. The answer to your question will be different if my hotel is located along the beach. You know, customers go swimming, have meals and do everything there. People stay in my hotel for business rather than vacation reasons and 
they use fewer services. For hotels like mine, the environment is of great importance. It is a tool for the hotel to do marketing."

\subsubsection{Awareness of environmental initiatives in the accommodation}

\section{business}

The conversation went on with the question whether the participants knew any environmental initiatives in the accommodation business, both national and international initiatives. It was found out that the participants knew nothing about international initiatives except LH2. Her hotel had environmental standards that would be applied for all branches worldwide. Regarding national initiatives, five managers (three from large hotels, two from medium hotels), making up 33.33 per cent of the total participants, knew of the Green Lotus label but only two hotels (one large hotel and one medium hotel) followed up and were granted the label. Another large hotel applied for the label but then did not follow up. Of the ten remaining managers, accounting for 66.67 per cent (two from the large hotels, two from the medium hotel and six from the small hotels) did not know any international or national environmental initiatives. Just four of them said it was unnecessary to know any initiatives since these initiatives and national environmental regulations probably had something in common and then being aware of the latter was sufficient.

\subsection{Objective 2: Environmental practices hotel managers are using} and their motivations

It was greatly encouraging that all the interviewees revealed that their hotels were applying some environmental practices. However, their motivations were different. Seven motivations were shown in the table below: 


\begin{tabular}{|c|c|c|c|c|c|}
\hline No. & Motivations & $\begin{array}{l}\text { LH } \\
\text { group } \\
\text { (per } \\
\text { cent) }\end{array}$ & $\begin{array}{l}\text { MH } \\
\text { group } \\
\text { (per } \\
\text { cent) }\end{array}$ & $\begin{array}{l}\text { SH } \\
\text { group } \\
\text { (per } \\
\text { cent) }\end{array}$ & $\begin{array}{l}\text { Total } \\
\text { (per } \\
\text { cent) }\end{array}$ \\
\hline 1 & $\begin{array}{l}\text { Protecting the } \\
\text { environment }\end{array}$ & 40 & 50 & 33.33 & 40 \\
\hline 2 & Saving cost & 60 & 75 & 33.33 & 53.33 \\
\hline 3 & $\begin{array}{l}\text { Providing a clean and } \\
\text { safe environment for } \\
\text { customers and staff }\end{array}$ & 20 & 0 & 50 & 26.67 \\
\hline 4 & Complying with laws & 20 & 50 & 0 & 20 \\
\hline 5 & $\begin{array}{l}\text { Attracting more } \\
\text { customers }\end{array}$ & 20 & 50 & 33.33 & 33.33 \\
\hline 6 & Building hotels' image & 40 & 25 & 0 & 20 \\
\hline 7 & $\begin{array}{l}\text { Showing corporate } \\
\text { culture }\end{array}$ & 0 & 25 & 0 & 6.67 \\
\hline
\end{tabular}

Table 5: Motivations of hotel managers to apply environmental practices

(Source: Author)

Some respondents provided one motivation but others gave more than one. Overall, there was no outstanding difference among percentages of motivation options. Although saving cost was the most selected reason that drove hotels to be environmentally friendly, only a little over half of the total number of interviewees picked up on this. Being commercial units, the fact that hotel managers pursued financial benefits is obvious. However, this is probably right only in the case of large and medium establishments. Breaking the percentage down into hotel sizes, the motivation "saving cost" was also mostly chosen by managers of large and medium businesses, namely 60 per cent and 75 per cent respectively. Only a third of interviewees from SH group conducted environmental practices in order to save money. For the remaining two thirds, cost saving was not their priority as their businesses were not large enough for cost related issues to be significant. Half of the small hotel managers, the largest group of responses by small hotel managers, 
selected "providing a clean and safe environment for customers and staff" as their strongest motivation to adopt eco practices.

"I am using some environmental practices to simply keep the hotel clean. The issue of cost is not my concern as my hotel is small and does not offer as many services as the bigger ones."

"Protecting the environment" made up the second highest percentage, namely 40 per cent of participants. It is meaningful that the motivation pertaining to a sense of social responsibility was picked up by a decent number of participants. The other motivations including attracting more customers; providing a clean and safe environment for customers and staff; complying with laws; building hotels' image; and showing corporate culture proved to be less important. It was surprising that only 20 per cent of all participants considered conducting environmental practices as a way to abide by the laws. The option was selected by only 20 per cent of the large hotel managers, half of the medium hotel managers and no small hotel managers.

To make it easy for interviewees to recall the practices they had been using, I summarized the most basic environmental activities and integrated them into my question list after studying some initiatives. The result is summarized in the table below: 


\begin{tabular}{|c|c|c|c|c|c|}
\hline No. & Environmental practices & $\begin{array}{l}\text { LH } \\
\text { group } \\
\text { (per } \\
\text { cent) } \\
\end{array}$ & $\begin{array}{l}\text { MH } \\
\text { group } \\
\text { (per } \\
\text { cent) } \\
\end{array}$ & $\begin{array}{l}\text { SH } \\
\text { group } \\
\text { (per } \\
\text { cent) } \\
\end{array}$ & $\begin{array}{l}\text { Total } \\
\text { (per } \\
\text { cent) }\end{array}$ \\
\hline 1 & $\begin{array}{l}\text { Environmental protection policy } \\
\text { (written or verbal) }\end{array}$ & 100 & 50 & 33.33 & 60 \\
\hline 2 & $\begin{array}{l}\text { Periodic environmental } \\
\text { protection plans }\end{array}$ & 80 & 75 & 16.67 & 53.33 \\
\hline 3 & $\begin{array}{l}\text { Periodic reports of } \\
\text { environmental protection }\end{array}$ & 100 & 75 & 16.67 & 60 \\
\hline 4 & Environmental officers & 40 & 50 & 0 & 26.67 \\
\hline 5 & $\begin{array}{l}\text { Educational courses in } \\
\text { environmental protection }\end{array}$ & 60 & 0 & 0 & 20 \\
\hline 6 & $\begin{array}{l}\text { Encouraging customers to } \\
\text { protect the environment }\end{array}$ & 100 & 100 & 50 & 80 \\
\hline 7 & $\begin{array}{l}\text { Goods purchased in large } \\
\text { quantity to reduce packing and } \\
\text { waste }\end{array}$ & 100 & 100 & 100 & 100 \\
\hline 8 & $\begin{array}{l}\text { Flyers posted around hotel to } \\
\text { remind staff to save resources }\end{array}$ & 100 & 50 & 100 & 86.67 \\
\hline 9 & $\begin{array}{l}\text { Water temperature in customer } \\
\text { rooms set between } 50^{-} 70^{\circ} \mathrm{C}\end{array}$ & 60 & 25 & 0 & 33.33 \\
\hline 10 & $\begin{array}{l}\text { Conditioner in customer rooms } \\
\text { set from } 24^{\circ} \mathrm{C}-26^{\circ} \mathrm{C} \text { in summer } \\
\text { and } 20^{\circ} \mathrm{C}-21^{\circ} \mathrm{C} \text { in winter }\end{array}$ & 60 & 25 & 0 & 33.33 \\
\hline 11 & $\begin{array}{l}\text { Electricity usage in customer } \\
\text { rooms observed regularly }\end{array}$ & 80 & 100 & 50 & 73.33 \\
\hline 12 & $\begin{array}{l}\text { Electric sensors set up to turn } \\
\text { lights on and off automatically }\end{array}$ & 40 & 25 & 0 & 20 \\
\hline 13 & Toilets adjusted to save water & 40 & 50 & 0 & 26.67 \\
\hline 14 & Using renewable energy & 40 & 25 & 0 & 20 \\
\hline 15 & $\begin{array}{l}\text { Using left toilet paper and } \\
\text { bathing utensils for other } \\
\text { purposes }\end{array}$ & 80 & 75 & 33.33 & 60 \\
\hline 16 & $\begin{array}{l}\text { Using old pillow and blanket } \\
\text { covers, and mattresses for other } \\
\text { purposes }\end{array}$ & 60 & 100 & 100 & 86.67 \\
\hline 17 & $\begin{array}{l}\text { Having appropriate practices to } \\
\text { handle poisonous waste }\end{array}$ & 100 & 50 & 33.33 & 60 \\
\hline 18 & $\begin{array}{l}\text { Private wastewater treatment } \\
\text { system }\end{array}$ & 100 & 100 & 33.33 & 73.33 \\
\hline 19 & Waste classification & 100 & 100 & 83.33 & 93.33 \\
\hline 20 & $\begin{array}{l}\text { Using environmentally friendly } \\
\text { products }\end{array}$ & 80 & 75 & 16.67 & 53.33 \\
\hline
\end{tabular}

Table 6: Environmental practices hotel managers had been using 
As can be seen in the table, all the hotels purchased products in large quantities which could reduce waste and achieve energy savings. However, this promising finding should be treated with caution. The purpose of this activity was to reduce packing and waste but all respondents explained that they did this for cost saving rather than environmental reasons. This activity was followed by waste classification with 93.33 per cent of participants engaged. Activities 8 and 16 follow and were selected by 86.67 per cent of the participants. Other popular environmental practices included encouraging customers to protect the environment; classifying waste at source; observing electricity usage in customers' rooms; and building private wastewater treatment system. Regarding activity 6 , the way hotel managers did was either putting a note to remind customers of their responsibility to protect the environment or leaving a card to ask them whether they wanted to have the towels washed. Towel reusing was one of the most selected environmental practices by participants in previous studies.

Running educational courses in environmental protection for staff, setting up automatic electric sensors and using renewable energy were least selected by respondents, namely 20 per cent of the total number of participants for each practice. 60 per cent of managers from large-sized hotels said as their hotels were parts of hotel chains, they had environmental courses for staff which were run annually or at an orientation programme. None of the medium and small hotels did this. Instead they usually reminded their staff at periodic meetings or by emailing. For the other two practices, only two large hotels and one medium hotel applied the practice, given the relatively high cost of setting up these systems. The second least popular environmental activities were environmental officers and adjusting toilets to save water. In the majority of cases, staff were assigned to look after environmental issues under their concurrent employment. Usually heads of divisions would take this role. Only a few respondents chose the activity 13 as its outcome could be adverse sometimes. 
Looking at the results of each hotel size group, it is noticeable that the $\mathrm{SH}$ group conducted fewer practices than the LH group and the MH group. Seven out of 20 practices were not selected by any SH respondents. Most of the remaining practices did not require high costs to run, which could be the reason why small businesses adopted them. Another notable point is that while activities 2, 3 and 18 were obligatory under environmental protection laws as mentioned in the previous chapter, they were picked up by respectively 16.67 per cent (activity 2), 16.67 per cent (activity 3) and 33.33 per cent (activity 18) of SH respondents. The percentages of activities 2 and 3 for the $\mathrm{MH}$ and $\mathrm{LH}$ respondents were higher but not 100 per cent, namely 75 per cent and 75 per cent for the MH group and 80 per cent and 100 per cent for the LH group. This point will be discussed further in the next chapter.

\subsection{Objective 3: Difficulties that prevent hotel managers from} conducting environmental practices

When being asked about difficulties in conducting environmental practices, one out of 15 interviewees (one from large hotel and two from medium hotels) said that their hotels did not face any, making up 20 per cent of all interviewees. LH1 explained that as he and the management company of the hotel had been in this industry for a long time, they were well aware that enterprises must be environmentally responsible if they wanted to grow. This explains why his hotel had conducted almost all environmental practices mentioned in the Green Lotus manual before this initiative was introduced. Regarding MH1 whose hotel had been operating since 1999 and was state-owned, she answered "no" since there had been effective cooperation between staff, customers and the management team. This hotel was granted Green Lotus label, $4^{\text {th }}$ level since 2013. MH2 who also found no difficulties in carrying on environmental practices in his hotel gave a different reason. His hotel had an advantage over the others as it was newly built and therefore: 
"Environmental practices were integrated since the hotel was designed. Those practices pertain to building materials, waste and wastewater treatment, tree system ..."

(MH2)

Since having no barriers to the adoption of environmental activities, all three managers expressed that their establishments would keep running those activities in the future and would initiate new ones if they found them effective.

The majority of interviewees, namely 80 per cent, pointed out some difficulties that prevented them from adopting environmental performance.

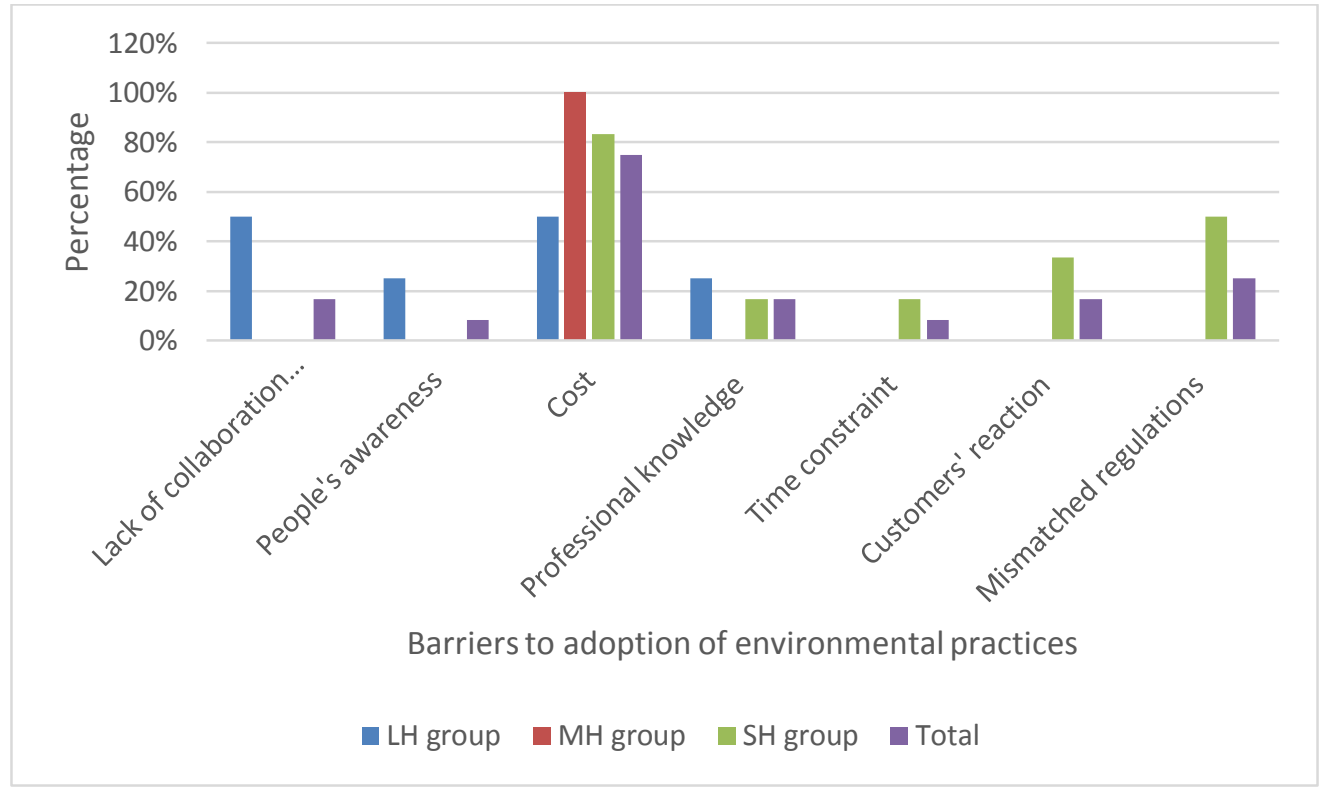

Figure 14: Hotel managers' difficulties in adopting environmental practices

(Source: Author)

Looking at the chart above, cost issue was the most common difficulty that confronted all three hotel size groups, namely 50 per cent, 100 per cent and 83.33 per cent for $\mathrm{LH}, \mathrm{MH}$ and SH groups respectively. This was also the only difficulty that medium hotel managers mentioned. Explaining this situation, the interviewees agreed 
that environmental practices were expensive, therefore it would be difficult if they wanted to follow environmental movement. MH4's words summarized all responses when he said that:

"Finance is the biggest difficulty. It covers everything. In some cases, enterprises want to adopt environmental practices but they have to make sure that their financial situation allows them to. The environment won't be looked after unless an enterprise's finances are good."

It is interesting to see that while cost was the most noticeable barrier to the environmental protection, it was also mostly selected as the motivation as shown above. This finding is similar with previous studies (Ayuso, 2006; Chan, 2004; Hobson \& Essex, 2001; Stabler \& Goodall, 1997; Tzschentle et al., 2004).

Mismatched policies came second which was pointed out by 50 per cent of interviewees and surprisingly all of them were from small-sized hotels. They gave examples of policy making problem. According to SH3, her hotel started operating in 2006 when the regulation on constructing private wastewater treatment systems was still on the table. When it finally came out in 2007, there was no instruction for hotels which were already in operation. This confused hotel businesses, especially small ones as they couldn't upgrade the existing systems due to limited budget and space. Waste classification was another problem mentioned by SH5. She said while the government tried to encourage people to classify waste, they did not provide separate rubbish bins. As such, the policy was claimed to be like "watching flowers while riding on horseback". Added to those problems, SH1 thought that current environmental regulations could not solve the problems completely. To illustrate this, he said instead of advising people not to use plastic bags, the government should increase tax on manufacturers. The remaining difficulties were less common, including customers' reaction as not being satisfied; lack of professional knowledge to start environmental practices; lack of collaboration between hotels and authorities; 
time constraints; and people's awareness. When mentioning time constraints, SH1 meant that because the majority of environmental practices were encouraging rather than obligatory, they must be adopted step by step, which would consequently take time. It would not be feasible to progress through the process rapidly.

\subsection{Objective 4: Collaboration between the city government and the} accommodation businesses

There is no doubt that both the government and the private sector have important roles towards sustainable development. However, the collaboration between these two actors is even more important. To find out how the cooperation between the city government of Da Nang and the accommodation establishments was going, the semi-structured interview addressed the question: "how do you know about environmental policies and did you receive any guidance from the authorities on how to conduct them?". The responses were disappointing. 80 per cent of the participants from the LH group answered that they knew about environmental policies issued by either the national or local government through official documents sent by post, conferences and meetings. 20 per cent said that they usually came across environmental policies through conferences only. However, all of them had the same answer to the second question. They rarely received any assistance from the authorities on how to follow new policies. The way the government did, according to their opinions, was just to spread the documents and then go to the field and inspect. Usually the participants studied the policies on their own.

Although the LH interviewees came to know about environmental policies through different channels, sadly 80 per cent of them had never heard of the Strategy to Develop Vietnam Sustainably 2011 - 2020 before. The remaining 20 per cent had heard of the strategy but did not know what it was about. When asked about the scheme to develop Da Nang into an environmental city by 2020, all replied that they had been told about the scheme but none of them got the information from official documents sent by the government. As the information was from unofficial sources, the interviewees' understanding of the scheme was very limited. Consequently, little 
did they see their role in promoting the scheme. Answering the question about how the interviewees perceived the relationship between their businesses and the success of the scheme, 40 per cent thought that they could contribute to that if they ran practices of environmental protection, although the contribution could be minor. By contrast, the other 60 per cent agreed that being a great marketing tool, the scheme would bring them more customers if it was a success.

Similar to the $\mathrm{LH}$ group, the MH group also received environmental documents from the government by post, email or through conferences. However, as the $\mathrm{MH} 2$ and $\mathrm{MH} 3$ complained, the documents usually reached them many days after the documents were issued. Sometimes the gap could be a month or more. Also, receiving guiding documents or demonstrations from the authorities was considered to be uncommon, which was shared by all MH interviewees.

"To be honest, I haven't received any assistance from the government so far."

"Absolutely no. Usually they sent documents and we studied ourselves. After sending out, they will come here to check and fine. The problem is it's not unusual for us to receive documents late. I don't know why but it seems like they don't care at all."

(MH3)

Regarding the Strategy to Develop Vietnam Sustainably 2011-2020, 75 per cent of MH participants said that this was the first time they had heard of the strategy, which meant that they did not know what it was about. The remaining 25 per cent already knew about the strategy but the understanding was very general. The participants tended to be more aware of local documents. All the MH participants knew the city's policy to become an environmental city by 2020 . They all got the name through communication channels such as television, newspapers and websites. As a result, their attention was not sufficient enough to get what the scheme meant. 
"I heard of the scheme but I don't know the details. I suppose being aware that the tourism city must be the environmental city, the government conducts the scheme to make a good impression on tourists and then create a particular brand for the city."

As a result of such thinking, $\mathrm{MH} 2$ believed there existed a connection between his hotel and the scheme's success. Accordingly, his business would be a beneficiary. Sharing the MH2's opinion, three other managers, making up 75 per cent of the $\mathrm{MH}$ group, also thought there was a connection but gave different clarifications. Although each person expressed their own ideas in different way, overall they all thought their businesses had significant influence on the scheme's accomplishment.

"I think the scheme will encourage enterprises to invest more on environmental protection activities."

"If only my hotel is counted, the contribution to the scheme's success will be minor. But if we summarize the contributions of all hotels located in Da Nang city, the total contribution will be huge".

The SH group shares some common points with responses from the other two groups. Two thirds of participants from this group received environmental papers from the government. However, within this group of participants, there was only 25 per cent who had received assistance from the government and felt satisfied. According to the SH5, normally her hotel received environmental documents with the guidance attached if any. After that, the environmental officers would go to the hotel several times to check and remind staff of what was expected. Penalties for not following these guiding documents would be applied only after these visits. Meanwhile, a third said that they had not received any environmental papers so far. 
That also meant they had not received any assistance from the authorities on how to follow environmental policies. One in three of the SH participants had heard of the Strategy to develop Vietnam sustainably 2011-2020 but none of them knew its content. The response to the scheme to develop Da Nang into an environmental city by 2020 was more optimistic. All the SH interviewees had heard of the scheme, mostly through television and newspapers but their understanding was very limited. Consequently, it would be easy for them to make assumption.

"I heard of the scheme through the television news. I don't know the details but I think it mentions something like we should plant more trees. It must be like that."

As the participants did not have sufficient information about the scheme, it would be impossible to expect them to see their businesses as contributors to the scheme's success. All of them gave the same answer when being asked about the relationship between their businesses and the scheme's accomplishment. That was if the scheme was a success, it would bring more tourists and their hotels would benefit from that.

\section{Conclusion}

The aim of this chapter was to present the findings about the response of hotel managers in Da Nang city, Vietnam to environmental concerns. These findings are based on the information collected from the participants through semi-structured interviews. Generally, the participants' awareness of sustainable issues including sustainable concepts; the role of the private sector in sustainable development; environment-hotel relationship and environmental initiatives in the accommodation sector was positive. However, managers of the different hotel size groups presented different levels of awareness. The managers of small hotels tended to have less awareness than managers of larger hotels but the difference in awareness between medium hotel managers and large hotel managers was not clear. Cost was identified by most of the participants as the strongest motivation to make them become 
environmentally friendly. Adopting some environmental practices could help them to reduce operational budgets in the long term. At the same time, cost was also selected by the majority of the interviewees as the biggest barrier against their willingness to have their hotels "go green". They agreed that it was hard to afford to install environmentally beneficial systems and pursue environmental initiatives. The data collected also showed that the collaboration between the government and the privately owned accommodation businesses in Da Nang city, Vietnam was not as sufficient nor effective as had been expected. 


\section{CHAPTER 6: DISCUSSION AND RECOMMENDATIONS}

\subsection{Research implications}

\subsubsection{Commercial concern or social concern?}

Tourism is a profit-oriented industry and as one of its sub sectors, the accommodation business, is equally so. Being commercially operated, accommodation enterprises pursue targets such as increasing revenue, profits, number of customer arrivals, customer satisfaction, etc. Since the notion of sustainable development started decades ago, businesses in general and accommodation businesses in particular have been increasingly required to act ethically and responsibly towards society. That means they are expected to fulfil their social and environmental responsibilities in addition to their commercial ones. This research focussed on the environmental roles and responsibilities of the accommodation sector.

It can be noted from the findings that in response to environmental issues, participants showed their significant concern about commercial benefits. When being asked about the concepts of sustainable development and sustainable tourism, a considerable percentage of participants defined them in economic terms. They expressed their interest in businesses' revenue, profits or number of customers only, not their responsibility towards the environment and society. As such, they placed greater importance on their businesses than on their social responsibility. This thinking, as a result, can shape the way they see other related issues. Discussing the hotel-environment relationship, almost half of the participants thought the environment had an influence on hotel business, but denied the reverse effect. They reasoned that their businesses depended on tourist volumes to survive. A change in environmental conditions might lead to a change in the number of tourist arrivals, consequently directly affecting their businesses. Pertaining to the motivations to adopt environmental tools, more than half of the participants selected the economic option "saving cost", making up the largest share. Also, up to 75 per cent of 
participants considered finance as the biggest barrier that made them feel reluctant to adopt any environmental practices.

These findings confirmed the results of previous studies in other parts of the world. The research of Hobson et al. (2001) showed that most businesses interpreted the concept of sustainable tourism in terms of economics and visitor volumes. Some respondents strongly expressed that the environment was of great importance to the tourism industry but felt their businesses were not responsible for any damage to the environment. The research also revealed that cost saving was the strongest driving force for hospitality businesses to go green. Similar results could be found in other studies (see also Ayuso, 2006; Bohdanowicz, 2005; Bohdanowicz, 2006; Stabler \& Goodall, 1997; Tzschentle et al., 2004; Vernon et al., 2003). The results might be disappointing, yet they were considered reasonable. Vernon et al. (2003) pointed out that, being commercial enterprises, they would naturally be pursuing economic interests. Putting economic targets above all other targets, they are "at some distance from the resource conservation implications of the concept" (p.57). Furthermore, as Hobson et al. (2001) argue, the fact that hotel managers were not aware of the sustainable concepts is not necessarily a serious problem. The attitude towards the adoption of environmental practices is more important. The fact that cost saving motivates hotel managers to deploy eco initiatives is also not necessarily a negative issue, provided that the outcome is the same as they are driven by ethical factors. However, while the researcher agrees with this argument, it is advisable to treat it with caution. It can be noticed from the findings of this research that most of the small hotel managers held a rudimentary understanding of sustainable concepts. Simultaneously, they tended to adopt fewer environmental practices than managers of larger hotels. Cost saving was not their major motivation to become environmentally friendly. Therefore, it would probably be better for managers to have a good understanding which could become the root of action.

It is fortunate that during the semi-structured interviews, the environmental concern was featured in some answers of participants. Almost half of the interviewees showed their concern for the community and the environment in addition to the 
growth of their properties when defining sustainable development and sustainable tourism. Responding to the question of the relationship between hotel business and environmentally sustainable development, 73 per cent mentioned the severe impacts that their hotels could have on the environment. This high percentage was encouraging but it is better to consider it deeply. Bohdanowicz $(2005,2006)$ and Candrea and Bratucu (2012) found similarly positive responses, and argued that the intention to appear environmentally friendly to improve their image in the public domain could drive the participants to overstate their responses. At the same time, the research findings also reveal that the percentage of participants who said the desire to protect the environment prompted them to carry out eco-friendly instruments was much lower than 73 per cent, namely 40 per cent.

During the semi-structured interviews, both commercial concerns and social concerns are presented to different extents. This suggests that these two concerns have a certain role in deciding the hotel managers' attitude towards environmental concerns. Their awareness of sustainable concepts is important, but it only partly influences their decision to "go green" given the existence of other influential factors. However, even so, raising awareness of environmental protection for accommodation managers is not a redundant activity.

\subsubsection{Does hotel size relate to the extent of managers' awareness and their} actions towards environmental protection?

The literature reveals that hotel size has a connection with managers' awareness and their action on environmental concern. The findings of previous studies shared common points given that overall micro businesses had less awareness of sustainable information than the larger businesses (Bohdanowicz, 2005; Bohdanowicz, 2006; Vernon et al., 2003). They had limited understanding of sustainable concepts, green initiatives and the possible impacts they could have on the environment. Furthermore, the knowledge seemed to be more widespread among large accommodation establishments. Previous studies (Hobson \& Essex, 2001; Mensah, 2006) have also exposed that the extent of implementation of environmental 
tools in large and medium hotels is higher than in smaller ones. The reasons behind this finding lie in the issues of finance and the management model. Some environmental practices are costly, thereby large establishments are more advantaged than small ones given their more favourable financial conditions and economies of scale. Also, large hotels are usually branches of chains which have stringent management standards. To promote their businesses, company headquarters usually ensure their standards are followed in all of their branches. Analysing this finding, Mensah (2006) thought "this fact should be a cause for concern" (p.428) because large hotels make up only three per cent of the total number of hotels in his research location. Meanwhile, the majority of hotels in this area are very small, and as a result their total impact on the environment could be "catastrophic" (p.429).

The findings of this research were in line with previous studies that had found that small businesses generally had less awareness of environmental issues than large and medium ones. This was shown in the answers for questions of sustainable concepts, the role of the private sector in sustainable development and environmental initiatives in the accommodation sector. Generally, SH managers had simple understandings of sustainable concepts. Mostly they saw themselves as beneficiaries from sustainable development rather than as contributors. None of them knew any international or national eco initiatives. However, a different finding of the research was that medium sized hotel managers demonstrated a better knowledge of sustainable concepts compared to respondents from larger hotels. Regarding the adoption of environmental instruments, this research coincides with previous studies. It agreed with them that small enterprises became involved in eco activities to a lesser extent than that of larger ones. The participation levels of large hotels exceeded that of medium hotels in 11 of the 20 activities assessed and of small hotels in 17 activities. The gap between large and small hotels was much more significant than that between large and medium hotels. A reason for this could be the higher numbers of barriers the participants of small hotels were confronted with compared to the large hotel and medium hotel participants. 
In conclusion, it seems that hotel size can affect the awareness of managers towards environmental issues to a relative degree. Still there are cases when managers of smaller hotels have better knowledge of these issues. Again, similar to the above discussion of commercial concern and social concern, high environmental awareness of managers is necessary yet insufficient for deciding the level of their involvement in environmental protection. However, it indicates an important point that the government should increase the effort to reach all enterprises, especially the small enterprises. Obviously, the more widespread the environmental information is, the better the situation can be. Meanwhile, hotel size has a substantial influence on the level of environmentally friendly participation. Inexpensive practices are adopted in almost all hotels. However, costly practices are usually conducted by only larger hotels. This raises the question of possible environmental support that the small enterprises can access in order to realize their social responsibility.

\subsubsection{Legal involvement of enterprises in environmental protection}

The increasing concern of people all over the world for sustainable issues, especially environmentally sustainable issues, has forced governments to integrate them into laws. By doing this, governments show their citizens the serious attitude towards environmental protection and how vital this issue is. Implementing environmental protection to a certain extent is no longer voluntary but compulsory. In Vietnam, the environmental law was born not long after the Doi Moi policy was introduced. From this point onwards, a number of circulars and decrees have been introduced to assist enterprises and individuals to realize their legal responsibilities towards the environment. However, current environmental policies in the accommodation sector show that most of the environmental practices in this sector are voluntary and the number of obligatory practices is small. Within 20 basic environmental practices that the researcher mentioned in the semi-structured interviews, there were only four that every accommodation enterprise within the country is required to adopt by the law including: (i) signing an environmental protection commitment; (ii) making periodic reports of the environmental situation; (iii) having appropriate practices to handle poisonous waste; and (iv) having a private 
wastewater treatment systems. The findings reveal that not all establishments carried out these practices. This happened in all three hotel groups in which the group of small hotels presented the lowest percentage. Regarding the motivations to adopt environmental instruments, only one fifth of the participants thought they were complying with laws.

It can be concluded from the research results that the legal involvement of accommodation businesses in environmental protection is not as high as it should be, particularly among small sized hotels. A minority of them associated this involvement with a reaction required by laws. There are some reasons behind this that were revealed during the semi-structured interviews. The first noticeable reason pertains to the limited understanding of hoteliers of the relevant environmental laws. During the interviews, one hotelier told me:

"I don't know anything about environmental policies or laws or anything similar. I do things the way I think is right. But the environmental officers keep visiting my hotel, looking for mistakes and fining us. They make me sick whenever I see them visiting."

It was valuable to receive such answers from the respondents. Although this could be an individual opinion, it raises some ideas worth consideration. First, it may indicate that this hotelier has no understanding of environmental laws. Also, this hotelier may believe that mastering environmental laws is unnecessary. It is the responsibility of the governmental officers to show enterprises how to do things, not enterprises' responsibility to find out about laws themselves. In addition, for some hoteliers, they complied with laws by adopting some environmental instruments but they were not aware that they had done.

Lax management is the second reason that explains why there has been insufficient legal participation of the hotel enterprises in environmental protection. The findings show that the percentages of the large and medium hotels adopting four 
of the activities mentioned above far exceeded those of the small hotels. Putting aside the issues of awareness, motivations and barriers that were already discussed in the above sections, this finding may indicate an imbalance in governmental management among different hotel categories.

"Honestly, I haven't had the periodic reports of environmental protection in the past few years. But I did not hear any comments from the environmental agencies, so I think it's just fine."

Another reason worth mentioning relates to policy making. In 2005, a policy of building private wastewater treatment facilities came out with a set of standards. It instructed potential hoteliers to build an appropriate wastewater treatment system but sadly it did not instruct owners of hotels that were built before 2005 how to follow the policy. Discussing this, there was a conflict in response between the chairman of the Da Nang Tourism Association and the officer of the Department of Culture, Sports and Tourism. When asked about this issue, the chairman said it was the justification of enterprises given the available assistance from environmental agencies in carrying out the new policy. Conversely, the officer of the Department of Culture, Sports and Tourism admitted that this was a dilemma that the authorities had been facing. It would be unreasonable to fine hotels which were already in service before 2005. From the enterprises' point of view, finance was the biggest problem that prevented them from following the new policy, and finance was not included in the available assistance from environmental agencies.

\subsubsection{Is existing collaboration between the government and privately owned accommodation businesses sufficient?}

The literature shows that achieving sustainable development in general and in specific industries requires the participation of different stakeholders. Within the accommodation sector, the collaboration between the government and enterprises plays a vital part in influencing enterprises' attitude towards environmental 
protection. However, the research interviews with hotel managers in Da Nang city, Vietnam revealed that insufficient collaboration between the city authorities and privately owned accommodation businesses exists. This raises the question of whether the government has fulfilled all of its expected roles.

The research results show that the government has not fulfilled its role in raising people's awareness of sustainable issues, in this case the accommodation enterprises. The semi-structured interviews inquired about the interviewees' awareness of the two basic programmes at both national and local levels, namely the strategy to Develop Vietnam Sustainably in the period from 2011-2020 and the scheme to build up Da Nang into an environmental city by 2020, and the response was overall disappointing. The majority of the participants were aware of the two programmes through informal sources such as newspapers or television rather than through government documents, which contributed to their insufficient understanding. Most of them could not see their important role in realizing the scheme. Instead, their only thought was how the scheme's success could affect their businesses. Similarly, although the Green Lotus manual was issued early in 2012, only one third of the participants were aware of this national initiative. The remaining two thirds did not know the label or any other initiatives, thinking that they were similar to laws and complying with laws was enough. Bohdanowicz's study (2005) illustrates a similar finding. This showed a large gap in participants' perceptions of environmental initiatives that the government should be the one to fill in.

The semi-structured interviews with hotel managers also revealed that newly issued regulations were not delivered to enterprises as early and completely as they should have been. Being a citizen, one must study and comply with the laws on one's own. However, policy makers are expected to make information about their policies reach as close as possible to their intended recipients. According to the interviewees, the government did organize conferences about sustainable concepts but the regularity was low, the content was not at the necessary level of depth and the presenters themselves were not informative enough. 
"I attended some conferences organized by the Department of Culture, Sports and Tourism several times. Honestly, I felt these conferences were tiring and unhelpful. The presenters delivered information in the manner they wanted and did not care about listeners. It seemed like they themselves were not enthusiastic in their job."

Also regulations pertaining to the accommodation industry seemed to not be among the top interests of the government. Currently there are no master plans acknowledged at either the national or local level for sustainable development of the accommodation sector. Also, there are no specific laws to apply in case of breaches of environmental discipline. Failures to follow environmental standards in the accommodation industry will be charged according to the laws of service sector.

The government seems to have limited understanding of the contribution of the private accommodation businesses to environmental protection. The private sector did not feature itself in the two basic sustainable programmes mentioned in previous chapters, namely the strategy to Develop Vietnam Sustainably in the period 2011-2020 and the scheme to build up Da Nang into an environmental city by 2020 . The private sector is poorly informed of environmental protection procedures and therefore may not be aware of how important their contribution could be to achieving sustainable development. Also, as mentioned in the methodology chapter, there was one state-owned hotel manager that the researcher had a chance to talk with. It was noticeable that during this interview, all questions received very positive answers. The manager revealed that she was always updated with the latest information about the industry through regular conferences held by the head office. The hotel had been granted a Green Lotus - level 4 status in early 2013 and although that was the highest level for the medium sized hotel, she expressed her determination to achieve level 5 in the coming years.

Within the privately owned accommodation industry, the government's attention to small hotels seemed to be less than that to larger hotels. The reports on 
the growth of accommodation businesses in the city and the hotel-environment relationship provided by the officer of the Department of Culture, Sports and Tourism showed that the city government itself did not consider the impacts caused by small hotels as severe as those caused by larger establishments. In the conversation between the researcher and the Chairman of Da Nang Tourism Association, the Chairman himself only mentioned the large hotels located along the eastern sea of the city in all responses. This would be problematic looking at the chart below. According to the growth forecast of the city's accommodation industry in the period 2014-2020, the number of small sized hotels (two stars and equivalent) will increase significantly compared to the numbers of hotels of other sizes. Current legal management of small sized hotels reveals a serious breach that requires remedying before the situation becomes worse or out of control.

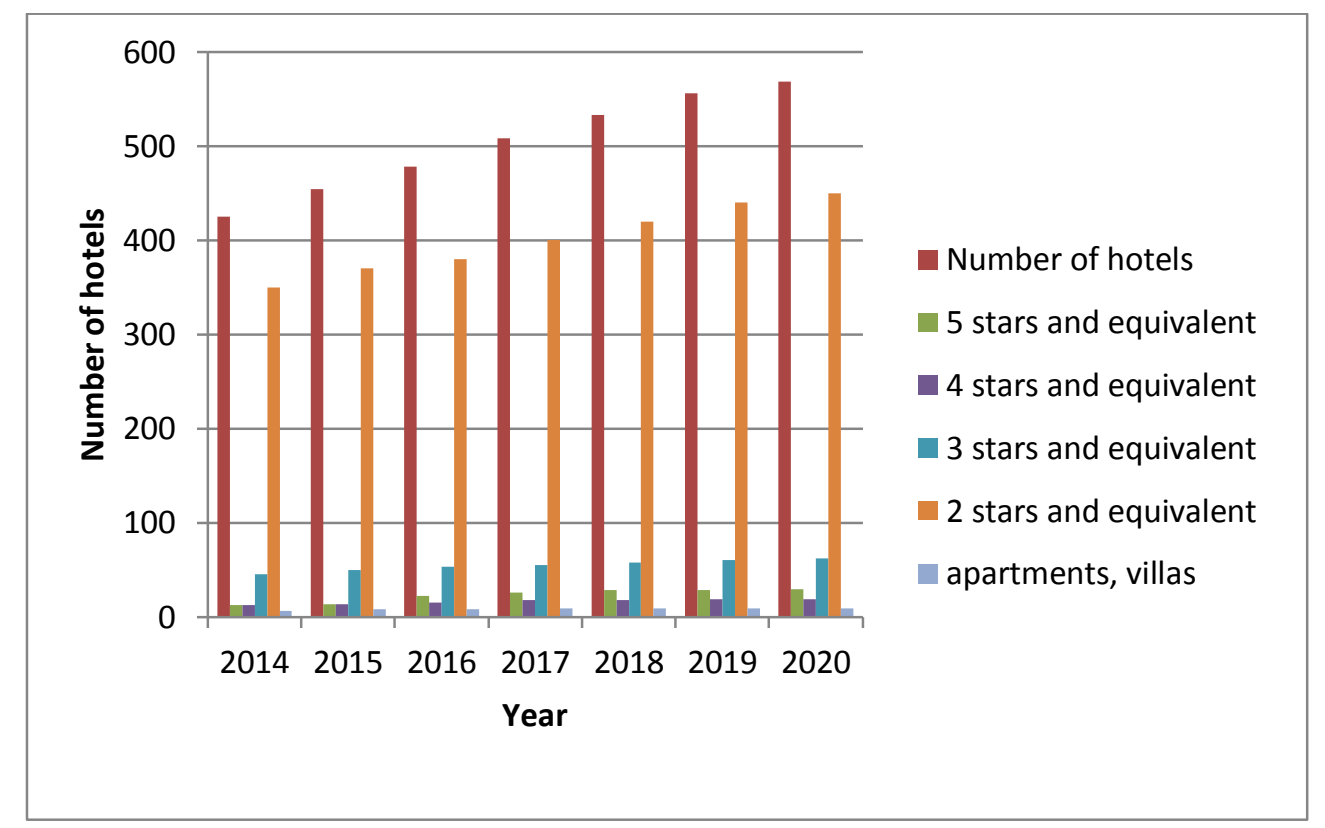

Figure 15: Forecast of hotel growth in Da Nang city 2014-2020

(Source: Da Nang Department of Culture, Sports and Tourism)

In addition, being an association that assists the government to fulfil its role, the $\mathrm{Da}$ Nang Tourism Association was claimed to be performing inefficiently. Only 40 per cent of the participants had been a member of the Association, but these participants 
agreed that most of the activities held by the Association focused on the commercial rather than the social issues within the industry.

\subsection{Possible solutions}

From what was discussed above, this research points to several possible solutions:

(i) Regarding the environmental practices described under laws, public inspection should be conducted more rigorously, thoroughly and equally distributed among different hotel sizes.

(ii) Newly issued policy documents should be delivered to the relevant parties as soon as they are approved. This could be done through many channels but it is better for the relevant parties to get the information directly from the government. I suggest one department should be in charge of spreading all of the industry relevant documents rather than different departments as is the current practice.

(iii) Raising awareness of environmental protection among hotel managers and workers:

$>\quad$ Specialized agencies collaborate with each other to organize awareness raising activities that focus on the most basic sustainable concepts right through to international and national initiatives and the benefits associated with joining such initiatives;

A network should be established for hotel managers to share lessons learnt from adopting environmental practices, especially the network of same size hotels on the grounds that they share some common points such as financial conditions, management models, etc. 
$>$ A master plan on the accommodation industry should be created, including perspectives from all sectors to encourage a sense of inclusion and collaboration.

\subsection{Research limitations}

Despite the considerable effort of the researcher, the research's limitations are inevitable. First, the sample is not large enough to generalize the entire accommodation sector. The researcher's initial intention was to reach a certain number of participants but the objective and subjective causes came up and the expected number of participants was reduced. Second, the researcher collected information from hotel managers with one manager from each hotel. The opinion of one person, even though he/she is in overall charge, cannot be concluded to represent the opinions of all hotel employees. The pressure to appear as having an environmentally friendly approach could make hotel managers overstate their responses. Another limitation that I found was in line with one criticism against the interview-based qualitative method which is whether the interviewees actually do what they say. Several weeks before my fieldtrip started, one hotel was publicly criticized for discharging wastewater into the sea without treatment. This had been a focus of public attention at the time. However, it conflicted with the hotel managers' assurance when participating in my research that the hotel had been abiding by the relevant environmental laws.

\subsection{Recommendations for future research}

Given the limitations of the research discussed above, future studies on a similar topic could be improved in a number of ways. The current strong growth of the national and local tourism industries is conducive to strong growth in the accommodation sector in the coming years. In this case, a recommendation would be to scale up this research to widen the picture. This could be done by either increasing the number of managers of privately owned accommodation enterprises or inviting hotel employees to join the research. In the latter case, the method could be changed into a mixed one that uses interviews with managers and questionnaires with other 
employees. Another recommendation would be to also recruit managers of stateowned hotels as interviewees. This would allow for a comparison between the responses of privately-owned accommodation companies and those of state-owned ones, which would in turn reveal any existing collaboration between the government and these two types of hotel business. Furthermore, considering the importance of the research topic, it would be beneficial to upgrade the research scope to the national level with the involvement of hotel managers throughout the country.

\section{Concluding remarks}

A debate over the relationship between tourism and development has been taking place for decades. The deterioration of the environment is blamed on the explosive growth of the tourism industry. This can be seen through the industry's pollution of the natural environment; restriction on the farmed environment; overconsumption of natural resources; and destruction of wildlife habitats. Simultaneously, it is thought to help protect the environment by providing funds for conservation, raising people's awareness and motivating them to take action. As such, the way the industry is run will impact on the achievement of sustainable development in general and sustainable tourism development in particular. This idea has inspired scholars worldwide to examine how managers working in the accommodation sector, a branch of tourism, respond to environmental issues. Studies have been conducted in different parts of the world, but mostly in developed countries. In developing countries, where the tourism industry is flourishing and the environment is fragile, few studies have been concluded. This led the researcher to carry out the research on this topic in Da Nang city, Vietnam - an emerging tourism market for both domestic and international tourists.

Participants in the research were intended to be managers of privately-owned accommodation businesses only. The literature shows that the private sector plays an important role in achieving sustainable development. First, businesses are built on natural and social input, and then they have responsibilities to contribute to sustainable development. Second, they have human, financial and technological 
power to fulfil that responsibility. Consequently, it is clear as to why the private sector has long been a partner of development organizations in promoting development objectives. In the context of Vietnam, the selection of private businesses is significant in the sense that the country's economy has just become market-oriented since the end of 1980s and state-owned businesses had preciously been prioritized by the government over privately-owned ones. It is therefore expected that the research would find out how the government and the private sector in Vietnam collaborate to tackle environmental concerns.

The research findings reveal a weak and disjointed collaboration between these two parties. Regarding the private sector, their engagement in environmental protection is low compared to what was expected. The most noticeable point presented in the research is the insufficient participation of the private hotels in adhering to obligatory environmental practices. Also, the private businesses generally presented a passive attitude towards accessing policies, laws and information related to sustainable development in general and environmental protection in particular. They maintained that it was the government's responsibility to disseminate information, rather than them who should be proactive in accessing information sources themselves. Environmental protection was therefore partial. There were no networks among hotel businesses either within the group of same sized hotels or across the different sizes. The establishment of such networks was not viewed as important by the participants. Therefore, if private businesses were proactive in accessing information, promoting networks to share experiences and learn from each other, their say in sustainable development would be more effective.

The research findings indicate that the government has been under ineffective management: policies have not been properly defined and management over enterprises has not been strict. Both of these scenarios have allowed businesses to disobey laws. Also, the government's management of accommodation businesses has not been comprehensive in terms of hotel size and hotel location. The attention has tended to be placed on large hotels and hotels located along the beach. Although the number of medium and small hotels and the number of hotels located in the city centre 
are higher, the government's attention to these groups of hotels has been lower. In addition, the private sector's power is not as valued as it should be, which could in part explain the passiveness of businesses when dealing with environmental concerns.

In conclusion, for the private sector's contribution to sustainable development to be effective, there are a lot of tasks that need to be achieved as suggested above. However, the most important aspect for consideration is a proactive collaborative approach on the part of both the government and the private sector to assure Da Nang city’s position as "an environmental city” by 2020. 


\section{References:}

Abdel Wahaab, R. (2003). Sustainable development and environmental impact assessment in Egypt: Historical assessment. The Environmentalist, 23(1), 49-70.

Achterberg, W. (1993). Can liberal democracy survive the environmental crisis? Sustainability, liberal neutrality and overlapping consensus. In A. Dobson \& P. Lucardie (Eds.), The politics of nature: Explorations in green political theory (pp. 81-101). New York, NY: Routledge.

Adesina, K. I., \& Ngozi, E. (2013). Hospitality business vs environmental sustainability: A study of Soarak hotel and Casino Lagos. International Journal of Science and Research, 2(9), 288-293.

Álvarez Gil, M. J., Burgos Jiménez, J., \& Céspedes Lorente, J. J. (2001). An analysis of environmental management, organizational context and performance of Spanish hotels. Omega, 29(6), 457-471.

Anwar, S., \& Nguyen, L. P. (2010). Foreign direct investment and economic growth in Vietnam. Asia Pacific Business Review, 16(1-2), 183-202.

APAT. 2002. Tourist accommodation EU eco-label award scheme - Final report. Italian National Agency for the Protection of the Environment and for Technical Services. Rome, Italy.

Ashley, C., Boyd, C., \& Goodwin, H. (2000). Pro-poor tourism: Putting poverty at the heart of the tourism agenda. Retrieved from http://www.odi.org/sites/odi.org.uk/files/odi-assets/publications-opinionfiles/2861.pdf

Asia Invest Programme. (2008). Analysis of the state of the art of the tourism sector in the Thai Nguyen province of Vietnam. Retrieved from http://asiantour.progetti.informest.it/market analysis/vietnam.pdf 
Ayuso, S. (2006). Adoption of voluntary environmental tools for sustainable tourism: Analysing the experience of Spanish hotels . Corporate socialresponsibility and environmental management , 13 (4), 207-220.

Baker, S. (2006). Sustainable development. New York, NY: Routledge.

Bansal, P. (2002). The corporate challenges of sustainable development. The Academy of Management Executive (1993-2005), 16(2), 122-131.

Barbour, R. S. (2008). Introducing qualitative research: a student guide to the craft of doing qualitative research. London, United Kingdom: Sage Publications.

Beech, J. G., \& Chadwick, S. (2006). The business of tourism management. New York, NY: Financial Times/Prentice Hall.

Binns, T. (2008). Dualistic and unlinear concepts of developments. In V. Desai \& R. B. Potter (Eds.), The companion to development studies (pp. 75-80). London, United Kingdom: Hodder Education.

Bohdanowicz, P. (2005). European hoteliers' environmental attitudes greening the business. Cornell Hotel and Restaurant Administration Quarterly, 46(2), $188-204$

Bohdanowicz, P. (2006). Environmental awareness and initiatives in the Swedish and Polish hotel industries-survey results. International Journal of Hospitality Management, 25(4), 662-682.

Bowen, H. R. (1953). Social responsibilities of the businessman. New York, NY: Harper \& Row.

Brenner, N., \& Theodore, N. (2005). Neoliberalism and the urban condition. City, 9(1), 101-107.

Buckley, R. (2011). Tourism and environment. Annual Review of Environment and Resources, 36, 397-416. 
Business Action for Sustainable Development 2012. (2011). Contribution for Rio+20 compilation document. Retrieved from http://www.uncsd2012.org/content/documents/424BASD_FINAL_1\%20No v2011 input for Rio20.pdf

Candrea, A. N., \& Bratucu, G. (2012). The perspectives for environmental management in small and medium accommodation units. The case of Brasov, Romania. Management \& Marketing, 7(3), 465.

Castro, C. J. (2004). Sustainable development: Mainstream and critical perspectives. Organization \& Environment, 17(2), 195-225.

Cater, E. (2008). Tourism and the environment. In V. Desai \& R. B. Potter (Eds.), The companion to development studies (pp. 331-334). London, United Kingdom: Hodder Education.

Chan, E. S. W. (2008). Barriers to EMS in the hotel industry. International Journal of Hospitality Management, 27(2), 187-196.

Chan, E. S. W., \& Wong, S. C. K. (2006). Motivations for ISO 14001 in the hotel industry. Tourism Management, 27(3), 481-492.

Clapp, J. (1998). The privatization of global environmental governance: ISO 14000 and the developing world. Global Governance, 4(3), 295-316.

Costache, S. (2012). Tourism, friend or foe to the economic sustainability of developing countries? Romanian Economic and Business Review, 7(2), 60.

Creswell, J. W. (2003). Research design: Qualitative, quantitative, and mixed methods approaches. Thousand Oaks, CA: Sage Publications.

Da Nang Department of Culture Sports and Tourism. (2014). Report on the development trend of the accommodation sector in Da Nang city and impacts of the environment on the sector. 
Da Nang People's Committee. (2008). Issuance of the scheme "Building Da Nang into an environmental city". Retrieved http://thuvienphapluat.vn/archive/Quyet-dinh-so-41-2008-QD-UBND-dean-xay-dung-Da-Nang-thanh-pho-moi-truong-vb194143.aspx

Da Nang portal. (n.d.). "Five Nos" city: From idea to reality. Retrieved from http://www.danang.gov.vn/portal/page/portal/danang/chuyen_de/dbgt_asxh/ chuong_trinh_5_khong

Da Nang portal. (n.d.). Programme to develop Da Nang tourism from 2011-2015. Retrieved from http://www.danang.gov.vn/portal/page/portal/danang/chuyen de/Thong tin _quy_hoach/quy_hoach_nganh/van_hoa?p_pers_id=\&p_folder_id=6034227 \&p_main_news_id=6309277\&p_year_sel=

Desai, V., \& Potter, R. B. (2008). The companion to development studies. London, United Kingdom: Hodder Education.

Dryzek, J. S. (1992). Ecology and discursive democracy: Beyond liberal capitalism and the administrative state. Capitalism Nature Socialism, 3(2), 18-42.

Erdogan, N., \& Baris, E. (2007). Environmental protection programs and conservation practices of hotels in Ankara, Turkey. Tourism Management, 28(2), 604-614.

General Statistics Office of Vietnam. (2014). Statistics Handbook 2013. Ha Noi, Vietnam: Thong Ke.

Government Portal. (2009). Decree on assistance for medium and small enterprises. Retrieved from http://www.chinhphu.vn/portal/page/portal/chinhphu/hethongvanban?class_i $\underline{\mathrm{d}=1 \& \text { mode }=\text { detail \&document } \mathrm{id}=88612}$ 
Government Portal. (n.d.). Overview on Vietnam's geography. Retrieved from http://www.chinhphu.vn/portal/page/portal/English/TheSocialistRepublicOf Vietnam/AboutVietnam/AboutVietnamDetail?categoryId=10000103\&articl $\underline{\text { eId }=10000505}$

Guest, G., Namey, E. E., \& Mitchell, M. L. (2013). Collecting qualitative data: A field manual for applied research. Thousand Oaks, CA: Sage Publications.

Hammersley, M. (2005) Ethnography: Potential, practice, and problems: Criticism of interview-based qualitative research. Qualitative Research Methodology Seminar Series. United Kingdom: University of Southampton.

Harris, J. M. (2000). Basic principles of sustainable development, working paper 00-04. Retrieved from http://ase.tufts.edu/gdae/publications/working papers/sustainable\%20develo pment.pdf

Heberer, T., \& Kohl, A. (1999). Private entrepreneurship and social change in transitional economies - The sociopolitical impact of private industry in Vietnam - Six theses. In T. Heberer, A. Kohl, T. Lai \& N. D. Vinh (Eds.), Aspects of private sector development in Vietnam (pp. 22-31). Retrieved from https://www.uni-due.de/ineast/fileadmin/publications/gruen/paper24.pdf

Herrmann, K. K. (2004). Corporate social responsibility and sustainable development: The European Union initiative as a case study. Indiana Journal of Global Legal Studies, 11(2), 205-232.

Hesse-Biber, S. N. (2010). Mixed methods research: Merging theory with practice. New York, NY: Guilford Press.

HITT. (n.d.). HITT inception analysis - Vietnam. Retrieved from http://www.hittinitiative.org/wp/wp- 
content/uploads/2013/03/HITT_Inception_Analysis_VIETNAM_English.pd $\underline{\mathrm{f}}$

Hobson, K., \& Essex, S. (2001). Sustainable tourism: A view from accommodation businesses. The Service Industries Journal, 21(4), 133-146.

Holden, A. (2008). Environment and tourism. New York, NY: Routledge.

Hsieh, Y.-C. (2012). Hotel companies' environmental policies and practices: A content analysis of their web pages. International Journal of Contemporary Hospitality Management, 24(1), 97-121.

Huge, J., \& Waas, T. (2011). Corporate social responsibility for sustainable development - reflections on theory, practice and on the role of government. Retrieved from http://www.steunpuntdo.be/papers/Working\%20Paper\%2029_Hug\%C3\%A 9.pdf

Institute of Company Secretaries of India. (2010). India INC. and inclusive growth: Backgrounder. Paper presented at the 38th National convention of company secretaries, Kolkata.

International Finance Corporation. (2011). International finance institutions and development through private sector. Retrieved from http://www.miga.org/documents/IFI_report_09-13-11.pdf

ISET. (2011). Da Nang climate change resilience strategy, Vietnam. Retrieved from http://www.accrn.org/sites/default/files/documents/1\%20DaNang\%20Resil ience\%20Strategy $0 . p d f$

IUCN. (1980). World conservation strategy: Living resource conservation for sustainable development. Retrieved from http://cisdl.org/naturalresources/public/docs/wcs.pdf 
Jayawardena, C., Patterson, D. J., Choi, C., \& Brain, R. (2008). Sustainable tourism development in Niagara: Discussions, theories, projects and insights. International Journal of Contemporary Hospitality Management, 20(3), 258-277.

Jovicic, D., \& Sinosich, R. (2012). Ethical bases of sustainable tourism. Faculty of Tourism and Hospitality Management in Opatija. Biennial International Congress. Tourism \& Hospitality Industry, 308-315.

Kasim, A. (2006). The need for business environmental and social responsibility in the tourism industry. International Journal of Hospitality \& Tourism Administration, 7(1), 1-22.

Kasim, A. (2007). Towards a wider adoption of environmental responsibility in the hotel sector. International Journal of Hospitality and Tourism Administration, 8(2), 25-49.

Kasim, A., \& Scarlat, C. (2007). Business environmental responsibility in the hospitality industry. Management, 2(1), 5-23.

Kirk, D. (1998). Attitudes to environmental management held by a group of hotel managers in Edinburgh. International Journal of Hospitality Management, 17(1), 33-47.

Kulovesi, K. (2007). The private sector and the implementation of the Kyoto Protocol: Experiences, challenges and prospects. Review of European Community \& International Environmental Law, 16(2), 145-157.

Le, L. T. (2010). Inappropriateness in Vietnamese environmental law. Retrieved from http://yeumoitruong.vn/threads/nhung-bat-cap-trong-luat-moi-truongviet-nam.10614/ 
Le, Q. V., \& Nguyen, C. M. (2005). Institutional constraints and private sector development: The textile and garment industry in Vietnam. ASEAN Economic Bulletin, 22(3), 297-313.

Le, Y., Hollenhorst, S., Harris, C., McLaughlin, W., \& Shook, S. (2006). Environmental management: A study of Vietnamese hotels. Annals of Tourism Research, 33(2), 545-567.

Loseke, D. R. (2003). Thinking about social problems: An introduction to constructionist perspectives. New York, NY: Aldine de Gruyter.

Marris, G., Allcock, A., \& Sipaseuth, K. (2003). Managing tourism in the protected areas of the Lower Mekong region. Parks-Protected Areas as Engines for Development, 13(3), 23-35.

Marshall, C., \& Rossman, G. B. (2011). Designing qualitative research. Los Angeles, CA: Sage Publications.

Mason, J. (2002). Qualitative researching. London, United Kingdom: Sage Publications.

Mbaiwa, J. E. (2011). Hotel companies, poverty and sustainable tourism in the Okavango Delta, Botswana. World Journal of Entrepreneurship, Management and Sustainable Development, 7(1), 47.

Meadows, D. H., Meadows, D. L., Randers, J., \& Behrens, W. W. (1972). The limits to growth. New York, NY: Universe Books.

Mensah, I. (2006). Environmental management practices among hotels in the greater Accra region. International Journal of Hospitality Management, 25(3), 414-431.

Mikkelsen, B. (1995). Methods for development work and research: A guide for practitioners. Thousand Oaks, CA: Sage Publications. 
Ministry of Culture Sports and Tourism. (2011). National tourism development strategy to 2020 and vision to 2030 in Vietnam. Retrieved from http://vietnamtourism.gov.vn/dmdocuments/vanban/QD2473TTG.pdf

Ministry of Culture Sports and Tourism. (2012). Set of criteria of the sustainable tourism Green Lotus Label issued. Retrieved from http://moitruongdulich.vn/en/index.php?options=items\&code=3339

Ministry of Natural Resources and Environment. (2014). Da Nang - "Singapore in Vietnam". Retrieved from http://tuoitre.vn/Can-biet/suc-khoe-doisong/602756/da-nang--singapore-trong-long-viet-nam.html

Mok, C., \& Lam, T. (1997). Hotel and tourism development in Vietnam. Journal of Travel \& Tourism Marketing, 7(1), 85-91.

Moon, J. (2007). The contribution of corporate social responsibility to sustainable development. Sustainable Development, 15(5), 296-306.

Nam, H. (2014). Accomodation sector contributes $70 \%$ to the tourism's revenue. Retrieved from http://www.langvietonline.vn/Du-Lich/133379/Co-so-luutru-dong-gop-70-doanh-thu-nganh-du-lich.html

Nghiep, L. T., \& Quy, L. H. (2000). Measuring the impact of Doi Moi on Vietnam's gross domestic product. Asian Economic Journal, 14(3), 317332.

Nichols, P. (1991). Social survey methods: A fieldguide for development workers (Vol. 6). Oxford, United Kingdom: Oxfam Publications.

O'Rourke, D. (2002). Motivating a conflicted environmental state: Communitydriven regulation in Vietnam. The Environmental State under Pressure, 10, 221-244. 
Overton, J. (1999). Sustainable development and the Pacific Islands. In J. Overton \& R. Scheyvens (Eds.), Strategies for sustainable development: Experiences from the Pacific (pp. xiv+306-xiv+306). New York, NY: Zed Books.

Patton, M. Q. (1980). Qualitative evaluation methods. Beverly Hills, CA: Sage Publications.

Peeters, P. M., Gössling, S., Scott, D., \& Hall, C. M. (2010). The future of tourism: Can tourism growth and climate policy be reconciled? A climate change mitigation perspective. Tourism Recreation Research, 35(2), 119.

People's Committee of Da Nang city. (2010). Tourism planning to 2020 in Da Nang.

Pepper, D. (1998). Sustainable development and ecological modernization: A radical homocentric perspective. Sustainable Development, 6(1), 1-7.

Pham, T. T., Moeliono, M., Nguyen, T. H., Nguyen, H. T., \& Vu, T. H. (2012).The context of REDD+ in Vietnam: Drivers, agents and institutions (No. CIFOR Occasional Paper no. 75). Center for International Forestry Research (CIFOR), Bogor, Indonesia.

Potter, R. B. (2008). Theories, strategies and ideologies of development. In V. Desai \& R. B. Potter (Eds.), The companion to development studies (pp. 6165). London, United Kingdom: Hodder Education.

Prime Minister of Vietnam. (2011). National socio-economic development strategy 2011 - 2020 in Vietnam. Retrieved from http://www.vietnamplus.vn/chienluoc-phat-trien-kinh-texa-hoi-20112020/76079.vnp

Prime Minister of Vietnam. (2012). Decision on issuance of the Strategy to develop Vietnam sustainably 2011 - 2020 in Vietnam. Retrieved from http://vanban.chinhphu.vn/portal/page/portal/chinhphu/hethongvanban?class _id=2\&mode=detail\&document_id=157753 
Redclift, M. (2008). Sustainable development In V. Desai \& R. B. Potter (Eds.), The companion to development studies (pp. 275-278). London: Hodder Education.

Richards, L., \& Morse, J. M. (2013). Readme first for a user's guide to qualitative methods. Thousand Oaks, CA: Sage Publications.

Rostow, W. W. (1960). The stages of economic growth: a non-Communist manifesto. Cambridge, United Kingdom: University Press.

Schaumburg-Müller, H. (2005). Private sector development in a transition economy: The case of Vietnam. Development in Practice, 15(3/4), 349-361.

Scheyvens, R. (2002). Tourism for development: Empowering communities. Upper Saddle River, NJ: Prentice Hall.

Scheyvens, R. (2012). Tourism and Poverty. New York, NY: Routledge.

Sharpley, R. (2000). Tourism and sustainable development: Exploring the theoretical divide. Journal of Sustainable Tourism, 8(1), 1-19.

Socio-economic information of Da Nang city. (n.d.). Labour force allocation in economic sectors. Retrieved from http://ktxh.danangcity.gov.vn/home.aspx?page=bang-thongke\&id=Sunbiz_411227412988

Sofield, T. H. B. (2003). Empowerment for sustainable tourism development. Amsterdam, Netherlands: Pergamon.

Stabler, M. J., \& Goodall, B. (1997). Environmental awareness, action and performance in the Guernsey hospitality sector. Tourism Management, 18(1), 19-33.

Steinberg, S. R., \& Cannella, G. S. (2012). Critical qualitative research reader. New York, NY: Peter Lang. 
Strauss, A. L. (1987). Qualitative analysis for social scientists. New York, NY: Cambridge University Press.

Suntikul, W., Butler, R., \& Airey, D. (2008). A periodization of the development of Vietnam's tourism accommodation since the open door policy. Asia Pacific Journal of Tourism Research, 13(1), 67-80.

Swarbrooke, J. (1999). Sustainable tourism management. New York, NY: CABI Pub.

Ta, L. T. M. (2012). Difficulties in implementing environmental laws and ensuring relevant legal rights for the vulnerables. Retrieved from https://www.iucn.org/es/noticias/noticias_por_fecha/2012/?11857/Nhng-btcp-trong-thi-phap-lut-moi-trng-va-bo-m-quyn-moi-trng-cho-ngi-c-tr-giupphap-ly

Telfer, D. J., \& Sharpley, R. (2008). Tourism and development in the developing world. New York, NY: Routledge.

Tourism portal Da Nang city. (2011). Beautiful city on the river, the sea. Retrieved from http://www.danangtourism.gov.vn/portal/page/portal/dulich_en/Intro?expan $\underline{\text { dable }=100}$

Tran, T. (2013). Tourism destroys landscape - Season 4: Tourism bears the consequences. Retrieved from http://www.thanhnien.com.vn/pages/20130316/du-lich-huy-diet-canh-quanky-4-nganh-du-lich-ganh-chiu-hau-qua.aspx

Trung, D. N., \& Kumar, S. (2005). Resource use and waste management in Vietnam hotel industry. Journal of Cleaner Production, 13(2), 109-116. 
Tzschentke, N., Kirk, D., \& Lynch, P. A. (2004). Reasons for going green in serviced accommodation establishments. International Journal of Contemporary Hospitality Management, 16(2), 116-124.

UNEP. (n.d.). Tourism and environmental conservation. Retrieved from http://www.unep.org/resourceefficiency/Business/SectoralActivities/Touris $\underline{\mathrm{m} / \text { FactsandFiguresaboutTourism/ImpactsofTourism/EnvironmentalImpacts/ }}$ TourismandEnvironmentalConservation/tabid/78779/Default.aspx

United Nations. (1972). Report of the United Nations conference on the Human Environment. Stockholm.

United Nations. (1987). Report of the World Commission on Environment and Development - Our common future. Retrieved from http://conspect.nl/pdf/Our Common Future-Brundtland Report 1987.pdf

United Nations. (1992). Agenda 21. Paper presented at the United Nations conference on environment and development, Rio de Janerio, Brazil.

United Nations. (1999). Tourism and sustainable development. Retrieved from http://www.un.org/ga/search/view doc.asp?symbol=E/CN.17/1999/5\%20\& Lang $=\mathrm{E}$

United Nations. (2011). Business action for sustainable development 2012: Contribution for Rio+20 compilation document. Retrieved from http://www.uncsd2012.org/content/documents/424BASD FINAL 1\%20No v2011_input_for_Rio20.pdf

Vernon, J., Essex, S., Pinder, D., \& Curry, K. (2003). The 'greening' of tourism micro-businesses: Outcomes of focus group investigations in South East Cornwall. Business Strategy and the Environment, 12(1), 49-69. 
Vietnam National Administration of Tourism. (2014). Accommodation businesses in the period from 2000-2014. Retrieved from http://vietnamtourism.gov.vn/index.php/items/13461

Vietnam Trade Promotion Agency. (n.d.). Vietnam's rice export for the first 6 months of 2013. Retrieved from http://www.vietrade.gov.vn/en/index.php?option=com_content\&id=2027:vi etnams-rice-export-for-the-first-6-months-of-2013\&Itemid=232

Wade, M. (2005). Good company citizenship. In U. Petschow, J. Rosenau \& E. V. Weizsacker (Eds.), Governance and sustainability: New challenges for states, companies and societies (pp. 186-199). Sheffield, United Kingdom: Greenleaf.

Wang, C., \& Balasubramanyam, V. N. (2011). Aid and foreign direct investment in Vietnam. Journal of Economic Integration, 26(4), 721-739.

WBCSD. (2002). Corporate social responsibility: The WBCSD's journey.

Witherell, B., \& Maher, M. (2001). Responsible corporate behaviour for sustainable development. Organisation for Economic Cooperation and Development.The OECD Observer (226/227), 62.

World Bank. (2004). World development report 2005: A better investment climate for everyone.

World Tourism Organization. (1998). Guide for local authorities on developing sustainable tourism. Madrid: World Tourism Organization.

World Tourism Organization. (2013). UNWTO Annual Report 2012. Retrieved from http://dtxtq4w60xqpw.cloudfront.net/sites/all/files/pdf/annual report 2012. pdf 
World Tourism Organization. (2014). UNWTO annual report 2013. Retrieved from http://dtxtq4w60xqpw.cloudfront.net/sites/all/files/pdf/unwto_annual_report _2013_web.pdf

World Travel and Tourism Council. (2013). Travel \& Tourism: Economic impact 2013 world. Retrieved from http://www.wttc.org/site_media/uploads/downloads/world2013_1.pdf

Yam, S. (2013). The practice of corporate social responsibility by Malaysian developers. Property Management, 31(1), 76-91. 


\section{Appendix 1: Ethics approval}

TE WHARE WĀNANGA O TE ŪPOKO O TE IKA A MĀUI

\begin{tabular}{|l|l|}
\hline TO & Trang Nguyen \\
\hline COPY TO & John Overton \\
\hline FROM & Dr Allison Kirkman, Convener, Human Ethics Committee \\
\hline DATE & 5 May 2014 \\
\hline PAGES & 1 \\
\hline SUBJECT & $\begin{array}{l}\text { Ethics Approval: 20846 } \\
\text { Response of privately owned accommodation businesses in Da } \\
\text { Nang city, Vietnam to environmental concerns }\end{array}$ \\
\hline
\end{tabular}

Thank you for your application for ethical approval, which has now been considered by the Standing Committee of the Human Ethics Committee.

Your application has been approved from the above date and this approval continues until 28 February 2015. If your data collection is not completed by this date you should apply to the Human Ethics Committee for an extension to this approval.

Best wishes with the research.

Allison Kirkman

Human Ethics Committee

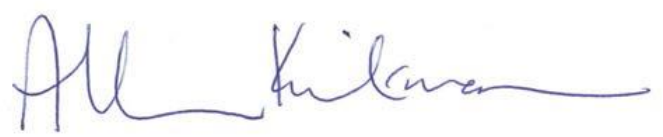




\section{Appendix 2: Information sheet}

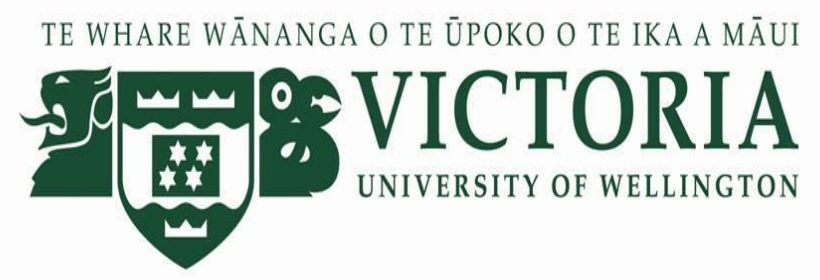

\section{INFORMATION SHEET}

\section{Researcher: Trang Nguyen, School of Geography, Environment and Earth Science, Victoria University of Wellington}

I am a Masters student in Development Studies at Victoria University of Wellington. As part of this degree I am undertaking a research project leading to a thesis. The project I am undertaking is examining the response of privately owned accommodation businesses in Da Nang city, Vietnam, to environmental concerns. This research project has received approval from the Victoria University Human Ethics Committee with the approval number 20846. The statement about the Human Ethics Committee granting approval is attached below.

I am inviting managers of privately owned accommodation businesses in $\mathrm{Da}$ Nang city, Vietnam, to participate in the study. Participants will take part in semi-structured interviews on the voluntary basis. Participants decide the date and venue for the interviews. Participants can withdraw themselves (or any information they have provided) from this research project within one week after the interview without having to give any reason. Participants can check the transcripts of the interview before publication if they request. Participants can ask for the audio digital recording of interviews to be returned to them.

Responses will form the basis of my research project and will be put into a written report on a confidential basis. It will not be possible for you to be identified personally. All material collected will be kept confidential. No other person besides me and my supervisor Prof John Overton will see the data collected. The thesis will be submitted for marking to the School of Geography, Environment and Earth Science and deposited in the University Library. It is intended that one or more articles will be submitted for publication in scholarly journals. Data collected will be destroyed two years after the end of the project. 
If you have any further questions or would like to receive further information about the project, please contact me at nguyentran9@myvuw.ac.nz or my supervisor Prof John Overton, at the School of Geography, Environment and Earth Science at Victoria University, phone + 644 4635281, email john.overton@vuw.ac.nz.

\section{Trang Nguyen}




\section{Appendix 3: Consent form}

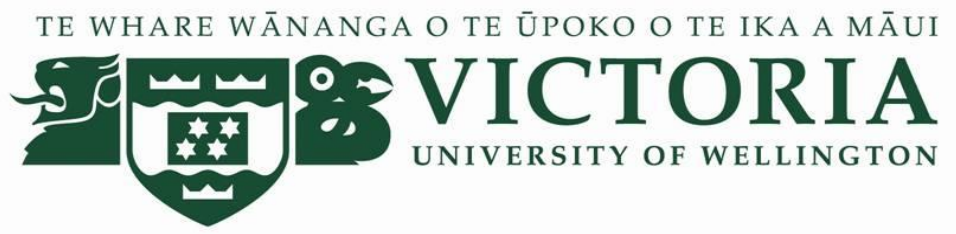

\section{CONSENT TO PARTICIPATE IN RESEARCH}

Title of project: Response of privately owned accommodation businesses in Da Nang city, Vietnam to environmental concerns

I have been given and have understood an explanation of this research project. I have had an opportunity to ask questions and have them answered to my satisfaction.

I understand that:

$\checkmark$ My participation in this project is entirely voluntary;

$\diamond$ The interview will be audio digital recorded;

$\checkmark$ I may withdraw myself (or any information I have provided) from this project within one week after the interview without having to give reasons;

$\checkmark$ Any information I provide will be kept confidential to the researcher and the supervisor;

$\checkmark$ The audio recording of interviews can be returned to me upon request;

$\checkmark$ I will have an opportunity to check the transcripts of the interview before publication if I request, and a summary of the research will be sent to me upon request via the email address I provide.

I agree to take part in this research, and I want

to be returned to me via the email address

Signed:

\section{Name of participant:}

Date: 